Florida International University FIU Digital Commons

FIU Electronic Theses and Dissertations

University Graduate School

3-20-2013

\title{
The Influence of HOPE VI Public Housing on Public Schools
}

Donna A. Comrie

Florida International University, dcomr001@fiu.edu

DOI: $10.25148 /$ etd.FI13042502

Follow this and additional works at: https://digitalcommons.fiu.edu/etd

Part of the Education Policy Commons, Public Administration Commons, Public Affairs Commons, and the Urban Studies Commons

\section{Recommended Citation}

Comrie, Donna A., "The Influence of HOPE VI Public Housing on Public Schools" (2013). FIU Electronic Theses and Dissertations. 873.

https://digitalcommons.fiu.edu/etd/873

This work is brought to you for free and open access by the University Graduate School at FIU Digital Commons. It has been accepted for inclusion in FIU Electronic Theses and Dissertations by an authorized administrator of FIU Digital Commons. For more information, please contact dcc@fiu.edu. 


\section{FLORIDA INTERNATIONAL UNIVERSITY}

Miami, Florida

\section{THE INFLUENCE OF HOPE VI PUBLIC HOUSING ON PUBLIC SCHOOLS}

A dissertation submitted in partial fulfillment of the

requirements for the degree of

DOCTOR OF PHILOSOPHY

in

PUBLIC AFFAIRS

by

Donna Comrie

2013 
To: Dean Kenneth Furton

College of Arts and Sciences

This dissertation, written by Donna Comrie, and entitled The Influence of HOPE VI Public Housing on Public Schools, having been approved in respect to style and intellectual content, is referred to you for judgment.

We have read this dissertation and recommend that it be approved.

N. Emel Ganapati

Howard Frank

Leonard Bliss

Hai Guo

Sukumar Ganapati, Major Professor

Date of Defense: March 20, 2013

The dissertation of Donna Comrie is approved.

Dean Kenneth Furton College of Art and Sciences

Dean Lakshmi Reddi University Graduate School

Florida International University, 2013 
(C) Copyright 2013 by Donna Comrie

All rights reserved. 


\section{DEDICATION}

I dedicate this dissertation to my family, Dalton, Henrietta and Darrell Comrie. Your constant and unwavering support allows me to take risks. 'No man is an island.'

Patricia Whitlock: 'Friends are the family we choose'. In addition, my colleague and friend, Agatha Caraballo, "Thank you!" 


\section{ACKNOWLEDGMENTS}

To the members of my dissertation committee, Dr. Emel Ganapati, Dr. Leonard Bliss, Dr. Howard Frank, and Dr. David Guo, I thank you for your time and direction throughout this process. To my chair, Dr. Sukumar Ganapati, your patience, kindness, and understanding are second to your knowledge and support of this awesome task. I am forever grateful.

I would like to thank the staff of the FIU Metropolitan Center for providing a setting where I could learn about the interworking of city government and begin the initial phase of my dissertation.

To the participants/interviewees in Philadelphia, PA and Washington, DC, your insight made this dissertation possible. Thank you for inviting me into your homes and offices to learn about your community development contributions.

The financial support of the FIU Dissertation Evidence Acquisition (DEA) Fellowship, Morris and Anita Broad Research Award (FIU), and the ASPA Florida Chapter Annual Scholarship contributed to my development and ability to complete this endeavor.

Lastly, I thank Florida International University and the Department of Public Administration. The resources of the FIU Writing Center, the FIU Statistical Consulting Department, and graduate assistant, Angelina Low, were instrumental in this process. As a full-time student in the doctoral program with GA/TA financial support, I have had the opportunity of a lifetime. Few individuals will have the chance to practice the skill of learning in such a warm and nurturing environment. 


\section{ABSTRACT OF THE DISSERTATION \\ THE INFLUENCE OF HOPE VI PUBLIC HOUSING ON PUBLIC SCHOOLS}

by

Donna Comrie

Florida International University, 2013

Miami, Florida

Professor Sukumar Ganapati, Major Professor

In the United States, public school enrollment is typically organized by neighborhood boundaries. This dissertation examines whether the federally funded HOPE VI program influenced performance in neighborhood public schools. In effect since 1992, HOPE VI has sought to revitalize distressed public housing using the New Urbanism model of mixed income communities. There are 165 such HOPE VI projects nationwide. Despite nearly two decades of the program's implementation, the literature on its connection to public school performance is thin. My dissertation aims to narrow this research gap. There are three principal research questions:

(1) Following HOPE VI, was there a change in socioeconomic status (SES) in the neighborhood public school? The hypothesis is that low SES (measured as the proportion of students qualifying for the Free and Reduced Lunch Program) would reduce.

(2) Following HOPE VI, did the performance of neighborhood public schools change? The hypothesis is that the school performance, measured by the proportion of $5^{\text {th }}$ grade students proficient in state wide math and reading tests, would increase. 
(3) What factors relate to the performance of public schools in HOPE VI communities? The focus is on non-school, neighborhood factors that influence the public school performance.

For answering the first two questions, I used t-tests and regression models to test the hypotheses. The analysis shows that there is no statistically significant change in SES following HOPE VI. However, there are statistically significant increases in performance for reading and math proficiency. The results are interesting in indicating that HOPE VI neighborhood improvement may have some relationship with improving school performance. To answer the third question, I conducted a case study analysis of two HOPE VI neighborhood public schools, one which improved significantly (in Philadelphia) and one which declined the most (in Washington DC). The analysis revealed three insights into neighborhood factors for improved school performance: (i) a strong local community organization; (ii) local community's commitment (including the middle income families) to send children to the public school; and (iii) ties between housing and education officials to implement the federal housing program. In essence, the study reveals how housing policy is de facto education policy. 


\section{TABLE OF CONTENTS}

CHAPTERS

PAGE

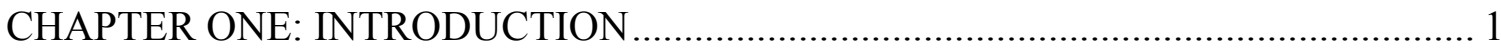

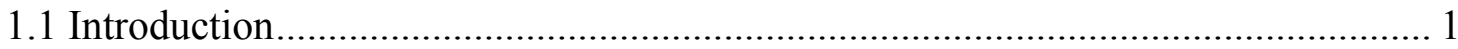

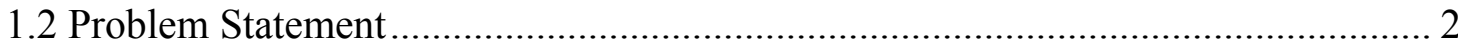

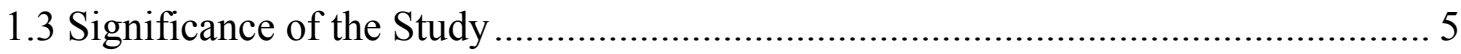

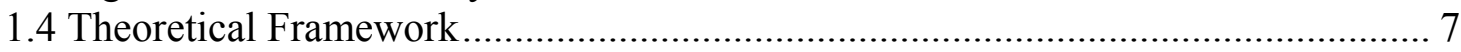

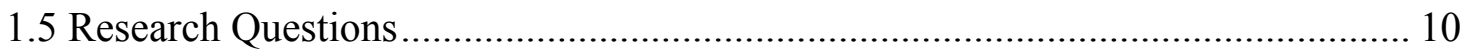

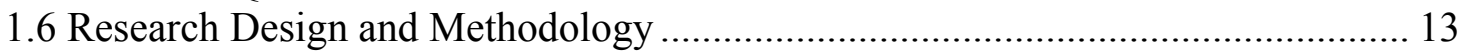

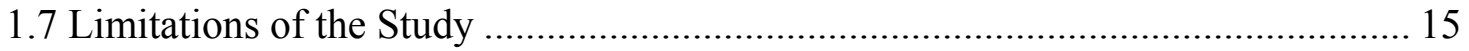

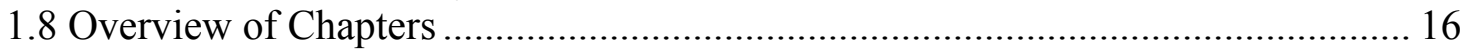

CHAPTER TWO: PUBLIC HOUSING \& EDUCATION — A LITERATURE REVIEW

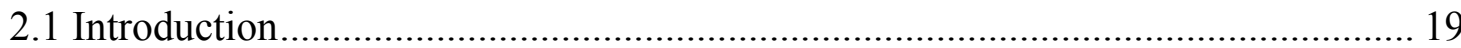

2.2 Public Housing \& Concentrated Poverty ............................................................. 20

2.3 Efforts to Reform Severely Distressed Public Housing........................................... 23

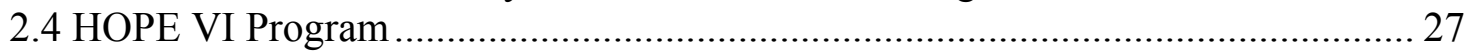

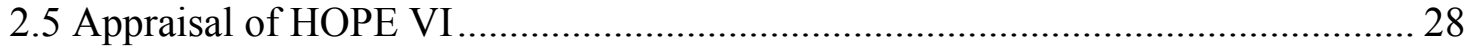

2.6 Public Education and Concentrated Poverty ........................................................... 31

2.7 The Link between Public Housing \& Public Education ............................................ 41

2.8 The Difficulty/Obstacles of Linking Public Housing to Public Education ............ 43

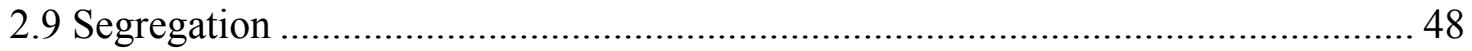

2.10 Housing Policy as De Facto Education Policy ……....................................... 49

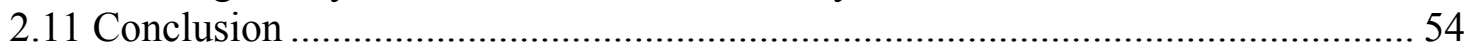

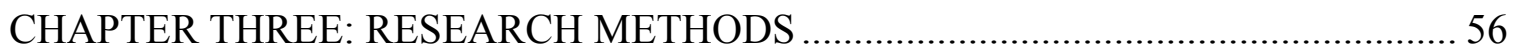

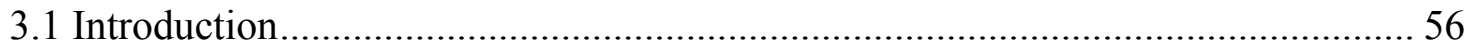

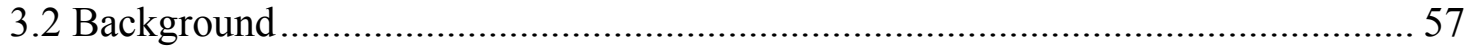

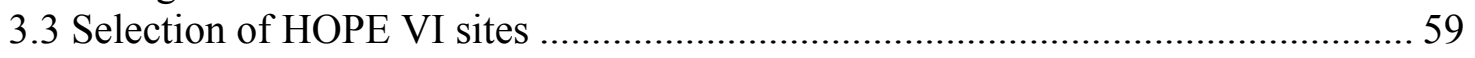

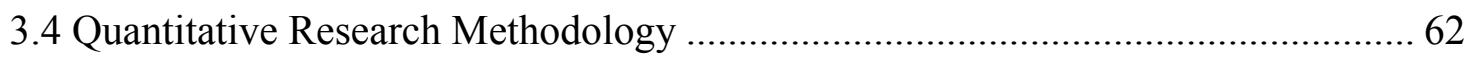

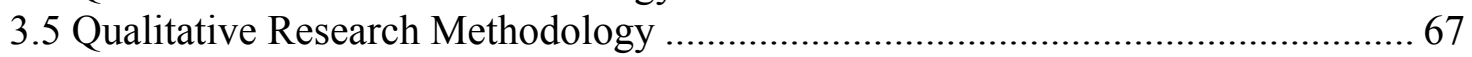

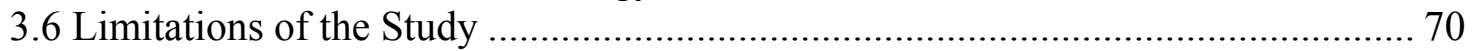

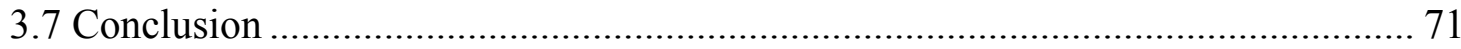

CHAPTER FOUR: SCHOOL SOCIO-ECONOMIC STATUS AND PERFORMANCE

.

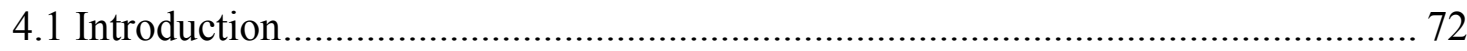

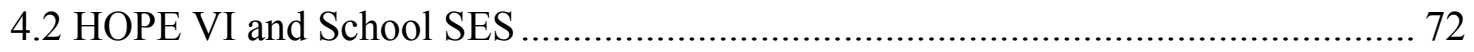

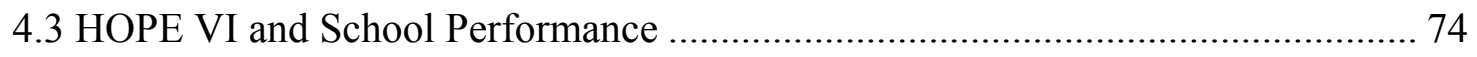

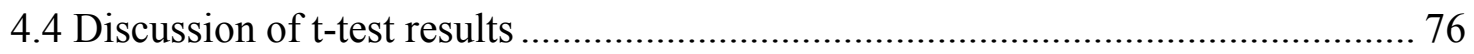

4.5 HOPE VI and School SES: Regression Analysis (Model A) ................................. 80

4.6 HOPE VI \& School Performance: Regression Analysis (Model B) ....................... 84 


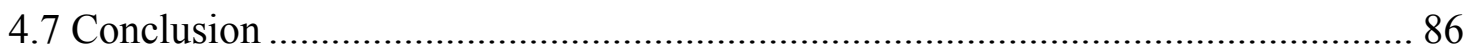

CHAPTER FIVE: FACTORS THAT INFLUENCE SCHOOL PERFORMANCE........ 89

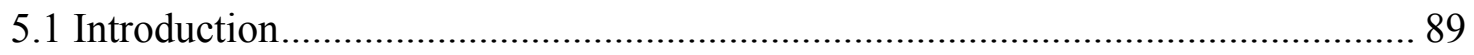

5.2 Selection of case study schools.................................................................... 90

5.3 Case Study Methodology ................................................................................. 93

5.4 Case Study of Andrew Jackson Elementary School in Philadelphia...................... 98

5.5 Case Study of Dr. R. Drew Elementary School, Washington, DC....................... 104

5.6 Comparative Analysis of Factors that Influence School Performance ................ 109

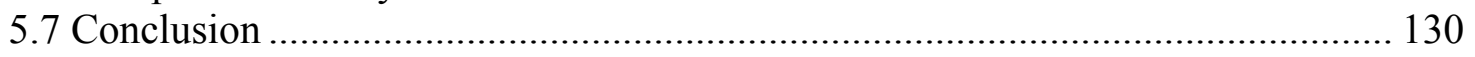

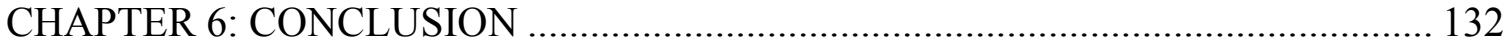

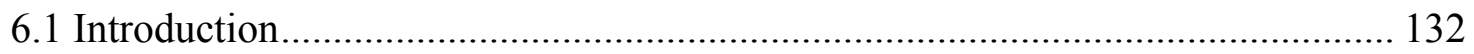

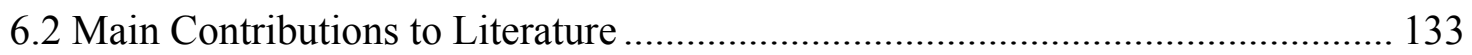

6.3 Implications for Policy and Practice ............................................................... 138

6.4 Recommendations for Future Research ......................................................... 143

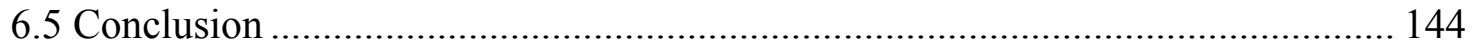

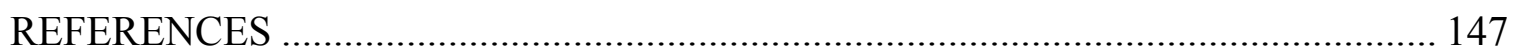

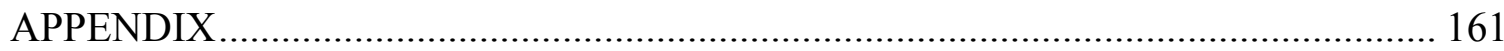

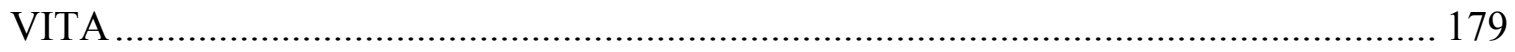




\section{LIST OF TABLES}

TABLE

PAGE

Table 1. US Income Eligibility Guidelines for the Free \& Reduced Lunch Program ...... 33

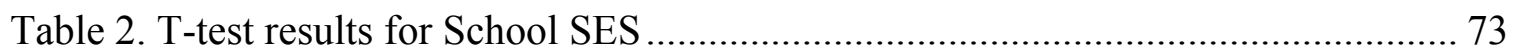

Table 3: T-test results for Average Reading Proficiency School Scores......................... 74

Table 4: T-test results for Average Math Proficiency School Scores............................. 76

Table 5. Regression Model A: Variables and Descriptions ...................................... 81

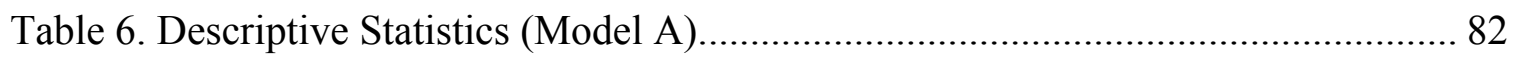

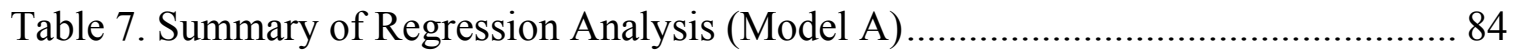

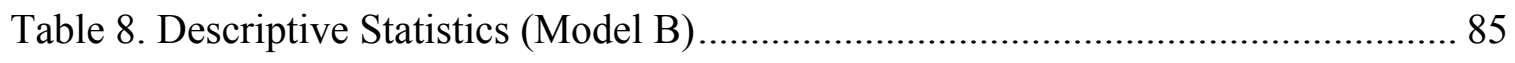

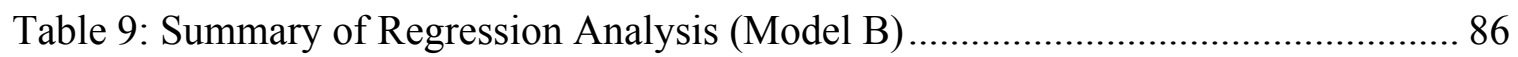

Table 10. HOPE VI Demolition Grants in Philadelphia and Washington, DC ............... 92

Table 11. HOPE VI Revitalization Grants in Philadelphia and Washington, DC........... 93

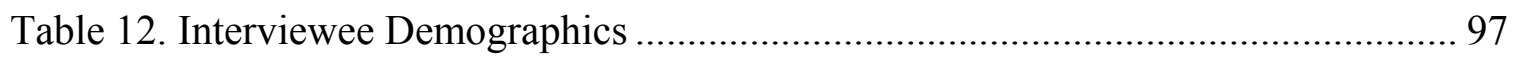

Table 13. School Performance and FRLP Rate of Andrew Jackson Elementary School,

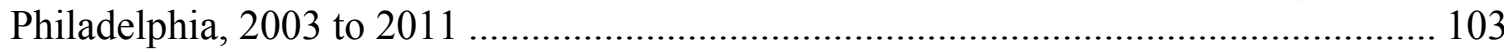

Table 14. Comparison of Proficiency of the School with the School District and State, 2008 to 2011

Table 15. School Performance and FRLP Rate of Drew Elementary School, Washington, DC, 2003 to 2011 . 109

Table 16: List of Universal Companies' partnerships to support HOPE VI transitional residence 115

Table 17. Enrollment at Andrew Jackson Elementary School 125 


\section{LIST OF ACRONYMS AND ABBREVIATIONS}

AYP

$\mathrm{CNU}$

DCHA

DOE

FRLP

GAO

HHS

HUD

PFS

PHA

PHA

NCLB

RTTP

SES

STEM
Adequate Yearly Progress

Congress for the New Urbanism

District of Columbia Housing Authority

United States Department of Education

Free and Reduced Lunch Program

U.S. Government Accountability Office

Department of Health and Human Services

United States Department of Housing and Urban Development

Performance Funding System

Philadelphia Housing Authority

Public Housing Authority

No Child Left Behind

Race to the Top

Socio-economic Status

Science, Technology, Engineering, and Mathematics Education 


\section{CHAPTER ONE: INTRODUCTION}

\section{$\underline{1.1 \text { Introduction }}$}

My dissertation examines how community revitalization initiatives influence neighborhood school performance. Specifically, it explores whether or not the social integration of neighborhoods through HOPE VI led to a change in performance at neighborhood public schools. In effect since 1992, HOPE VI is a public housing program administered by the United States Housing and Urban Development Department (HUD), and is based on the New Urbanism model of revitalizing neighborhoods through mixed income and mixed use communities. There are 165 such HOPE VI communities nationwide. Despite nearly two decades of the program's implementation, the scholarly literature on its connection to public school performance is thin. My aim is to narrow this research gap.

In the United States, public school enrollment is typically organized by neighborhood boundaries (also known as 'neighborhood schools'). These boundaries inextricably link public schools and neighborhoods. In inner cities, economic segregation compounded with the profound effects of concentrated poverty, high crime rates, and low quality housing have affected the performance of neighborhood schools (Bolton, 1992; Crane \& Manville, 2008). Although school improvement was not an immediate goal of HOPE VI, its efforts of social integration could arguably improve the neighborhood public schools' performance. HOPE VI specifically targeted concentrated poverty, poor housing conditions, and unsafe/unfit neighborhoods. There was no component of the revitalization initiative that targeted school performance. Subsequently in 2010, the 
HOPE VI program has since been broadened into the Obama Administration's Choice Neighborhoods initiative, which includes better educational outcomes. The Promise Neighborhood program established in 2010 by the Department of Education (DOE) follows the success of the Harlem Children's Zone in New York City to "significantly improve the educational and developmental outcomes of children and youth in distressed communities" (DOE, 2011, p. 1). It is in this context that my dissertation's aim to examine the relationship between the HOPE VI program and school performance becomes significant.

\section{$\underline{1.2 \text { Problem Statement }}$}

Concentrated poverty has a profound effect on the nation's inner cities. Public schools that serve poor communities are at a distinct disadvantage, as they are reliant on a relatively weak base- property tax. In addition, the school variables (per pupil spending, teacher salaries, and limited resources) and non-school variables (family income, parent educational level, parent participation, housing) issues create additional barriers. In response to concentrated poverty, HOPE VI sought to transform public housing by adopting New Urbanism, an urban design and planning movement. New Urbanism incorporated environmental balance, social integration, traditional planning, and modern technology (Katz, Bressi, \& Scully, 1994). Essentially, HOPE VI, by incorporating the elements of New Urbanism, aimed to revive inner cities, combat sprawl, expand mixeduse and mixed income developments, and provide affordable housing.

Although HUD's original design for public housing was created as temporary homes for low-income households to overcome short term poverty, HOPE VI 
communities were created with different principles. The design of HOPE VI communities entailed: 1) long term living, 2) community participation, 3) mixed income residents, 4) historic preservation, 6) low-maintenance (but not poor quality), and 6) the livable, workable, and walkable neighborhoods (HUD, 2000). In the end, HOPE VI's housing and community revitalization projects, incorporated five main goals:

- Changing the physical shape of public housing by replacing the worst public housing (characterized by physical deterioration, uninhabitable living conditions, high levels of poverty, inadequate and fragmented services, high levels of abandonment and blighted neighborhood developments with less dense developments);

- Reducing concentrations of poverty by encouraging a greater income mix among public housing residents and promoting mixed-income communities by providing market-rate housing;

- Creating positive incentives (job training and placement, education, case management for family support services, money management/financial planning initiatives, first-time buyer programs, etc.) for residents to achieve self-sufficiency;

- Providing comprehensive services that assist residents in achieving selfsufficiency;

- Creating broad-based partnerships to leverage additional resources (Rafell et al., 2003, p. 3).

My study builds upon the limited research on relationship between affordable housing and education (e.g. Armstrong et al., 2012; Braconi, 2001; Lubell \& Brennen, 
2007; Mueller \& Tighe, 2007; and Popkin et al., 2004), while also contributing to the literature on federal initiatives in local communities, using the example of HOPE VI's New Urbanism approach. Public schools in high poverty neighborhoods are consistently at a stark disadvantage as compared those schools in the low poverty, high tax base neighborhoods (Carey, 2003; Cohen, 2009). As early as 1966, James Coleman's report, Equality of Educational Opportunity found that "low-income students that attend middleclass schools have higher levels of achievement, and/or larger achievement gains over time, than those that attend high-poverty schools" (quoted in Report of the Century Foundation Task Force on the Common School, 2002, p. 13). The US Department of Education had similar findings in its 1993 Prospect Report: though non-poor students perform consistently better than their low-income classmates, the performance of nonpoor students nevertheless declines as the proportion of their classmates below the poverty line increases (as cited in Puma et al., 1993). Higher concentrations of poverty in schools pose great challenges to school-wide student performance (Crowley, Roscigno \& Tomaskovic, 2006; Orr, Stone \& Stumbo, 2002; and Puma et al., 1993) which may include: limited resources for the classroom, lower teacher wages, teachers without certification, physical plant in disrepair, high student mobility, etc. Beyond suggesting that high poverty school performance rates are lower than low poverty schools, there is no study on the broader theme of evaluating neighborhood school performance as it relates to community revitalization. 


\subsection{Significance of the Study}

The present study fills an important gap in extant literature on the relationship between the HOPE VI program and neighborhood school performance. To date, there are only two case study-based reports that have examined the link between HOPE VI and local schools. The first study, Abravanel, Smith and Cove (2006), maintained that the authors could not adequately define "what it means to join housing revitalization with school improvement" (p. 44). The second study by Raffel, et al. (2003) concluded that the most effective approach for attracting families to HOPE VI is to create magnet schools, but also noted political and bureaucratic resistance.

My study is significant for three reasons: First, the research fills a crucial gap in the literature linking affordable housing to public school performance using an interdisciplinary approach that includes quantitative and qualitative analysis. Much of the extant research related to HOPE VI focuses overwhelmingly on three areas: 1) challenges and possibilities of mixed income policy (Bohl, 2000; Cousins, 2001; GAO, 1998; and Varady et al., 2005), 2) the impact of HOPE VI policy on residents, (Popkin, 2007, 2004 \& 2002; GAO, 2003) their children (Gallagher \& Beata, 2007; Popkin et al., 2002), and 3) neighborhood and housing conditions as it relates to safety, amenities, and health (Goetz, 2010; Popkin et al., 2002, Rinker 2007). The literature on school performance has focused on socio-economics, funding disparities (Carey, 2003; Carter, 2000; Cohen, 2009; and Myerson, 2000) and school-based solutions (Luebchow, 2009 and McKinney et al., 2007). Unlike the extant studies focusing on individual student achievement, my dissertation focuses on the organizational level, namely, the schools, while examining the broader context of community revitalization and its influence on school performance. 
Second, my study informs policymakers at the United States Department of Education (DOE) and Department of Housing and Urban Development Department (HUD), of overlap in terms of policy, funding, and service delivery. Reforms, both in education and housing policy, have been separate efforts. In fact, Proscio (2004) describes an "unnatural separation" between the two fields. The implementation of public housing spans the course of almost 75 years, yet few studies investigate the academic outcomes in the neighboring public schools. Thus far, student performance has been studied in isolation in terms of school quality and, in most cases, ignores the impact of public housing. Although a connection between affordable housing opportunities and academic attainment may exist, little empirical research has investigated the link between public housing and public education. The dissertation aims to be of academic and policy value among housing scholars and educational officials.

Third, the research is significant in the context of two recent federal programs initiated under the current Obama Administration, Choice Neighborhood and Promise Neighborhoods. The Choice Neighborhood program authorized in 2010 under the Department of Housing and Urban Development (HUD) is an extension of HOPE VI with the goal of creating mixed income communities while incorporating an emphasis on early childhood education. The Promise Neighborhoods program established by the Department of Education (DOE) in 2010 aimed to improve the educational and developmental outcomes of children and youth in our most distressed communities by focusing on neighborhood level initiatives. While the two federal programs have broader goals in integrating communities and schools, they continue to function in isolation. This dissertation prompts an integrated approach between the two agencies to better serve the 
recipients of public housing and public schools. Best practices, as they relate to DOE and HUD partnerships, are investigated as they relate to neighborhood revitalization and the implementation of federal programs.

\subsection{Theoretical Framework}

Three seminal works form the theoretical basis of this research: Jane Jacobs' The Death and Life of Great American Cities (1961), William Julius Wilson's The Truly Disadvantaged (1987), and Jean Anyon's Hidden Curriculum (1980). Jacobs (1961) argued that cities were deteriorating because of a lack of diversity and concentrated poverty. Wilson (1987) highlighted that social isolation reinforced the underclass in inner-city areas with fewer job opportunities. Lastly, Anyon (1980) described how the location of the schools influenced school expectations and overall educational performance. While the first two authors highlighted the neighborhood-level environmental factors, the last author showed the significance of organizational (i.e. school level) factors.

To operationalize the study using the three theoretical approaches, the dissertation is predicated on the concept that housing policy is de-facto school policy. As HUD has itself recognized, "Since the nation's schools are typically neighborhood based, lack of economic integration in the nation's schools is a direct reflection of the lack of economic integration in the nation's neighborhoods" (HUD, 2003, p. 4). My research is necessary because the current knowledge linking neighborhood revitalization, affordable housing, and public school performance is thin. 
Public housing, since its inception in 1937, has been the subject of countless debates. It has been construed to perpetuate concentrated poverty. Often, public housing has entailed accommodating low-income families in high-density areas. The negative impacts of high density, low-income housing developments manifested themselves in a variety of forms as the spatial concentration of poverty led to disproportionate rates of crime, unemployment, pollution, and low quality schools (Crane \& Manville, 2008; Bolton, 1992). Not only has concentrated poverty impaired revitalization efforts but public housing has lacked diversity. As early as 1961, Jane Jacobs in The Death and Life of Great American Cities discussed the issues of concentration and diversity. She rejected programs such as urban renewal which she felt destroyed communities and created economically isolated areas. Her critique of urban planners pushed for a diversity of uses, short walkable blocks, and the preservation of buildings of various conditions. The HOPE VI Revitalization Grant sought to replace high rise public housing projects with mixedincome, mixed-use, low-rise developments. Essentially, HOPE VI is the practical application of Jane Jacob's ‘diversity improves cities' philosophy. Did mixed income communities lead to mixed income schools? One objective of this dissertation is to test this theory by investigating the level of social integration at the neighborhood public schools.

One of the most notable writers of urban poverty, William Julius Wilson in The Truly Disadvantaged outlined two critical nuances that exacerbated concentrated poverty and increased racially segregated large metropolitan areas for blacks and Hispanics. Despite Civil Rights and the move toward desegregation, poverty and segregation became more pronounced between the 1970's to the 1980's in inner-city areas with the 
structural changes in the American economy which shed the need for unskilled workers. Affluent and educated blacks left the inner-city areas, whereby the 'truly disadvantaged', also referred to by Wilson as the "urban underclass," were left behind (Wilson, 1987). The lack of role models and educational opportunities reinforced the urban despair in the inner-city areas.

In a follow up to the 1987 work, Wilson (1991) expanded on the theories of joblessness and dislocation that negatively impacted a 'relatively young population' ( $\mathrm{p}$. 6). Several major issues created the shift: the economy transitioned from a goods producing to a service economy which led to a polarization of the labor market; there was a direct change from a low wage vs. high wage sector; technology improvements further transformed the production process; and relocation and suburbanization of manufacturing jobs made access to employment problematic. These very real issues were coupled with periodic recession, wage stagnation, and spatial and job mismatch. This onslaught of market transitions were not just a recipe for disaster but crippled the job potential for inner city, low-income, low-skilled workers.

The concentration and isolation of low income families, resulting from high rise projects where the 'urban underclass' were housed, had a significant impact not only on cities but also their neighborhood public schools. While HUD's public housing efforts, particularly in urban projects, experienced painful transitions, public schools succumbed to the same pressures related to concentrated poverty. To investigate Wilson's theory of social isolation and its effects in public schools, this research investigates the change in socio-economic status and its possible relationship to school performance following the implementation of HOPE VI. 
Beyond investigating the influence of neighborhoods, it is necessary to examine the dynamics of education within the school. Jean Anyon's Hidden Curriculum (1980) argued that the location and economic standing of the parents and surrounding community influenced school expectations and its performance. Anyon's work highlights social inequalities that go beyond access to resources. Essentially, students are taught to duplicate the working patterns of their parents. In low income schools, education is administered through training, regulations and consequences; in contrast, high income school students are encouraged to have original thoughts, practice ingenuity and have few restrictions related to behavior and/or conduct. My dissertation aims to determine if there is such influence of the 'hidden curriculum' in neighborhood public schools through quantitative and qualitative methods. Using quantitative methods, the study examines the relationship between students' socio-economic status and overall public school performance in communities that implemented HOPE VI program. Using qualitative methods, the study identified the factors that contribute to performance of public schools in HOPE VI areas.

\subsection{Research Questions}

Following the above theoretical framework, I have three objectives in this research. The first objective, following Jane Jacobs, is to investigate the level of social integration at the neighborhood public schools. Following Julius Wilson, my second objective is to examine the change in socio-economic status and its relationship to performance of schools in HOPE VI neighborhoods. The third objective, after Jean Anyon, is to examine the organizational factors at the school level that influenced the 
performance of the HOPE VI neighborhood public schools. Consequently, there are three principal research questions:

Q1: Following the implementation of HOPE VI, was there a change in socioeconomic status (SES) rates in the neighborhood public school?

H1: This question is important to consider since low SES (especially concentrated poverty) poses a great obstacle to school wide student performance (Kraus, 2008; Orr et al., 2002; and Puma et al, 1993). In this study, the proportion of students in the Free and Reduced Lunch Program (FRLP) is used to measure SES. The FRLP is well-recognized as an indicator of low SES in educational research. Consistent with the HOPE VI program's intent of mixed-income neighborhood, the hypothesis is that the HOPE VI program reduced the proportion of low-SES students in the neighborhood public schools. This hypothesis is tested since, despite its intended goal of mixed-income neighborhoods, HOPE VI neighborhood schools may not have achieved this goal: the project size may be too small to impact the neighborhood school FRLP composition, or higher-income parents may not send their children to such schools.

Q2: Following the implementation of HOPE VI, did the performance of neighborhood public schools change?

H2: The hypothesis is that schools located in HOPE VI neighborhoods were likely to improve their school performance, based on the extant literature that mixed SES contributes to better neighborhood public school performance. For example, the Department of Education's report, Prospects: The Congressionally Mandated Study of Educational Growth and Opportunity (Puma et al., 2003, p. 2) surmised, "school poverty 
depresses the scores of all students in schools where at least half of the students are eligible for subsidized lunch and seriously depresses the scores when more than 75 percent of students live in low-income households.” As early as 1966, researchers found that low-income students attending middle-class schools have higher levels of achievement, and/or larger achievement gains over time, than those attending highpoverty schools. The striking correlation between concentrated poverty and poor school performance is consistently reported in the education literature (Banks, 2001; Coleman et al., 1966; Kraus, 2008). In this dissertation, school performance is measured by math and reading state proficiency test scores. State-released scores are well-recognized as an indicator of school performance in educational research.

\section{Q3: What factors relate to the performance of public schools in HOPE VI communities?}

H3: Traditionally, higher performing schools are characterized by smaller proportions of low income and minority students (Carter, 2000; Mickesolson, 2011; Rusk, 2011). To close the 'achievement gap,' traditional reform efforts include federal mandates (No Child Left Behind and Race to the Top), school based reform (administrative training, classroom size, small schools, curriculum modifications) and professional development of teachers (education, training, sensitivity). Based on these previous studies, factors related to neighborhood revitalization (housing, training, mixed income, safety, social integration) are hypothesized to improve performance in HOPE VI neighborhood public schools. 


\subsection{Research Design and Methodology}

The dissertation includes both quantitative and qualitative research methods to answer the above three research questions. To test the first hypothesis that the proportion of FRLP students decreased in HOPE VI communities, I performed t-tests to examine if there is a significant difference in the FRLP composition before and after HOPE VI implementation. The tests are performed for two periods: three (3) years before and after the implementation of HOPE VI; and six (6) years before and after treatment for sensitivity analysis.

Similar to the first hypothesis, in order to test the second hypothesis, I used the ttest analyses to examine if there is significant difference in the school performance before and after HOPE VI implementation. The tests are performed for two periods: three (3) years before and after the implementation of HOPE VI; and six (6) years before and after treatment for sensitivity analysis.

In addition, two regression analyses are used to determine if there is a statistical relationship between HOPE VI as a community revitalization tool and the change in school SES and academic performance. The HOPE VI public housing variables include: demolition funding (dummy), change in the number of housing units, HOPE VI construction completion rates (years), and the funding amount as part of the Revitalization Grant. The data were collected for three years before and after the implementation of HOPE VI to determine school level change of the following variables: student demographics (race), proportion of students who qualify for FRLP, per-pupil allotment at each school district, student-teacher ratio, and school enrollment. The regression is performed for two models. The dependent variable in model one is the 
change in school SES (proportion of students that qualify for FRLP). The model two's dependent variable is the change in school performance (math and reading scores).

To examine the third question, I used a qualitative approach to examine organizational level factors that influence school performance. I conducted case studies of two schools - one with the highest change, and one with the lowest change in math and reading scores (best and worst performing) — following the implementation of HOPE VI. I arrived at the best and worst performing neighborhood public schools based on the quantitative analysis performed for school performance. According to the analysis, the Andrew Jackson Elementary School, which is the neighborhood public school for HOPE VI Martin Luther King Plaza project in Philadelphia, had the most improved performance. The Drew Elementary, which is the neighborhood public school of HOPE VI Capitol Gateway project in Washington, D.C., reported a drastic decrease in performance following the implementation of HOPE VI. In conducting the case studies of these two schools, I examined the collaboration between the HOPE VI project officials and the neighborhood school administrators, funding, the SES of the HOPE VI housing schemes and the HOPE VI construction completion schedules. I conducted a total of fourteen interviews in the two cities for the case studies of the two schools.

The primary sources for the case studies are interviews, site reviews, and attendance at local community, housing, and school board meetings. The secondary sources include historical data, congressional documents, articles from professional journals, newspaper articles, professional presentations from national conferences, and testimony before the House Subcommittees for Housing and Community Opportunity. To analyze the interviews, I used the NVivo 9 software, which supports the collection and 
organization of qualitative data and documents while providing search, query and visualization tools.

\subsection{Limitations of the Study}

The limitations of the dissertation are associated with the varied nature of implementing the HOPE VI program and changes in the broader national economic context. First, although the HOPE VI began in 1992, the project completion at the 165 nationwide sites ranged anywhere from two to 17 years. In a few cases HOPE VI conversions remain incomplete. Second, there has been some redistricting and reclassification of public schools after HOPE VI's implementation. In several school districts, students were no longer assigned to their neighborhood (closest) school. In some cases, the neighborhood school was designated as a magnet or charter school. Since all neighborhood children do not have access to the magnet or charter schools, they are not included in this study. This research specifically focuses on traditional public schools.

Third, the national housing and economic crisis of mid 2006 could affect the analysis because homeownership, one of the goals of HOPE VI, was negatively impacted during the research period. Yet, I do not consider the economic crisis to be a serious impediment since many families were permitted to rent or lease properties. Finally, the last limitation is the use of the case study method. The cases of examining the extremes

of school performance may not lend themselves to generalizations. However, the intent is not to generalize, but to get deeper insights into the organizational level factors that assist or impede in school performance. 


\subsection{Overview of Chapters}

The dissertation chapters are organized in the following manner. Chapter two examines the literature related to public housing and public education. The chapter draws on the three seminal works of Jane Jacobs' 1961 book, The Death and Life of Great American Cities, William Julius Wilson's 1987 book, The Truly Disadvantaged, and Jean Anyon's 1980 book, Hidden Curriculum. It outlines the evolution of public housing in the United States, including the efforts of the National Commission on Severely Distressed Housing, the application of New Urbanism, and the impact of HOPE VI. Then, the public education reforms are reviewed, focusing specifically on high poverty schools and federal school reform. The chapter also discusses the difficulty of making the connection between public housing and public education. It highlights why an interdisciplinary research approach is required, while avoiding the pitfalls most commonly associated with linking neighborhood changes with school performance. Lastly, the chapter outlines the notion of housing policy as de facto school policy.

Chapter three explains the research design and methods. In this, I explain the quantitative and qualitative techniques that are employed to answer the research questions. It outlines the operationalization and measurement of the independent and dependent variables. To test the first and second hypothesis on neighborhood level socioeconomic status changes and school performance respectively, t-tests and regression analyses are performed. Case study method is used for analyzing two neighborhood schools in order to gain insights into the factors that influence public school performance in HOPE VI areas. The data collection process is also presented in this chapter. 
Chapter four presents the results of the quantitative analyses of the t-tests and the regression model. The first two hypotheses are tested in this chapter. These hypotheses are that following the implementation of HOPE VI, the neighborhood public schools are likely to reduce the school FRLP rates and improve their school performance. The t-test analyses are carried out for testing if there is significant difference between the three years before and three years after; for sensitivity purposes, the same analyses are carried out for six years before and six years after. There are two regression models, the first using the school FRLP rates as the dependent variable, and the second using the public school performance as the dependent variable. The independent variables are demographic (race), socio-economic status (proportion of students who qualify for FRLP), financial (per-pupil allot at each school district), and education (student-teacher ratio, school enrollment).

Chapter five consists of the findings from the two case studies conducted in Philadelphia, PA and Washington, DC. The primary sources for the case studies are interviews, site reviews, and attendance at local community, housing, and school board meetings; these sources are then supplemented with secondary sources (e.g., historical data, congressional documents, articles from professional journals, newspaper articles,). To determine the housing factors that influence school performance, I conducted a full review of each city, the individual housing authority, site selection process, and other details related to the HOPE VI projects. I analyzed the interviews using NVivo 9 software to reveal the major themes.

The final chapter, chapter six, presents the study's conclusion including a discussion of implications of the study for public housing and public school officials, 
partnership initiatives, policy development, and program implementation strategies. The chapter reiterates the need for looking at housing policy as a de-facto education policy. 


\section{CHAPTER TWO: PUBLIC HOUSING AND EDUCATION—A LITERATURE REVIEW}

\subsection{Introduction}

This chapter is a review of the literature on public housing and public education. I examine the impact of neighborhood revitalization efforts on affordable housing and traditional public schools. Since my research problem is most closely associated with concentrated urban poverty and public schools, three seminal works that span these fields form the theoretical basis of this research: Jane Jacobs' The Death and Life of Great American Cities (1961), William Julius Wilson's The Truly Disadvantaged (1987), and Jean Anyon's Hidden Curriculum (1980). Jacobs (1961) argued that cities were deteriorating due to a lack of diversity and concentrated poverty. Wilson (1987) highlighted that social isolation reinforced the underclass in inner-city areas with fewer job opportunities. Lastly, Anyon (1980) described how the location of the schools influenced school expectations and overall educational performance. While the first two authors highlighted the neighborhood level environmental factors, the last author showed the significance of organizational (i.e. school level) factors.

The above three seminal works provide a good basis for linking HOPE VI program and public schools. Enacted in 1992, the federal HOPE VI program was a result of recommendations by the National Commission on Severely Distressed Public Housing, which was charged with providing a plan to alleviate severely distressed public housing nationally. The HOPE VI program has followed the principles of New Urbanism, which espouse mixed-income, mixed-use, and low-rise housing developments. Federal public school reforms have been mainly focused on alleviating high poverty schools. 
However, these school reforms have largely been independent of housing policies. This chapter highlights the obstacles to linking housing to education, the merits of making the connection, and to think of housing policy as de facto school policy.

\subsection{Public Housing \& Concentrated Poverty}

Since its inception in 1937, public housing has been the subject of countless debates. It has arguably perpetuated concentrated poverty as the means-tested approach resulted in low-income families being housed in high density areas. Public housing was originally built on a relatively small scale as two and three story walk-ups and garden apartments which were financed through bond initiatives and revenues generated by rents to cover costs. By the 1950s, high-rise building styles dominated the program. By the 1970s, rents were tied to incomes, in which only the poor tenants were eligible for public housing. Rents were often not enough to cover the maintenance costs, and the revenue gap led to the deterioration of many units (Stoloff, 2004).The National Commission on Severely Distressed Public Housing (1989) reported that 86,000 (six percent) of 1.4 million public housing units were severely distressed, characterized by physical deterioration, uninhabitable living conditions, high levels of poverty, inadequate and fragmented services, institutional abandonment and blighted neighborhoods. The negative impacts of high density, low-income housing developments manifested themselves in a variety of forms as the spatial concentration of poverty led to disproportionate rates of crime, unemployment, and low quality schools (Crane \& Manville, 2008; Bolton, 1992). 
Revitalization efforts in general, and public housing programs in particular, have reduced diversity in inner-city areas. As early as 1961, Jane Jacobs in The Death and Life of Great American Cities discussed the problems of concentration and lack of diversity. She argued that cities were deteriorating not only because of the mere concentration of poverty but also because the urban areas lacked diversity. Diversity, according to her, not only included ethnicity and race but also encompassed families of various incomes and preservation of buildings of various conditions (rehabilitation). In addition, she highlighted the need for places to have a diversity of uses to serve various functions. Jane Jacobs' writings had a profound influence on the New Urbanism movement that emerged later in the 1980s. Following her, the movement propounded the need for mixed-income, mixed-use and low rise developments for a vibrant urban life.

From a socio-economic perspective, one of the most notable writers of urban poverty, William Julius Wilson in The Truly Disadvantaged outlined the sociological nuances of concentrated poverty and racial segregation of Blacks and Hispanics in innercity areas. Poverty and segregation became more pronounced between the 1970's to the 1980 's because the economy shed the need for unskilled workers and affluent blacks left the ghettos which led to social isolation. Thus, the 'truly disadvantaged', also referred to by Wilson as the "urban underclass" was essentially left behind (Wilson, 1987).

In a follow up to the 1987 work, Studying Inner-City Social Dislocations: The Challenge of Public Agenda Research: 1990 Presidential Address, Wilson (1990) expanded on the theories of joblessness and dislocation that negatively impacted a 'relatively young population' (p 6). Several major issues created the shift: the economy transitioned from a goods producing to a service economy which led to a polarization of 
the labor market; there was a direct change from a low wage vs. high wage sector; technology improvements further transformed the production process; and relocation and suburbanization of manufacturing jobs made access to employment problematic. These very real issues were coupled with periodic recession, wage stagnation, and spatial and job mismatch. This onslaught of market transitions crippled the job potential for inner city, low-income, low-skilled workers.

In addition, the departure of middle income blacks meant that social and structural access to job networking was also broken. In this social context, "poor individuals with similar educational and occupational skills confront different risks of persistent poverty depending on the neighborhoods they reside in, as embodied in the formal and informal networks to which they have access..." (p.10). Essentially, when middle income families left, the community lacked the influence, information, and connections to employment. Wilson also noted that social context is not restricted to simply limited employment, but also poor schools.

By the early 1980s and as Wilson identified in the Truly Disadvantaged, the U.S. Department of Housing and Urban Development understood that a new approach to public housing and community redevelopment was necessary. Public housing and their residents had succumbed to numerous problems which included physical issues (discriminatory site selection, high housing density, and inexpensive construction techniques), social and economic problems (redlining of urban areas, federal subsidies for suburban development, poor property management, caps on rent payments), and the advent of social ills (illegal drugs, a culture of dependency, and disenfranchisement) (Salama, 1999, p. 95). 


\section{$\underline{2.3 \text { Efforts to Reform Severely Distressed Public Housing }}$}

Public housing authorities around the nation were confronting the problems of public housing and concentrated poverty. Since the 1970s, the housing authorities went so far as to demolish public housing projects that were crime-ridden and drug-havens. The Saint Louis Housing Authority, for example, demolished the famous Pruitt Igoe public housing project in 1972. Reformers of public housing called for new approaches to public housing, in order to alleviate the chronic problems. Towards this end, the U.S. Congress formed the National Commission on Severely Distressed Public Housing in 1989, with the goal of eradicating severely distressed public housing. The commission's team consisted of 16 committee members, 13 consultants, and 7 research and technical staffers. They traveled to 21 cities throughout the United States to gather data, record first-hand accounts, and document local solutions. The commission found that there were 86,000 units of severely distressed public housing. Severely distressed public housing was considered "unfit, unsafe, and unlivable" (p. 2). According to the commission, severely distressed public housing was characterized by four dimensions:

1. Families living in socially distressed conditions, whereby residents have high rates of unemployment, high drop-out rates from school, and very low household income

2. High rate of crime in the public housing developments and surrounding neighborhoods, because of economic conditions, violent crimes, and drug trafficking 
3. Barriers to managing the environment, where the public housing authority's basic management functions may be hindered because of its limited capacity, or local political and community conditions

4. Physical deterioration of buildings

To alleviate severely distressed public housing, the commission became keenly aware of the need to demolish inhabitable buildings. However, it made a clear warning: units should be replaced on a one-to-one basis and should "not increase or cause additional neighborhood problems" (p. 87). The decision to demolish, refurbish, restore, or retrofit, was dependent on two central questions: (1) Which method was most cost efficient and financially feasible? and (2) Which method would replace the same number of units and housing options? Demolition became the most popular alternative but the one-for-one replacement plan was not followed through (p. 94-96).

Beyond the extensive needs for physical improvements, the residents required social support. The commission argued that social services (welfare, food stamps, educational training, etc.) should be incorporated for low-income families. Unfortunately, federal agencies lacked coordination among themselves to provide such services. Consequently, the commission's plan envisaged partnering HUD with agencies such as the Department of Health and Human Services (HHS) to create a more 'integrated and holistic system' (p. 49). In addition, the commission recommended providing economic support for employment. The support included, but was not limited to: start-up and business funding, Public Housing Authority (PHA) resident entrepreneurship programs, and obtaining empowerment zone benefits (p. 54-58). 
The commission further deemed that the problem of concentrated poverty was compounded by public housing rent regulations that were means tested. The commission opined, "rent selection, rent calculation, and income eligibility regulations have screened out all but the poorest households for public-housing" (p. 110- 113). Thus, the poorest residents were isolated in large, high density settings. Meanwhile, the "working poor" were all but ignored. Affordable housing was not attainable because eligibility requirements shut the working poor out of assistance and, in fact, hindered their stability. In fact, “. .. an employed resident rent increased $\$ 1.00$ for every additional dollar earned" (p. 103). The practice of supporting only the poorest of families coupled with disincentive for improving or seeking employment led to high density high rises with concentrated poverty. Thus, the 'truly disadvantaged', coined by William Julius Wilson, were intrinsically isolated because of HUD eligibility requirements. Consequently, the Commission recommended that PHA modify their eligibility requirements to include stable working families. There was a push to integrate both family and income mixing in future public housing developments.

With the two-fold approach which included access to affordable housing as well as improving resident well-being, the commission broadened the scope of revitalizing public housing to improve the entire surrounding community. The commission emphasized public safety as a key factor to the success of public-housing. Essentially, "when field operations cannot function, vacant units remain vacant, uncontrolled rent and drug dealers are ignored, and graffiti is left on the walls...a sense of lawlessness is pervasive" (p. 65). To ensure a higher level of security, the commission proposed capital improvements of the public housing. The improvements were to incorporate key planning 
elements for safety, including proper site selection, distinguishing among family, adult, and senior residents' developments, safe outdoor recreational spaces, and human scale building design. The building's entry was controlled for safeguarding the residents.

The commission dealt extensively with the financial problems of PHAs related to capital improvements, modernization, management, and maintenance. The financial management was either poor or, in some cases, absent, resulting in the public housing projects becoming severely distressed. In some cases, federal, state and local funds had specific, designated appropriations that did not always match the needs of the project. For example, severely distressed public housing struggled with drug trafficking, gangs, escalating crime, and violence. Yet, HUD's Performance Funding System (PFS) formulas did not allow funding for security services (p. 105). Moreover, revitalization efforts had been stalled by red tape. Under the then modernization formula, PHAs were forced to choose between funding management or capital improvements. The Commission proposed a more streamlined, holistic approach that would include budget flexibility. Private and public partnerships would also bolster funding and accountability.

Lastly, the Commission proposed that Congress adopt an independent public housing accreditation process. Accreditation would enhance the monitoring system. Performance measures targeted evaluation, meeting standards, and implementation. Public housing revitalization would now take a holistic approach to change the surrounding community, thus resulting in neighborhood revitalization. Most importantly, the commission realized that the 'one size fits all model' was inappropriate as a national plan. 


\section{$\underline{2.4 \text { HOPE VI Program }}$}

The Housing and Urban Development (HUD) department's HOPE VI program emerged essentially in response to the findings of the Commission on Severely Distressed Public Housing. To address each negative finding by the commission, HUD sought to adopt new and innovative approaches since the early 1990s to deal with affordable housing, infrastructure improvements, and community development. This was a massive undertaking. At the same time, New Urbanism, an urban design and planning movement had been gaining momentum. The movement combined traditional planning and modern technology to create places that were contrary to the conventional suburban model of malls and highways. New Urbanism's ideals included environmental balance, social integration, and a true sense of community (Katz et al, 1994).

In October 1993, six architects at the forefront of this emerging movement-Peter Calthorpe, Andres Duany, Elizabeth Moule, Elizabeth Plater-Zyberk, Stefanos Polyzoides, and Daniel Solomon — took steps to incorporate a nonprofit organization that advocated for the principles of New Urbanism (Arendt, 2000). Their collective efforts resulted in the Congress for the New Urbanism (CNU) which promoted "walkable, neighborhood-based development as an alternative to sprawl". In addition, the organization focused on a "proactive, multi-disciplinary approach to restoring communities" (Congress for New Urbanism, 1997, p. 3).

By 2000, CNU and HUD joined forces to create Principles for Inner City Neighborhood Design. The broad range of principles included: citizen and community involvement, economic opportunity, diversity, vibrant neighborhoods, infill developments, mixed use, city-wide and regional connections, walkable streets, public 
open space, safety and civic engagement, dwelling as mirror of self, accessibility, local architectural character and design codes (HUD, 2000). These ideas and principles were incorporated into the HOPE VI project. Although HUD's original intent for public housing was to create temporary homes to alleviate short term poverty of low-income households, HOPE VI communities were created with the expectation of long term living.

\subsection{Appraisal of HOPE VI}

Much of the research related to HOPE VI focuses on three areas: 1) challenges and possibilities of mixed income policy (Fraser and Nelson, 2008; GAO, 1998; HUD, 2003; Popkin, 2004; Varady et al., 2005); 2) the impact of HOPE VI on residents (Popkin, 2007, 2004 \& 2002; GAO, 2003) and their children (Gallagher \& Beata, 2007; Popkin et al., 2002); and 3) neighborhood and housing conditions as they relate to safety, amenities, and health (Goetz, 2010; Popkin et al., 2002, Rinker 2007).

Since this dissertation seeks to determine the relationship between HOPE VI neighborhoods and the socio-economic status (SES) of students in neighborhood public schools, the ability of HOPE VI to create mixed income housing must be reviewed. To date, the results of HOPE VI use of mixed-income housing are inconclusive. In 1998, the U.S. Government Accountability Office (GAO) determined that some communities were too distressed to attract investors, partners, or leverage funds. Yet, economically viable communities in places such as Atlanta and Washington, DC were quite successful in creating mixed income communities. 
Eleven years following the implementation of HOPE VI, HUD (2003, p. 3) announced that "in practice, there is no single formula, or standard definition of mixedincome housing." Nonetheless, mixed-income housing in general terms refers to a development that provides market rate homes with a portion of units reserved for subsidized and/or under market rate. Essentially, mixed income housing allows access to families or individuals of various income levels, mainly to ensure housing for low income occupants. To date, there is no regulated percentage of housing that must be reserved for low income occupants. In each HOPE VI location across the country it is left to public housing officials, developers and planners to determine a healthy and sustainable mix.

Popkin et al (2004) found that HOPE VI was successful in "demolishing tens of thousands of severely distressed housing units, many of which were uninhabitable by any standard" (p. 47). In fact, across the nation, HOPE VI was successful along several quantifiable measures: new high quality housing that replaced distressed housing, publicprivate partnerships that leveraged funds and site management, giving vouchers for relocating residents to safer neighborhoods, revitalizing neighborhoods, and reduction in crime in completed projects. Notwithstanding these successes, some of the HOPE VI failed public housing residents drastically. Relocation and planning was not always accompanied with providing the voucher; some voucher users moved to other highly distressed communities; and the vouchers provided did not cover higher cost of rent and utilities in the private market. All of these lead to considerable neighborhood instability. In addition, as Popkin (2004, p. 50) highlighted, the HOPE VI did not meet the specific needs of 
"hard to house" families ...vulnerable families, including custodial grandparents, families with disabled members who need accessible units, large families, and "multiproblem" households with members who have mental and physical illnesses, substance abuse problems, or criminal records. These families often cannot meet the criteria for new, mixedincome developments - or in some cases, may be required to exclude certain family members if they want to return (p. 50).

The HOPE VI approach to demolition decreased subsidized housing units by " 22 percent of occupied units and 49 percent of all units" (p. 51).

Varady et al. (2005) questioned the fundamental feasibility of HOPE VI to create mixed income communities. In their comparative case study of HOPE VI projects in four cities (Cincinnati, Louisville, Baltimore, and Washington, DC), only Louisville was successful in attracting middle income families with children. This was partly due to the city-suburban school system, in which the children's school choice is not restricted to attendance in the neighborhood public school. The other three communities were only able to attract "middle income singles, childless couples and moderate income families with children" (p. 155). HOPE VI did little marketing to attract middle income families and engendered little or no collaboration between housing authorities and public schools.

Much like the Popkin (2004), Fraser and Nelson (2008) found that mixed income housing promoted neighborhood revitalization but did not meet the needs of lowerincome residents. They found that mixed income housing was successful in "lowering crime, improving economic indicators, and producing quality housing for market-rate and 
subsidized tenants...Yet, very low income residents faced barriers to self-sufficiency, health and general well- being" (p. 2141).

In summary, as a placed based strategy, HOPE VI has been effective in reclaiming neighborhoods, reducing crime, and improving the environment (Popkin, 2005; Fraser and Nelson, 2007). However, as a people based strategy, HOPE VI could be considered as being less successful for the most vulnerable population. To be eligible for the mixed income developments, residents must have stable employment, some education/training, and no criminal background. The poorest and/or most vulnerable residents are generally excluded from the revitalized neighborhood.

\subsection{Public Education and Concentrated Poverty}

While HUD's public housing programs underwent a significant transition in response to the problems of concentrated poverty, public schools have also been facing the same pressures related to concentrated poverty. High poverty public schools have been consistently at a stark disadvantage to their low poverty, high tax base counterparts (Carey, 2003; Cohen, 2009). Not only are students impacted by the "detrimental effects of poverty and human despair" but also by teacher absenteeism and their low performance. In inner city- high poverty schools, teacher absenteeism is high, the student attrition rates are extremely high, and have fewer teachers as indicated by the high teacher vacancy rates (McKinney et al., 2007, p.1).

The funding limitations create additional barriers in high-poverty schools, which affect teacher quality. Good teachers are hard to attract when the school lacks adequate funding. Funding disparities create discrepancies in teacher's pay - teachers in poor 
schools get paid less (Luebchow, 2007) and high-poverty schools are more often staffed with teachers with less skill and experience (Peske \& Haycock, 2006). Thus, students in poor schools have, on average, teachers with less education, experience, and skill (Carey, 2003). As teachers get more experience they opt to teach in more affluent schools with higher pay and better working conditions (McKinney et al., 2007).

Much like the dilemma in public housing, public schools are not only saddled with concentrated poverty but also have to deal with a lack of diversity. This lack of diversity in terms of income, race, and experience is not only a problem for high poverty schools but also has far reaching consequences. The US Department of Housing and Urban Development (2003) found that white suburban children were also disproportionately attending schools with little diversity. Public schools lack diversity because neighborhoods have similar real-estate values and there is sorting of households by their incomes. School boundaries have often been drawn around such homogenous neighborhoods. Systematic separation of class and race have stemmed from initiatives such as urban renewal which augmented housing shortages and increased housing prices, federal highway programs which reinforced segregation, discriminatory practices of FHA, bank redlining, exclusionary zoning, and closing or resetting boundaries of neighborhood schools (Anderson \& Jones, 2002). These practices have been discontinued for the most part but their lasting effects are evident by the lack of economic and racial diversity in cities and schools. 


\subsubsection{High Poverty Schools}

High poverty schools are labeled so based on the low socio-economic status of their student population. A school is classified as high poverty when $75 \%$ of the student population qualifies for Free or Reduced Lunch (FRLP) (Aud et al, 2011). Students who qualify for the federally sponsored National School Lunch Program receive nutritional low cost or free daily lunch. The current income eligibility guidelines in order to qualify for the FRLP are given in Table 1.

Table 1

US Income Eligibility Guidelines for the Free \& Reduced Lunch Program

\begin{tabular}{|c|c|c|c|c|c|c|c|c|c|c|c|}
\hline \multicolumn{12}{|c|}{ INCOMEEIGIBILITY GUIDEINES } \\
\hline \multirow{4}{*}{$\begin{array}{l}\text { HOUSEHOLD } \\
\text { SRE }\end{array}$} & & \multicolumn{4}{|c|}{ Effective from } & July 1,2011 & to & \multicolumn{2}{|c|}{ June 30,2012} & & \\
\hline & $\begin{array}{l}\text { FEDRAL POVERTY } \\
\text { GUIDEIINES }\end{array}$ & \multicolumn{5}{|c|}{ REDUCED PRICE MEALS - $185 \%$} & \multicolumn{5}{|c|}{ FREI MEALS - $130 \%$} \\
\hline & \multirow[b]{2}{*}{ ANNUAL } & & & TWICEPER & EVERY TWO & & & & TWICEPER & EVERY TWO & \\
\hline & & ANNUAL & MONTHLY & MONTH & WEEKS & WEEKLY & ANNUAL & MONTHLY & MONTH & WEEKS & WEEKLYY \\
\hline \multicolumn{12}{|c|}{48 CONTIGUOUS STATES, DISTRICT OF COLUMBIA, GUAM, AND TERRITORIES } \\
\hline $1 \ldots \ldots$ & 10,890 & 20,147 & 1,679 & 840 & 775 & 388 & 14,157 & 1,180 & 590 & 545 & 273 \\
\hline $2 \ldots \ldots$ & 14,710 & 27,214 & 2,268 & 1,134 & 1,047 & 524 & 19,123 & 1,594 & 797 & 736 & 368 \\
\hline $3 \ldots \ldots$ & 18,530 & 34,281 & 2,857 & 1,429 & 1,319 & 660 & 24,089 & 2,008 & 1,004 & 927 & 464 \\
\hline $4 \ldots \ldots$ & 22,350 & 41,348 & 3,446 & 1,723 & 1,591 & 796 & 29,055 & 2,422 & 1,211 & 1,118 & 559 \\
\hline $5 \ldots \ldots$ & 26,170 & 48,415 & 4,035 & 2,018 & 1,863 & 932 & 34,021 & 2,836 & 1,418 & 1,309 & 655 \\
\hline $6 \ldots \ldots$ & 29,990 & 55,482 & 4,624 & 2,312 & 2,134 & 1,067 & 38,987 & 3,249 & 1,625 & 1,500 & 750 \\
\hline $7 \ldots \ldots$. & 33,810 & 62,549 & 5,213 & 2,607 & 2,406 & 1,203 & 43,953 & 3,663 & 1,832 & 1,691 & 846 \\
\hline $8 \ldots \ldots$ & 37,630 & 69,616 & 5,802 & 2,901 & 2,678 & 1,339 & 48,919 & 4,077 & 2,039 & 1,882 & 941 \\
\hline For each add'I family & & & & & & & & & & & \\
\hline member, add & 3,820 & 7,067 & 589 & 295 & 272 & 136 & 4,966 & 414 & 207 & 191 & 96 \\
\hline
\end{tabular}

As the table shows, in 2011, a student hailing from a family of four with annual income of less than $\$ 24,055.00$ for the year would have qualified for free lunch. It is important to note that the FRLP guidelines are distinctive from the federal poverty lines established by the US Department of Health and Human Services. Even if a family is at the national poverty line set by HHS, according to FRLP guidelines, the student from such a family would qualify for reduced lunch, not free lunch. Essentially, high poverty 
schools serve a population where $75 \%$ of the students' families are very low-income, where the parent(s) may be either unemployed or be working poor.

Higher concentrations of poverty in schools pose great challenges to school-wide student performance (Kraus, 2008; Orr, 2002; and Puma et al., 1993). In 1993, the US Department of Education in the acclaimed Prospect Report found that the performance of even non-poor students declines when the proportion of their classmates below the poverty line increases. More specifically, "school poverty depresses the scores of all students in schools where at least half of the students are eligible for subsidized lunch, and seriously depresses the scores when more than 75 percent of students live in lowincome households (Puma et al., 2003, p. 4). The report echoed the findings of James Coleman's study conducted 30 years before. Coleman (1966) had found that low-income students that attend middle-class schools have higher levels of achievement, and/or larger achievement gains over time, than those that attend high-poverty schools. The striking correlation between concentrated poverty and poor school performance is fairly consistent among different studies (Banks, 2001; Coleman et al., 1966; Kraus, 2008).

It is in this context of school poverty, the work of Jean Anyon becomes crucial. In a 1980 ethnographical study of curricular pedagogy and pupil evaluation, Anyon gathered empirical evidence from five elementary schools differentiated by the socioeconomic status of students' families. Her observations led to a theory of social class and its relationship to educational, school-wide practices. She found that the schools could be divided into four tiers: (1) Working class schools, defined by a large population of parents that are blue collar unskilled or semi-skilled workers with approximately $15 \%$ unemployed; (2) Middle class schools, grouped by three interchangeable clusters-blue 
collar "rich" skilled workers, white collar working and middle classes, and middle management and capitalists who have "ownership of the apparatus of production (stocks) in society" (p. 69). (3) Affluent Professional Schools, characterized by a core of parents with professional career positions such as cardiologist, corporate lawyers and engineers; and the (4) Executive Elite School, characterized by parents that are presidents and vice presidents of such companies as AT\&T, City Bank, American Express, etc. and work in the Wall Street.

Anyon explains that "schooling" is not fully shaped by funding and the sheer allocation of resources. In fact, in each of the above schools the textbooks and the subject offerings were the same. Anyon does note that the number of supplies that accompany the textbooks differs. The schools in wealthier communities presented more supplementary materials that accompanied the text. Her evaluation of schools was not limited to a checklist of "physical, educational, cultural, and interpersonal characteristics" of each school environment (p. 87). Instead, she investigated the nuances that socioeconomic status of the children had on their "hidden curriculum" (teacher expectation, lesson implementation, student input and educational pedagogy). Her study revealed extensive differences among the schools. Despite being written in 1980, Anyon's findings are as relevant today as it was then. She was the first to recognize the importance of the intangibles in school education (teacher expectations, lesson implementation, and tone) for school and student success. Educators and policy makers thus far had focused on the tangibles (funding, teacher qualifications, classroom size, etc.) to discuss the disparities in school. 
The hidden curriculum is well illustrated by the stark contrast between two polar opposite schools. On one end, Working Class Schools are characterized by an extensive reliance on rote learning for every subject. Rote learning has long been criticized because it does not encourage critical thinking; instead students are taught through repetition and memorization. Students are expected to copy notes and follow steps with little input or decision making. Anyon describes this as an assembly line of learning. Students are rewarded for repetition and following orders rather than correct responses. The focus is on the 'mechanics' of assignment completion. There is little encouragement or need for reasoning and is divorced from the real world. Anyon likens teachers and their practices in working class schools to drill sergeants. The teachers' overall tone toward students is often laden in sarcasm. Often repeated comments include, "Shut up", "Shut your Mouth", "Throw your gum away" and "Why are you out of your seat?" (p. 76). Words such as "please, let's or would you prefer" were void from the dialogue (p. 76). Students demonstrate resistance through "indirect sabotage" which is noted as off topic conversation and delay of work.

On the other end, the Executive Elite School is shaped by "developing one's analytical intellectual powers" (p. 84). Rote learning is not considered a viable educational approach. Instead, students are expected to derive formulas, solve problems and draw on real world examples to make a series of decisions in each lesson. This form of intellectual freedom extends to all functions of classroom organization. Academically, students are prompted to challenge and defend answers through verbal, written and kinesthetic learning. In some cases, students take on the role of teacher to convey a point or demonstrate an activity. In fact, "children did not speak in terms of right and wrong, 
but whether they agreed with the answer that was given" (p. 84). Rules of obedience are observed in both schools, but there is deep contrast in teacher responses. Teachers in working class schools describe ill-mannered students as "sometimes flippant, boisterous, and occasionally rude"(p. 86). Teachers in Executive Elite schools reprimand by stating, "You must control yourself. You are responsible for your behavior"(p. 87). Overwhelmingly, teachers in these schools treat students with politeness-no sarcasm, nasty remarks, and few direct orders. Intellectual freedom is followed by unregulated school movement- there are no school bells and students are not required to line up. Students are not required to ask permission to leave the room.

The two above schools illustrate the deep contrasts in teacher expectation, lesson implementation, student input and educational pedagogy. Middle Class Schools and Affluent Schools fall within these two extremes. Anyon's seminal work thus highlights that the socioeconomic status is important for how schools perform. The intent of the HOPE VI program was to create mixed-income neighborhoods. Consistent with Anyon's approach, the change in socio-economic status of students would positively impact the performance of the neighborhood schools. Hence, my first hypothesis in the dissertation is that, following the implementation of the HOPE VI program, there was a change in the proportion of students with low socio-economic status in the neighborhood public schools. The second hypothesis is that schools located in HOPE VI neighborhoods were likely to improve their school performance. 


\subsubsection{Federal School Reform Policies}

Historically, the federal government's response to poor student achievement and dismal school wide performance in high poverty areas demonstrates a pattern of school based corrective actions. Concurrent to the Coleman report in 1966 which found that high poverty schools depressed the test scores of all students, US Education reform focused squarely on the Civil Rights Movement. With the passing of the historic 1954 legislation, Brown vs. Board of Education of Topeka, federal school reform sought to ensure racial and residential desegregation. Busing (also referred to as forced busing) was the sole federal response for nearly 20 years. In 1983, President Reagan's National Commission on Excellence in Education published "A Nation at Risk: The Imperative For Educational Reform.” Though controversial, the report highlighted both national and international academic problems. American students were no longer highly competitive when compared with other industrialized nations. In addition, some 23 million Americans were considered illiterate.

Under President Clinton, the slogan was one of 'investing more and demanding more,' where accountability became a priority. The Education Accountability Fund focused on improving failing schools and offering school choice (parents could opt for higher-performing public schools). The school reforms included lowering class size, hiring 100,000 quality teachers, enhancing college preparatory efforts, expanding the GI Bill and investing in advanced educational technology (The White House, 2008).

It was not until 2001 that No Child Left Behind (NCLB), a standards-based reform, under President George W. Bush tied accountability directly to testing and assessment. Each school was required to make strict academic gains in reading and 
mathematics. In addition, different subgroups and at-risk students required strict attention. The subgroups were identified using indicators such as race, socio-economic level special education, and English as a Second Language (ESL). For a school to earn a rating of Adequate Yearly Progress (AYP), the entire student body would have to meet pre-established academic targets/gains. The overall goal of NCLB established that by $2014,100 \%$ of students would be proficient in math, reading and science.

Measuring student achievement solely on test scores was a contentious matter among educators, administrators and parents. High poverty schools overwhelmingly scored lower than schools with no or little poverty amongst their student population. In addition, NCLB does not measure student academic growth or account for increased performance targets. Interestingly enough, 'wealthy' schools also began rejecting the merit of NCLB. According to the Center on Education Policy (2011), "In some states, schools considered high-performing by other measures have failed to make AYP, causing considerable public confusion and concern"(p. 3). The number of schools not conforming to the AYP increased over the years:

In 2007, 28 percent of schools failed to make AYP. By 2011, that number had risen to 38 percent, and Secretary of Education Arne Duncan warned that 82 percent of school could be failing to meet AYP by the end of 2011 if Congress didn't rewrite the law (McNeil, April 28, 2011).

The debate of federal versus state rights has been at the center of NCLB. The federal government established the goals and intent of NCLB, but each state is required to develop its own testing instruments, assessment strategies, and the baseline score for whether or not a student is considered proficient. Thus, AYP does not have a national 
standard. Despite these debates, "NCLB has been up for reauthorization since 2007, but... neither chamber of Congress has come up with a comprehensive alternative" (Resmovits, 2011).

By 2009, with the Obama administration, Race to the Top (RTTP) incorporated new priorities and de-emphasized NCLB. The administration's focus shifted to a broader and more intensive accountability model for teachers and principals, followed by a push for states to adopt national standards. The policies endorsed the $\mathrm{STEM}^{1}$ (science, technology, engineering, and math education) program, and promoted charter schools as an alternative to traditional public schools. To advance these ideals, the RTTP provided large competitive state wide grants ranging from $\$ 75$ million to $\$ 700$ million. Though education is a state and local issue, the federal government's financial incentives aimed to induce them to take tough reform decisions. In the context of a recession where government budgets faced cuts or deficits, teacher and principal performance came to be linked with student achievement for the first time. Even though President Obama criticized the NCLB act for its singular dependence on testing to determine student achievement, the RTTP linked student test achievement to teacher and principal performance. Despite objections by educators and teacher unions, almost all states applied for the RTTP funding, incorporating this measure of school performance. In the end, a total of ten of the 47 states were awarded RTTP funding. Each of the 10 winning states had incorporated STEM objectives throughout their RTTP proposal.

\footnotetext{
${ }^{1}$ STEM education is an interdisciplinary approach to learning where rigorous academic concepts are coupled with real-world lessons as students apply science, technology, engineering, and mathematics in contexts that make connections between school, community, work, and the global enterprise...(Tsupros, Kohler\& Hallinen, 2009).
} 
All of the federal initiatives in the past 60 years have one shared quality: school reform required school based corrective actions. With the exception of busing, which dealt explicitly with desegregation, academic improvements were pinned squarely on the shoulders of educators. Unlike the above federal school reform efforts, tis dissertation takes a broader look at non-school based approaches (such as neighborhood conditions of public housing enclaves) to improve school quality and performance.

\subsection{The Link between Public Housing \& Public Education}

Reforms, both in education and housing policy, have been separate efforts to improve the level of instruction in schools and the delivery of affordable housing. Although a connection between affordable housing opportunities and academic attainment may exist, little empirical research investigates the link between public housing and public education. Throughout the 1960s and 1970s the specter of dilapidated neighborhoods and derelict buildings drew more and more federal attention toward construction and renovation, housing assistance and financing, and urban infrastructure. Educators, meanwhile, were focusing ever more narrowly on what happened inside schools, classrooms and school systems, with little reference to other work underway in the streets beyond. To achieve social equity, courts increasingly mandated busing of children away from their neighborhoods, further deepening the divorce between where children lived and where they learned. It was as if the future of neighborhoods had somehow become all but unrelated to the future of the children living in them (Abravanel, Smith \& Cove, 2006, p. 2) 
As a result, a much broader view evolved to investigate the impact that housing had on academic achievement. More often, research focused on the issues of stability, levels of mobility, quality of housing and homelessness. In 1994, The United States General Accounting Office (GAO) reported that children with high mobility rates struggled academically to keep pace with children who encounter less or no mobility. Braconi (2001), in Housing and Schooling, investigated the impact of quality of housing on academic outcomes. He found that a negative housing environment (inadequate heat, inoperable plumbing, rodent infestation, overcrowding, lack of stability and security) could impede the ability of students to concentrate and decreases the child's school readiness. Mueller and Tighe (2007) found a connection between affordable housing, health, and educational outcomes. Much like the GAO (1994), the authors concluded that frequent mobility affected educational performance negatively. In addition, they also found a positive correlation between poor housing conditions, health problems, and poor educational performance.

Homelessness adds to the emotional stressors of youth and negatively impacts student performance. Homeless children are less likely to attend preschool, have higher rates of grade retention, and are more likely to drop out (National Law Center on Homelessness and Poverty, 2007; Lubell \& Brennan, 2007). Stability, mobility, housing quality and homelessness impact educational outcomes.

Lubell and Brennan (2007) found that affordable housing could lead to improved educational outcomes for children. Their study highlighted several additional findings: 
- Stable, affordable housing could contribute to children's educational achievement by reducing the frequency of unwanted moves that lead children to change schools.

- Affordable housing can reduce overcrowding (and other sources of housing-related stress) that lead to negative developmental and educational outcomes of children.

- Well-constructed, maintained, and managed affordable housing can help families address or escape housing-related health hazards (e.g., lead poisoning and asthma) that adversely impact learning.

- Homeownership may provide a platform for helping children do better in schools.

- Affordable housing may support children's educational achievement by reducing homelessness among families with children.

\subsection{The Difficulty/Obstacles of Linking Public Housing to Public Education}

Linking the impact of affordable housing to educational outcomes is a difficult task. In 2008, the New York University's Furman Center conducted the first large-scale study of New York's public housings and its correlation to academic performance (Public Housing and Public Schools, 2008). The study compared the educational outcomes of students living in public housing provided by the New York City Housing Authority (NYCHA) to those with similar family income but not living in public housing. The findings suggested that students who lived in public housing fared worse academically in both math and reading and were also less likely to graduate from high school in four 
years. It is possible that "families who live in public housing may differ from other poor families in ways that are hard to measure" (cited in Fernandez, 2008, p.1). Linking public housing to educational outcomes is thus a complex task. There are four major obstacles in making the link: a) school choice, b) the public's perception of public schools, and c) the implicit barriers to creating mixed income communities.

\subsubsection{School Choice}

The first obstacle in linking public housing to public education is school choice. Throughout the United States, school choice within the public school system has become increasingly prevalent. Urban families now have more educational outlets than any other time in American history. Parents select a different school if their child's school requires remedial measures. For example, in Florida,

Under NCLB, when schools do not meet state targets for improving the achievement of all students, parents have better options, including sending their child to another school. Parents whose children are enrolled in Title I schools that are identified in need of improvement, corrective action, or restructuring have the opportunity to transfer their children to a higherperforming school. (Florida Department of Education, 2005, p. 1)

The federal Voluntary Public School Choice program also "supports efforts to establish or expand intra-district, inter-district, and open enrollment public school choice programs" (U.S. Department of Education, 2011, p. 1). Since 1991, charter schools became another mode of school choice within the public school system. Unlike the school assignment requirement in traditional public schools, charter school enrollment is 
based on a lottery system where students are randomly selected from their initial application. Transportation is then provided by the local school district. Shortly after the opening of traditional 'brick and mortar' charter schools, 'cyber' charter schools have become a main stream alternative for students who are formally home schooled. Local school districts quickly followed this technology driven educational option and offered public cyber schools. In addition to these, the local governments also sponsor education vouchers (scholarships) that subsidize the cost of students attending private school. Even though the voucher system is controversial since public dollars go to private schools, it gives the greatest flexibility in school choice.

Although school choice benefits families, it distorts the performance results of neighborhood schools. As a result of school choice, tracking enrollment patterns by neighborhood address is problematic. Although children are assigned to locally designated public schools based on their address, parents could take advantage of the alternative school choices. School choice creates barriers for collecting data and tracking the schools attended by children living in public housing. Thus, the children in public schools may not account for the movement of neighborhood students who no longer attend their neighborhood school. Even if a neighborhood's socio-economic status improves, the neighborhood's public schools may not show the gain.

\subsubsection{Perception of Urban Public Schools}

Urban public schools are often perceived to be undesirable by middle income and high income families. Public confidence in public schools has dropped considerably in the last 30 years (Carr, 2007). With failing test scores, safety issues, and the appearance 
of catering to at-risk students, public schools are at a distinct disadvantage. The public perception is paramount to the decision making of middle income and high income families. Middle income families have greater access to school choice. Their choice, quite often, is to opt out of public schools and pay for private or religious schools. Carr (2007) notes that middle income families look for schools that offer the following elements: good test scores, basic skills, liberal arts, college prep, afterschool activities, and safety, discipline, and personal responsibility. Public schools appear to lack competitiveness in each of these areas. An overwhelming number of schools in urban school districts do not meet the target for Adequate Yearly Progress under NCLB, have a high degree of school violence, and have very few liberal arts options (i.e. dance, music, the arts), which are cut first in case of budget constraints. Well performing urban public schools (e.g., those with high test scores, where safety is not an issue, and students go on to attend college) do not catch the public attention. Consequently, middle income parents not only avoid urban public schools, but make personal sacrifices in order to pay high tuition so that their children can attend private or religious schools. Public school officials need to address both the perception and reality in order to attract middle income families.

\subsubsection{Barriers for Mixed Income Communities}

Creating mixed income communities is a difficult undertaking. HOPE VI, in many communities, suffered from two key consequences. The first was that attractive mixed-income residential communities steadily raised real estate values (Brazley \& Gilderbloom, 2007; Popkin et al, 2004) leading to gentrification. Second, in many other cases, homes priced at market value were undersold and remained vacant. The housing 
crisis (bubble) that began in 2006 exacerbated the problem. Foreclosures rose while credit extension became increasingly complex.

One of the goals of HOPE VI was to create neighborhood stability. Yet, in some cases, low income families would remain as renters since they could not qualify for mortgages. As National Low Income Housing Coalition (NLIHC), President Sheila Crowley pointed out, "HOPE VI doesn't solve the critical housing problems of the very poor and exacerbates them by making fewer units accessible" (cited in Pitkoff, 1999). With fewer units available and the higher real estate prices, the 'lowest income families were forced to transition to new neighborhoods. Though many families took advantage of the housing voucher system, some of them moved to other public housing projects, and a few entered the private market (Potkins, et. al, 2004). A few families, became homeless during this transition (Popkin \& Cove, 2007).

Another key element to consider for mixed income developments is that neighborhoods with a low tax base (such as areas with housing projects), also offer low levels of amenities. When individuals or families consider spending upwards of $\$ 500,000$ (which is the price of housing in some mixed-income developments), the city's delivery of services must also include: safety, convenient transportation, quality schools (public and private), access to consumption (luxury goods) and leisure (entertainment, theatre). Carlino and Saiz (2008) suggest that “Beautiful cities' (under the city beautiful philosophy that offer physical and psychological wellbeing and high aesthetics) disproportionally attracted highly-educated individuals and experienced faster housing price appreciation" (p. 2). 
In order to create true and balanced mixed income developments, the sites must provide access to quality schools (public and private), be near employment opportunities, and target those interested in downtown or proximate locations (Varady, et al., 2005). The problem associated with the maintenance of apartments and the transitioning of low income families to temporary housing must be addressed. Inevitably, the social fabricand not just the physical environment—must be considered (Husock, 2004).

\subsection{Segregation}

My research focuses extensively on economic integration which is the immediate goal of the HOPE VI project. Yet, one cannot ignore segregation. In the context of American history and race relations, Glaeser and Vigdor (2001) acknowledge that there has been a steady decline in segregation in the last three decades. However, the legacy of forced and institutional isolation has had a devastating impact. As Massey and Denton (1993, p. 136) point out, "residential segregation is not a neutral fact; it systematically undermines the social and economic well-being of blacks in the United States." Residential segregation means that members of the community are geographically, socially and economically isolated (Messy and Denton, 1993; Wilson, 1987).

With the passing of the Civil Rights Act, the elimination of redlining, and federal laws to support desegregation within schools, blacks have steadily integrated into communities which were once off limits. Yet, even with the shifts in policy, law and practice, all-black segregated communities have remained. Thus, Glaeser (2001, p. 5) finds that "the decline in segregation results from the integration of formerly all-white census tracts, rather than the integration of overwhelmingly ( 80 percent or more) black 
census tracts." Essentially, whites are less likely to move to communities where the residents are predominately black. This poses a serious hardship for the development and success of the HOPE VI projects. Clark (1986) points out that a number of factors including affordability, social preference, urban structure, and discrimination might explain residential separation.

Consequently, just as neighborhoods and neighborhood schools are inextricably linked school segregation mirrors residential segregation. Though Brown v. Board of Education was decided over 50 years ago to end segregation, "extreme segregation [the overlap between schools with high minority population and those with high levels of poverty was significant] is more common" (Rich, 2012, p. 1). Orfield, Kucsera and Siegel-Hawley (2012) note that schools are more segregated today than in the late 1960s. They see the reverse trend partly due to the 2007 ruling in Seattle Public Schools. The court struck down the school district's diversity measure. School assignment based on race or ethnicity was deemed unconstitutional. This dissertation research is premised on the approach that housing policy is de facto education policy. In this context, racial composition in the neighborhoods is undoubtedly important for the schools. However, class is as important since socio-economic integration has been one of the main goals of HOPE VI projects.

\section{$\underline{2.10 \text { Housing Policy as De Facto Education Policy }}$}

Championed by David Rusk, president of Metropolitan Research Corporation in Minneapolis, MN, the attention to the link between housing and school policy is growing. Rusk challenged educators, housing officials, and politicians to address the reality of the 
link between high poverty neighborhoods and schools: "High poverty neighborhoods produce high poverty schools...In high poverty schools most children will fail no matter how many extra resources are poured into their schools or how much accountability is required of their teachers" (2011, p. 21). School based remedies such as teacher training and evaluation, smaller class size, full day kindergarten, and curriculum improvements would have limited success in such a context (p. 28-29). Supporting Rusk's sentiment, Embry (2011) questioned the neglect of desegregation in national school reform. He noted three barriers to desegregation: no legal compulsion, resistance by suburban jurisdictions, and shortage of affordable housing in affluent neighborhoods. According to him, the "school-based variable that most profoundly affects student performance is the socioeconomic composition of the school" (Embry, 2011, p. 1).

Mickesolson (2011) provided a new perspective on the benefits of neighborhood desegregation for schools. Racially and socioeconomically integrated schools have both short and long term advantages for all students which include: higher test scores and grades for all students, increased likelihood of graduation from high school and college, and a better adult life-course trajectory. Integrated schools show a positive long term influence in diversity of future personal and workplace preference. Consequently, diversity in communities and schools promotes intergenerational preference for desegregation.

Rusk argues that Race to the Top funds, President Obama's chief educational reform policy, be used to acquire housing in high opportunity communities (determined by proximity to jobs) with high performing schools. Currently, education reform does not challenge racial and economic segregation. Rusk proposed plans to redistribute school 
enrollment in order to eliminate high poverty schools in Baltimore, Camden and Denver. In his approach, socioeconomic integration is bolstered not by simply placing children in better performing schools, but by the "educational resources provided by a child's fellow classmates" (p. 21). This model would "reinforce what school boards have the authority to do...reduce the school economic segregation index..." (p. 24). Embry suggested another clever alternative for school vouchers to couple as a housing voucher: "State aid to Baltimore City schools is $\$ 12,191$ per pupil, roughly the net cost of a rent subsidy needed to permit an urban family living in concentrated poverty to move to a lowpoverty, suburban neighborhood" (p. 32). Low income families would then be provided with the opportunity to improve their housing, while having access to good quality, low poverty public schools. Rusk's and Embry's proposals have good merit, are innovative and feasible. They are often criticized as creating a policy fantasy, void of political will, and impracticable. In his defense, Rusk notes that, "nationwide, some 500 cities, towns and counties have enacted mandatory inclusionary zoning laws" (p. 29).

Several researchers have investigated the impact of housing policy on schools. Ellen and Horn (2011) sought to determine whether housing subsidies provided families access to quality schools. The three subsidies included: public housing, Low Income Housing Tax Credit (LIHTC), and housing vouchers (some Section 8) in New York City. Using test scores as a measure of quality, they found that "public housing tenants had access to the lowest quality schools" (p. 10). Families using vouchers had access to schools with higher reading and math score averages. Assisted households are located in considerably lower performing schools than the average household in New York. They 
conclude, "Households with housing assistance do not appear to have the same educational opportunities as other households with similar income levels" (p. 13).

Using inclusionary housing as a method to avoid pockets of high poverty, Schwartz (2011) proposed several key approaches. She cites the example of Montgomery County, Maryland which created housing practices that catered to the needs of an influx of immigrants following employment in suburban centers. Inclusionary housing, which began in 1974 pre-dates mixed income housing and communities. In fact, the community, faced with the changing complexion of the neighborhood, welcomed affordable housing. Consequently, the county's inclusionary housing and zoning policy simultaneously impacted school performance. She observes, "Highly disadvantaged children with access to the district's lowest-poverty neighborhoods and schools begin to catch up to their nonpoor, high-performing peers throughout elementary school, while similarly disadvantaged children without such access do not" (p. 15). Moderate and low income families not only live in affluent neighborhoods throughout the county, but their children maximized the opportunity with improved academic performance. What started as housing policy to adequately position workers within close proximity to hard-to-fill, low paying jobs translated to improvements in access to both quality housing and quality schools. Most significantly, "by the end of elementary school, the initial, large achievement gap between children in public housing who attended the district's most advantaged schools and the non-poor students in the entire district was cut by half for math and one-third for reading"(p. 18). Essentially, low poverty schools (less than $20 \%$ of student qualifying receiving Free or Reduced lunch) made the greatest academic impact on low-income students. 
McKoy and Vincent (2011) provide an expanded approach to urban planning which integrates housing, transportation and education. In the approach, urban planning extends beyond the municipality's scope to explore regional connections. The focus shifts to sustainable communities that are both equitable and healthy. Since neighborhood segregation is predetermined by land use plans and zoning policies, neighborhood school demographics simply mirror these patterns. They argue that planners must avoid fragmentation and urban sprawl. Utilizing case studies, they explored housing and education partnerships in several cities. In order to offer low income students access to higher performing schools, San Francisco implemented busing and HOPE VI mixed income housing, Baltimore instituted vouchers to move families to lower poverty neighborhoods, Oakland tracked the achievement of students before and after using Section 8 vouchers, and Washington, DC became the site to investigate housing and enrollment patterns. The Washington, DC plan served as an introduction to "attract and retain families, plan for school closure, and determine school assignment policy”(p. 55).

Each of the above partnerships was accompanied by new transportation patterns or access to new communities. Indeed, transit-oriented development (TOD), which emerged in response to environmental and economic concerns, "resulted in mixed land use, higher than usual densities, and pedestrian friendly designs without being antiautomobile" (p. 56). The range of neighborhood redevelopment solutions is wide, where strategic access to housing, quality schools, and employment are quintessential.

In his approach to looking at housing policy as school policy, Phillip Tegeler (2011), Executive Director of the Poverty \& Race Research Action Council (PRRA), offered the following recommendations (Tegeler, 2011, p. 71-72): 1. Collaboration of 
housing and school officials and at four levels of government (federal, state, regional and local) should incorporate federal initiatives with place based strategies, while states focus on targeted investments, it is noted that regional level planning requires transportation considerations, and local level planning should address new schools, school types (traditional, magnet, charter), enrollment patterns, and review of voucher programs for housing and education. 2) Promotion of school integration should include: housing mobility counseling that focuses on school quality, shared school performance data with families, coordinating school and housing data with Section 8 Management Assessment Program (SEMAP) and offering families inter-district school and housing transfers. 3) Public housing redevelopment must incorporate: magnets schools as an attraction to public housing developments, incentives for PHA to promote racial and economic school integration and bundle social services and educational options to public housing services.

\subsection{Conclusion}

To investigate social class as it relates to neighborhoods and schools, this dissertation draws on three influential writers: Jane Jacobs, William Julius Wilson, and Jean Anyon. Jacobs (1961) argued that cities were deteriorating because of lack of diversity and concentrated poverty. Wilson (1987) highlighted that social isolation reinforced the underclass in inner city areas with fewer job opportunities. Anyon (1980) described how the location of the schools influenced school expectations and overall educational performance. These seminal writers help provide a framework for the dissertation. 
Historically, the federal initiatives have required school based corrective actions. With the exception of busing, which dealt explicitly with desegregation, academic improvements were based squarely on the shoulders of educators. Unlike the efforts of federal school reform, this dissertation seeks to develop non-school based, community revitalization approaches (using neighborhood and public housing research) to improve school quality and performance.

Although a connection between affordable housing opportunities and academic attainment may exist, little empirical research investigates the link between public housing and public education. Traditionally, the research has focused on individual effects of housing (or lack thereof) on student achievement. The research themes are related to mobility, stability, homeless, and negative housing environment. The literature highlights the difficulty of making the connection in three major areas: data collection on student tracking; the problem of poor perception of urban public schools by middle and upper class families; and barriers to creating mixed income communities. Understanding housing policy as de facto school policy sets the basic premise for this dissertation. 


\section{CHAPTER THREE: RESEARCH METHODS}

\section{$\underline{3.1 \text { Introduction }}$}

This chapter describes the research methods used to examine the influence of HOPE VI public housing on public education. Using both quantitative and qualitative methods, the study explores whether or not the implementation of HOPE VI influenced a change in socioeconomic status (SES) of neighborhood public schools and their school performance. In effect since 1992, the HOPE VI Revitalization Grant is a public housing program administered by the Housing and Urban Development department (HUD) that targeted 165 of the most distressed high rise public projects nationwide. The goal of the program has been to transition extant public housing projects into mixed-income, mixed use communities.

In the United States, public school enrollment is typically organized by neighborhood boundaries. These boundaries inextricably link schools and neighborhoods. The lack of economic integration in the schools is a direct reflection of the lack of economic integration in the nation's neighborhoods (HUD, 2003, p. 4). As inner cities dealt with the profound effects of concentrated poverty that include escalated crime rates, low quality housing, and urban blight (Crane \& Manville, 2008; Bolton, 1992), public schools serving poor communities have been at a distinct disadvantage, as they are reliant on a relatively weak tax base. Although school improvement was not an immediate goal of HOPE VI, its efforts of social integration could arguably influence the neighborhood public schools' performance. Thus, as outlined in Chapter 1, there are three research questions in this study: 
1. Following the implementation of HOPE VI, was there a change in socioeconomic status (SES) of the neighborhood public school?

2. Following the implementation of HOPE VI, did the performance of neighborhood public schools change?

3. What factors relate to the performance of public schools in HOPE VI communities?

The rest of this chapter explains the research design and methodology to answer the above questions. First, the background of the study is reiterated for setting up the context of the study. Second, the process of selecting the HOPE VI sites for the study is outlined. Third, the quantitative techniques used to answer the first two research questions are described. Fourth, the qualitative techniques to answer the third research question are presented. Fifth, the limitations of the data collection and the research methods are acknowledged. Finally, the chapter concludes with a summary of the research methods.

\subsection{Background}

The current knowledge linking the HOPE VI neighborhood revitalization program, affordable housing, and public school performance is extremely limited. Much of the extant research related to HOPE VI focuses overwhelmingly on three areas: 1) challenges and possibilities of mixed income policy (Bohl, 2000; Cousins, 2001; GAO, 1998; Varady et al., 2005 ), 2) the impact of HOPE VI policy on residents (GAO, 2003; Popkin, 2007, 2004 \& 2002) and their children (Gallagher \& Beata, 2007; Popkin et al., 
2002), and 3) neighborhood and housing conditions as it relates to safety, amenities, and health (Goetz, 2010; Popkin etal., 2002, Rinker 2007).

Although HOPE VI was enacted in 1992, there are only two studies to date that link the HOPE VI program specifically to neighborhood public schools. Both studies relied exclusively on case studies. The first study by Abravanel, Smith and Cove (2006) focused on five HOPE VI communities (Atlanta, Milwaukee, Tacoma, Tucson, and Washington, DC) was inconclusive- the authors determined that they could not adequately define "what it means to join housing revitalization with school improvement" (p. 44). This could have been due to the differences in the nature of schools (charter schools, magnet schools, new public schools, and facilities improvements), although all served a high percentage of low income students. The second study by Raffel et al. (2003) sought to determine if the mixed-income strategy could attract families to HOPE VI communities and neighborhood schools. Only one (Louisville, KY) of the four case study sites (Baltimore, MD; Cincinnati, Ohio; and Washington, DC) was successful in attracting mixed income families; all attracted the "upwardly mobile singles and childless couples" (p. 151). The authors opined that the most effective approach for attracting families to HOPE VI is to create magnet schools but noted political and bureaucratic resistance.

This dissertation explicitly advances the research linking HOPE VI communities and schools by combining quantitative and qualitative research. The quantitative component has a national scope, which can yield generalizable recommendations for informing national, state, and local level policies. The qualitative component uses case studies of the best and worst performing HOPE VI neighborhood public schools to get 
deeper insights into the factors relating to school performance in such neighborhoods. This research is thus the first in making a comprehensive study of the relationship between the HOPE VI program and neighborhood public school performance.

\section{$\underline{3.3 \text { Selection of HOPE VI sites }}$}

There are 165 public housing projects (see appendix A) that were listed as recipients of HOPE VI funding in 22 cities across the United States from 1993 to 2012. These sites received HOPE VI funding since they were the most distressed public housing sites. I identified the local school district of each project by using a search of districts in the same zip code as that of the HOPE VI sites. I then used the local school district's school locator map to identify the neighborhood public school. In cases where the school locator map was not available, I used Google Maps to identify the closest public school. In this manner, I chose a total of 153 schools that were listed as elementary (K-5 \& K-8) schools (in some cases, one school served more than one public housing site).

Not all HOPE VI project schools form the empirical basis of my study since, during my search to determine neighborhood schools, it became apparent that a number of school districts were following the practice of redistricting (i.e. changing the neighborhood boundaries of the schools). In several school districts, students were no longer assigned to their neighborhood (closest) school. In some cases, the neighborhood school was designated as a magnet or charter school. Magnets require a special selective process based on academic history and/or cognitive abilities, while charters, by law, enforce lotteries to determine student attendance. Both procedures limit access to 
neighborhood children. To overcome this limitation and not to skew the data, I did not include charter and magnet schools in the study. This research focuses specifically at traditional public schools.

The schools not included in this study are from eight cities, excluded because of the different reasons. These are as follows: I did not include neighborhood public schools of HOPE VI projects in the four cities of Baltimore, Durham, Helena, and New York City since, as of 2012, their sites remained under construction and the new housing was incomplete. Each of the sites experienced different problems which impeded completion.

In Baltimore, the Hollander Ridge Development was approved in 1996 but was interrupted by a three year legal battle between the Housing Authority of Baltimore City and the American Civil Liberties Union (ACLU). The ACLU claimed that the city "reneged on its promise to provide quality homes for families... and practiced segregation of public housing tenants for decades"(James, 1999, p. 1). A federal judge allowed the Housing Authority to convert the public housing complex into a gated retirement village.

In Durham, during construction of Few Gardens project (which was approved in 2000), the Durham Housing Authority (DHA) was cited for financial mismanagement, illegal appropriations, and misspent millions of dollars. The executive director was removed in 2003. HUD began a partial takeover of the DHA HOPE VI Project by 2004. This led to a "public relations nightmare", limited flexibility and strained partnership, which eventually hindered the completion of the project (Fraser \& Kirk, 2007).

In Helena, the construction of Stewart Homes was consistently delayed by the Helena Housing Authority (HHA) Board. The HHA switched funds for the federal public 
housing project which was authorized in 1997 to federal tax credit and section 8 vouchers. The HHA started the planning process again in 2012.

In New York, the New York City Housing Authority (NYCHA) made little progress in the Prospect Plaza project over the course of 13 years of the project period. Although families in the 369 unit building were relocated in 1999, only 37 townhomes were built near the site since then. The delay was because of disputes between NYCHA and developers and ensuing financing delays.

I did not include two cities of Mobile, Alabama and New Orleans, Louisiana because they were deeply affected by Hurricane Katrina. The HOPE VI developments were also destroyed by the Hurricane. The city of Boston was not included since the school choice is administered city-wide under the 'Student Assignment Plan'. The student assignment plan divides the city into three geographic zones for elementary and middle schools. Students could choose from within the zone in which they live, or one that is within their walking zone, or from city-wide schools for K-8, middle, and high schools (Student Assignment Policy, 2012). Lastly, Atlanta was removed since the Atlanta Public Schools were accused of strategic and long term cheating on standardized testing. This problem made their school scores unreliable for the study purposes. The American Journal-Constitution (2011) reported unethical behavior across every level: “Teachers and principals erased and corrected mistakes on students' answer sheets. Area superintendents silenced whistle-blowers and rewarded subordinates who met academic goals by any means possible" (Vogell, 2011, p. 1).

When the above sites are removed, the number of HOPE VI project sites and their neighborhood school in the study's scope reduced to 116 . The largest recipients of 
revitalization funds included: Chicago (eight projects); Baltimore (six projects); Atlanta (five projects); and Washington, DC (five projects). Four projects were awarded to each of the following cities: Kansas City, Philadelphia, Oakland, San Francisco, and Seattle. While large scale projects were awarded, on average, cities had small projects (see Appendix A).

\subsection{Quantitative Research Methodology}

The first two research questions of this study utilize quantitative research methods to answer them. The hypotheses, the operationalization of the variables, and the analytical techniques used are as below.

Q1: Following the Implementation of HOPE VI, was there a change in socioeconomic status (SES) of the neighborhood public schools?

Low SES (especially concentrated poverty) poses a great obstacle to school-wide student performance (Orr, Stone \& Stumbo, 2002; Puma et al., 1993; and Kraus, 2008) and the question addresses the phenomenon. In this study, the proportion of students in the Free and Reduced Lunch Program (FRLP) is used to measure low SES. The FRLP is well recognized as an indicator of low-SES in educational research. Consistent with the HOPE VI program's intent of mixed-income neighborhood, the hypothesis is that following the implementation of the HOPE VI program, the proportion of low-SES students reduced in the neighborhood public schools. This hypothesis needs to be tested since, despite its intended goal of mixed-income neighborhoods, HOPE VI neighborhood schools may not have achieved this goal: the project size may be too small to impact the neighborhood school FRLP composition; higher-income parents may not send their 
children to such schools. To test this hypothesis, first, a t-test is performed to examine if there is a significant difference in the FRLP composition before and after HOPE VI implementation. The tests are performed for two periods: three (3) years before and after the implementation of HOPE VI; and six (6) years before and after treatment for sensitivity analysis.

In addition to the t-test, I performed a regression analysis to test if the schools SES are influenced by the HOPE VI project. The regression model (A) is as follows.

Model A: School SES $=f($ HOPE VI project site housing characteristics + HOPE VI Public Housing Authority (PHA) housing characteristics + school characteristics).

In the above model, the change in school SES is calculated as the percentage point differences between proportions of children qualifying for FRLP three years before and three years after HOPE VI was implemented. The HOPE VI project site characteristics capture the site specific characteristics of the projects, the PHA characteristics capture the organization specific characteristics of the implementing organization, and the school characteristics are used as controls. The HOPE VI characteristics are: (a) construction completion rates (i.e. years taken to complete the HOPE VI project); (b) whether or not the site obtained a demolition grant (dummy variable), and (c) number of public housing units in the project. The PHA characteristics are: (a) whether or not the PHA obtained the demolition grant (dummy variable); the number of PHA housing units lost in demolition; and amount of HOPE VI revitalization funding received. The school characteristics used as control variables are: (a) per pupil allotment per school, (b) change in proportion of minority students, and (c) proportion of African American students. 
Q2: Following the implementation of HOPE VI, did the performance of neighborhood public schools change?

The hypothesis is that schools located in HOPE VI neighborhoods would improve their school performance. This hypothesis is based on the extant literature that mixed SES contributes to better neighborhood public school performance. For example, the DOE (Puma et al., 2003) surmised, "school poverty depresses the scores of all students in schools where at least half of the students are eligible for subsidized lunch and seriously depresses the scores when more than 75 percent of students live in low-income households" (p.2). Coleman (1966) found that low-income students attending middleclass schools have higher levels of achievement, and/or larger achievement gains over time, than those that attend high-poverty schools. The striking correlation between concentrated poverty and poor school performance is consistently reported in the education literature (Banks, 2001; Coleman et al., 1966; Kraus, 2008). In this dissertation, school performance is measured by math and reading state proficiency test scores. State-released scores are well recognized as an indicator of school performance in educational research. A t-test is performed to examine if there is a significant difference in the school performance before and after HOPE VI implementation. The tests are performed for two periods: three (3) years before and after the implementation of HOPE VI; and six (6) years before and after treatment for sensitivity analysis.

Similar to the first question, I conducted a regression analysis to test if school performance increased after HOPE VI project was implemented. The regression model (B) is as follows: 
School Performance $=f($ HOPE VI project site housing characteristics + HOPE VI Public Housing Authority housing characteristics + school characteristics).

The dependent variable, school performance, is the sum of changes in proficiency in math and reading. The change is the percentage point difference between the share of $5^{\text {th }}$ grade students deemed proficient in each of the subjects three years before and three years after HOPE VI was implemented. The HOPE VI project site characteristics capture the site specific characteristics of the projects, the PHA characteristics capture the organization specific characteristics of the implementing organization, and the school characteristics are used as controls. The HOPE VI characteristics are: (a) construction completion rates (i.e. years taken to complete the HOPE VI project); (b) whether or not the site obtained a demolition grant (dummy variable), and (c) number of public housing units in the project. The PHA characteristics are: (a) whether or not the PHA obtained the demolition grant (dummy variable); the number of PHA housing units lost in demolition; and amount of HOPE VI revitalization funding received. The school characteristics used as control variables are: (a) per pupil allotment per school, (b) change in proportion of minority students, and (c) proportion of African American students.

The t-tests above are justified since the t-test determines "whether the means of two groups are statistically different from each other" (Trochim, 2006, p. 1). If the FRLP and school performance means of the neighborhood schools in the HOPE VI project are significantly different before and after the implementation of the project, then it could be reasonably surmised that there is an influence of the project on the two metrics of the schools. Similar t-test analyses have been used in peer reviewed articles. Kleit, Carlson and Kutzmark (2003) used the t-tests to investigate the well-being and community 
perceptions of residents following the HOPE VI redevelopment of Holly Park \& Roxbury Village in Seattle Washington. Using paired t-test with pre- and post-test measures drawn from surveys and interviews, they found that most residents in both groups "considered their current neighborhoods and housing units to be improvements over their previous situation" (Kleit, Carlson and Kutzmark, 2003, p. 155). In their study, Fred Brooks et al. (2011) sought to determine the outcomes of voucher users and revitalized public-housing residents 6 years after displacement. The t-test revealed that residents who moved back to the revitalized public housing had significantly fewer material hardships than residents remaining in the voucher program. These articles support the use of t-test analysis in this dissertation research to compare FRLP and school performance scores before and after the implementation of HOPE VI projects.

I used the regression models to further test the hypotheses since the regression is one of the most widely used statistical models to determine the strength of the relationship between one dependent variable and a series of other changing variables (i.e. independent variables). The regression models (A) and (B) above are drawn from research methods used in the studies by Brazley and Gilderbloom(2007), Brooks et al., (2011), Clampet-Lundquist (2004), and Kleit, Carlson and Kutzmark (2003). These studies also separated the HOPE VI characteristics and the PHA characteristics to examine the site specific and the organization specific influences on the dependent variables. I have used the school characteristics as control variables since these could also arguably influence the outcomes of FRLP and school performance. 


\subsection{Qualitative Research Methodology}

The third research question in this study is examined using qualitative research methodology. The question is: What were the factors that relate to higher performing public schools in HOPE VI areas? Traditionally, high performing public schools have small proportions of low-income and minority students. To close the achievement gap of low performing schools, traditional federal reform efforts (e.g. No Child Left Behind and Race to the Top) have been school-based. They focus on school reforms (such as administrative training, classroom size, small schools, curriculum modifications) and professional development of teachers (education, training, sensitivity). The qualitative approach in this study focuses on non-school based, neighborhood-level factors that influence school performance. In order to gain insights into the factors affecting the higher performance of schools, I conducted case studies of two schools. I selected the best and worst performers (as revealed by the quantitative analysis) in order to obtain the insights into factors that lead to the two extremes of performance. In this, the schools with the highest and lowest math and reading scores were selected for the case study analysis. The case studies examine specific factors such as the collaboration between the HOPE VI project officials and the neighborhood school administrators, funding, the socio-economic status of the HOPE VI projects and the HOPE VI construction completion schedules. The analysis of the case studies provides insights into the factors that influence public school performance in HOPE VI areas.

Using quantitative analysis, I determined that the HOPE VI project schools in Philadelphia and Washington, D.C. were appropriate to study. These two schools emerged to be the best and worst-performing in terms of the math and reading scores. 
These two sites also offer rich materials in terms of the HOPE VI project context. I conducted fourteen interviews with representatives from the two cities, who included Public Housing Authority (PHA) administrators, school principals, community representatives/leaders and residents of the HOPE VI Community. I interviewed them about their perceptions of school performance, neighborhood quality, and intervening factors such as poverty (specifically, FRLP), school leadership, class size, etc. I used the NVivo 9 software analyzing the interviews. I supplemented these primary sources with secondary sources such as historical data, congressional documents, articles from professional journals, newspaper articles, professional presentations from national conferences, and testimony before the House Subcommittees for Housing and Community Opportunity.

The case studies provide an excellent method to investigate the nuances of the project specific characteristics that are not otherwise revealed in a quantitative approach. They combine methods such as participant and direct observations, interviews, examinations of records, and primary and secondary data in order to tell a rich story relevant to the context. Previous case studies of HOPE VI have related to neighborhoods and housing (Buron et al, 2002), mixed use (Shwartz and Tajbakhsh, 1997; Varady, Raffel, Sweeney \& Denson, 2005) and families and their children (HUD, 2000; HUD, 2003).

In 2002, the Abt Associates conducted a case study of eight cities to investigate the effect of HOPE VI redevelopment on the original residents living in distressed public housing projects. The firm surveyed 818 original residents and held 24 in-depth interviews to understand living conditions and well-being in the housing projects. In the 
eight cities, the study revealed that "many, but not all, new housing environments for relocated residents are an improvement over their original distressed public housing" (Buron et al., 2002, p. 114). A majority of the original residents in their sample were living in decent housing in neighborhoods that have lower poverty rates than their original public housing developments.

Varady et al. (2005) also utilized comparative case study analysis in four HOPE VI developments (in Cincinnati, Louisville, Baltimore, and Washington, DC) to examine if they indeed resulted in mixed income housing. Their data gathering techniques included: semi-structured in-person, telephone interviews, document analysis of HOPE VI reports, newspaper articles, and direct observation. In addition, they conducted 28 interviews with individuals who were familiar with the HOPE VI program in their city, particularly with respect to linkages with the schools, which included housing authority staff, residents, school officials, city planners, developers, and other community members. The authors found that only one (Louisville) of the four sites was successful in attracting middle income families to the new HOPE VI development.

To date, only two case study-based reports have examined the link between HOPE VI initiatives and local schools. In their study, Abravanel, Smith and Cove (2006) concluded that they could not adequately define "what it means to join housing revitalization with school improvement" (p. 44). Meanwhile, Raffel, et al. (2003) opined that the most effective approach for attracting families to HOPE VI is to create magnet schools, but also noted political and bureaucratic resistance. Much like these two studies, this dissertation also utilizes case studies to further investigate the factors that influence public school performance in HOPE VI areas. 


\subsection{Limitations of the Study}

One of the important limitations of this study is that the 2006-2008 economic crises in the country could affect my analysis since homeownership, a goal of HOPE VI, was negatively impacted during this period. Although it is important to be cognizant of this external factor, I do not consider this to be a serious impediment considering many families were permitted to rent/lease during this period.

In addition, it is important to note the three inherent obstacles of linking public housing and public education. The first obstacle is school choice. Despite the fact that school choice (Title I, voluntary school choice program, charter, cyber, and vouchers) are geared to benefit families, it also distorts the performance results of neighborhood public schools. With the introduction of school choice, tracking enrollment patterns by neighborhood address proves problematic. The most proactive parents opt out of poor performing schools. Second, urban public schools are undesirable to middle income and high income families. Public confidence in public schools has dropped considerably in the last 30 years (Carr, 2007). Thus, middle income parents not only avoid urban public schools, but make huge sacrifices such as paying ever increasingly high tuitions to have their children attend private or religious schools and/or relocate to live in better school districts. Third, creating mixed income communities is extremely difficult. In some cases, attractive mixed-income residential communities steadily raised real estate values (Brazley \& Gilderbloom, 2007; Popkin, 2004;). This often led to gentrification. In other cases, homes priced at market value were undersold and remained vacant. Raffel et al. (2003) adds that HOPE VI was not successful in attracting mixed income families; all 
attracted the "upwardly mobile singles and childless couples" (p. 151). All three obstacles were specifically addressed in chapter two.

\section{$\underline{3.7 \text { Conclusion }}$}

The dissertation aims to be of academic as well as policy value among housing scholars and educational officials. Hence, I use both quantitative and qualitative methods to enhance the validity of my analysis and findings. The data analysis includes a t-test and regression analysis to determine (a) if after the establishment of HOPE VI neighborhoods, the socio-economic status (SES) of students in neighborhood public schools declined, and (b) if there was an increase in school performance following the implementation of HOPE VI. Following these quantitative research methods, I identified the best and worst performing schools in terms of two indicators - math and reading scores. These two schools at the extreme provide a good context to identify the factors that contributed to public school performance in HOPE VI areas. Hence, I conducted case studies of these two schools. I focus on non-school factors affecting the school performance since these factors have largely been ignored in the current federal school reforms such as Race to the Top and No Child Left Behind. 


\section{CHAPTER FOUR: SCHOOL SOCIO-ECONOMIC STATUS AND PERFORMANCE}

\section{$\underline{4.1 \text { Introduction }}$}

In effect since 1992, HOPE VI is a public housing program administered by the United States Department of Housing and Urban Development (HUD). The initiative aims to revitalize neighborhoods through mixed income and mixed-use communities. There are 165 HOPE VI communities nationwide that received revitalization grants to build, improve and refurbish neighborhoods. This dissertation examines the implementation of HOPE VI in order to determine whether community change relates to neighborhood public school performance. Specifically, it explores whether or not the social integration of neighborhoods leads to a change in the proportion of students who are considered to be of low socioeconomic status (SES) and/or improvements in reading and math test scores.

The first question in the dissertation investigates the level of social-economic integration of schools following the implementation of HOPE VI. The second question seeks to determine the change, if any, in performance of neighborhood public schools following the implementation of HOPE VI. Two quantitative techniques are utilized to analyze these questions - t-test analysis and regression models.

\subsection{HOPE VI and School SES}

The first research question asks: Following the Implementation of HOPE VI, was there a change in neighborhood public school socioeconomic status (SES)? Consistent with the goals of HOPE VI to create a mixed-income neighborhood, the hypothesis is that the neighborhood public school would have more mixed SES. In the HOPE VI program, 
a part of the housing has been market rate, and another part has been for low-income households at subsidized prices. It is thus reasonable to expect that the neighborhood public schools would have mixed SES. In this context, the SES is measured as the proportion of school children qualifying for Free or Reduced Lunch Program (FRLP). If over 75 percent of the children qualify for FRLP, the school is considered a high poverty one.

I tested the hypothesis by comparing the means of the school children qualifying for FRLP before and after the HOPE VI program implementation. I conducted the t-tests to determine if the means are different for two time intervals: six years before and six years after; and three years before and three years after the implementation of HOPE VI. The two periods are considered in order to check the robustness of the t-test results over time. The results of the t-tests are shown in Table 2.

Table 2

T-test results for School SES

\begin{tabular}{|c|c|c|c|c|c|c|c|}
\hline & $\mathrm{N}$ & Mean & $\mathrm{SD}$ & $\begin{array}{l}\text { Mean- } \\
\text { difference }\end{array}$ & $\mathrm{df}$ & $\mathrm{t}$ & P-value (2-tailed) \\
\hline 6 years before HOPE VI & 42 & 0.72 & .023 & \multirow{2}{*}{-0.031} & \multirow{2}{*}{41} & \multirow{2}{*}{1.036} & \multirow{2}{*}{0.30} \\
\hline 6- years after HOPE VI & 42 & 0.68 & 0.21 & & & & \\
\hline 3 years before HOPE VI & 87 & 0.74 & 0.20 & \multirow{2}{*}{-0.005} & \multirow{2}{*}{86} & \multirow{2}{*}{-.475} & \multirow{2}{*}{0.63} \\
\hline 3 years after HOPE VI & 87 & 0.74 & 0.19 & & & & \\
\hline
\end{tabular}

As the table reveals, there is no statistically significant difference between the schools' SES before and after the HOPE VI implementation. This result holds for both the three years and the six years comparison periods. In fact, the mean values are approximately in the same range across these years. The t-tests show that we fail to confirm the hypothesis. This result is interesting because it shows that the HOPE VI project has not had an impact on the proportion of students qualifying for FRLP. There 
could be several reasons for this, as explored in the next chapter. The HOPE VI project could be much too small for making any significant change in the neighborhood conditions that serves the public schools. Well-off parents may not send their children to the neighborhood public school.

\section{$\underline{4.3 \text { HOPE VI and School Performance }}$}

The second question in the dissertation asks: Following the implementation of HOPE VI, did the performance of neighborhood public schools change? The hypothesis is that, following the implementation of HOPE VI, neighborhood school performance moved in a positive direction with higher scores. The school performance is measured in terms of proportion of $5^{\text {th }}$ grade students who are proficient in math and reading scores.

Similar to the first question, I employed the t-test analysis to investigate whether or not there is a change in school performance. I conducted the t-tests to determine if the means of school performance are different for two time intervals: six years before and six years after; and three years before and three years after the implementation of HOPE VI. The two periods are considered in order to check the robustness of the t-test results over time. The results of the t-tests are shown in Tables 3 and 4 for reading and math respectively.

Table 3

T-test Results for Average Reading Proficiency School Scores

\begin{tabular}{|c|c|c|c|c|c|c|c|}
\hline & $\mathrm{N}$ & $\begin{array}{l}\text { Mean } \\
\text { (Percent) }\end{array}$ & $\begin{array}{l}\text { SD } \\
\text { (Percent) }\end{array}$ & $\begin{array}{l}\text { Mean- } \\
\text { difference }\end{array}$ & df & $\mathrm{t}$ & $\begin{array}{c}\text { P-value } \\
\text { (2-tailed) }\end{array}$ \\
\hline 6 years prior & 4 & 19.30 & 12.38 & \multirow{2}{*}{-43.875} & \multirow{2}{*}{3} & \multirow{2}{*}{-4.664} & \multirow{2}{*}{$.02 *$} \\
\hline 6- years post & 4 & 63.18 & 18.26 & & & & \\
\hline 3 year prior & 24 & 39.37 & 19.34 & \multirow{2}{*}{-10.58} & \multirow{2}{*}{23} & \multirow{2}{*}{-2.36} & \multirow{2}{*}{$.02 *$} \\
\hline 3 year post & 24 & 63.10 & 20.32 & & & & \\
\hline
\end{tabular}

*Statistically significant 
With respect to reading proficiency, Table 3 shows that the mean of the students with reading proficiency increased significantly during both the comparison periods of 6 years and 3 years before and after implementation of HOPE VI program. The results clearly show that the differences are significant at $2 \%$ significance levels, which are within the margins of acceptance in social science literature (generally, 5\% is considered as a rule of thumb for being significant). The HOPE VI thus had a significant influence on reading proficiency.

In addition to reviewing the significance of the t-test, the degree of association for a sample was measured using eta squared. Eta squared indicates the proportion of variance in the dependent variable accounted for by the independent variable (Becker, 1998; Wendorf, 2012). The results for this study found that the effect size for reading 6 years and 3 years before and after HOPE VI implementation was small $\left(\eta^{2}=0.019\right.$, 0.027). Cohen (1992) suggests effect sizes for eta squared ( $\eta 2)$ where 0.0099 constitutes a small effect, 0.0588 a medium effect and 0.1379 a large effect. Thus, the effect size of reading scores indicates that at the time the scores were recorded accounts for $1.9 \%$ and $2.7 \%$ of the variance of the difference in mean reading test scores.

With respect to math proficiency, Table 4 shows that the mean of the students with math proficiency increased significantly during both the comparison period of 6 years before and after implementation of HOPE VI program, and was significant for the 3 and 6 years periods before and after implementation of the HOPE VI program. The results clearly show that the differences are significant at $4 \%$ and less than $1 \%$ significance levels. The results for this study also found that the effect size for math scores 6 years and 3 years before and after HOPE VI implementation was, again, small 
$\left(\eta^{2}=0.045,0.009\right)$. The effect size indicates that at the time the scores were recorded accounts for $4.5 \%$ and $.9 \%$ of the variance of the difference in mean math test scores. Nonetheless, in both these cases, the math proficiency scores increased. Albeit weaker at 6 years before and after, there is evidence that math proficiency increased. Overall, the results show that the percentage of students considered proficient in reading and math increased after the implementation of HOPE VI program.

Table 4

T-test Results for Average Math Proficiency School Scores

\begin{tabular}{|c|c|c|c|c|c|c|c|}
\hline & $\mathrm{N}$ & $\begin{array}{l}\text { M } \\
\text { Percent }\end{array}$ & $\begin{array}{l}\text { SD } \\
\text { Percent }\end{array}$ & $\begin{array}{l}\text { Mean- } \\
\text { difference }\end{array}$ & $\mathrm{df}$ & $\mathrm{t}$ & $\begin{array}{l}\text { P-value } \\
\text { (two-tailed) }\end{array}$ \\
\hline 6 years prior & 4 & 24.58 & 87.30 & \multirow{2}{*}{-38.53} & \multirow{2}{*}{3} & \multirow{2}{*}{-3.32} & \multirow{2}{*}{$0.04 *$} \\
\hline 6- years post & 4 & 63.10 & 20.32 & & & & \\
\hline 3 year prior & 25 & 42.53 & 20.56 & \multirow{2}{*}{-13.26} & \multirow{2}{*}{24} & \multirow{2}{*}{-2.85} & \multirow{2}{*}{$0.00 *$} \\
\hline 3 year post & 25 & 55.79 & 22.27 & & & & \\
\hline
\end{tabular}

* Statistically significant

\subsection{Discussion of t-test results}

My hypotheses stated that following the implementation of HOPE VI, neighborhood public schools were likely to: 1) reduce the school FRLP rates; and 2) improve their school performance. While the first hypothesis is not supported, the second hypothesis is supported. The results are interesting in the context of the extant literature that high poverty schools have low performance. The correlation between concentrated poverty and poor school performance is consistently reported in the education literature (Banks, 2001; Coleman et al., 1966; Kraus, 2008). The results show that the HOPE VI program does not make much difference in the neighborhood public schools' SES composition, as measured by the share of children qualifying for the FRLP. Yet, the HOPE VI program does show that there is some relationship between the implementation 
of the program and the school's performance measured in terms of percentage of $5^{\text {th }}$ grade students considered proficient in reading and math. How do we explain the difference in connection with the existing literature?

The contrasting results may be explained in several ways. First, the implementation of the HOPE VI plan, to create mixed income communities, was inconsistent: in a number of communities supply and demand did not align; affordability remained an issue for the poorest residents; and in others areas, gentrification was evident (Brazley \& Gilderbloom, 2007; Popkin et al., 2004; Raffel et al. 2003). The Department of Housing and Urban Development acknowledged that, "in practice, there is no single formula or standard definition of mixed-income housing" (HUD, 2003, p 3). To date, there is no regulated percentage of housing that must be reserved for low-income occupants. In each HOPE VI location across the country, it is left to public housing officials, developers, and planners to determine a healthy and sustainable mix. Subsequently, even when mixed-income was considered a 'success' there were no guarantees that middle income families would send their children to the neighborhood public school. The lack of creating fully integrated communities may help explain why there was no change in school SES rates.

Second, the lack of significant change in FRLP rates before and after HOPE VI program may also be attributed to better tracking of low-SES families. Originally, FRLP was tracked based on worksheets completed by families at the beginning of the school year, with no major oversight or advertisement by districts. Today, FRLP rates are strictly monitored because school funding is associated with these proportions. The United States Department of Education calculates funding under Title I of the Elementary and 
Secondary Education Act (hereby referred to as Title I) using data from the Census Bureau, per-pupil education expenditures, and the number of children from low-income families. Title I funding targets, "the achievement gap between disadvantaged students and their more advantaged peers and [focus on] how to improve the performance of children from low-income families" (GAO, 2002, p 2). The funding formula allocates additional aid to high poverty schools as, "studies have indicated that schools with higher numbers and percentages of poor children may have higher costs associated with raising student performance" (p 2). By 2001, more stringent guidelines were enforced to include requirements related to No Child Left Behind (NCLB) Laws, standardized testing was mandated, while performance was monitored in accordance with student demographics. School poverty rates are more likely to be accurate due to a more sophisticated approach to collecting FRLP data, the incentive of increased Title I funding, and the requirements of NCLB. Thus, these two procedural developments may have led to increased accuracy of FRLP reporting in recent years.

Third, urban public schools are usually undesirable to middle-income and highincome families. Public confidence in public schools has dropped considerably during the last 30 years (Carr, 2007). Several communities replaced traditional public schools with magnet or charter schools. Generally, students with the most proactive parents tend to opt out of poor performing schools to attend charter schools, while students with higher test scores are systematically offered placement in magnet schools. If middle and highincome families avoid public schools, while the more involved families seek charter or magnet options, then traditional public schools are left serving an increasing population of students from low-income families. 
Fourth, the reading and math scores may have improved, but the scores still show that significant improvement is required in the scores when compared to the national average. Six years prior to HOPE VI, the average of the percentage of children considered proficient in 5th grade reading and math were $22.02 \%$ and $24.25 \%$, respectively. Nationwide, less than $25 \%$ of all students attending public schools in HOPE VI communities were considered proficient. It shows that more than $75 \%$ of all students were performing below grade level. Six years after the implementation of HOPE VI, the percentage of children proficient in reading and math doubled to $54.31 \%$ and $50.64 \%$ respectively. This is a vast improvement, but when compared to district, state, and national scores, these are still dismal results. Moreover, the improvements in scores may be more closely tied to the No Child Left Behind Act (NCLB), authorized in 2001. President George W. Bush created NCLB to tie accountability directly to testing and assessment. Each school was required to make academic gains in reading and mathematics. As a result, sub-groups and at-risk students now required more strict attention. Indicators, such as race, socio-economics, special education, and English as a Second Language (ESL), were used to identify student sub-groups and ensure that theoretically no child would be left behind. Equally important, and for the first time, standards-based test scores would be released to the public. High poverty schools overwhelmingly scored lower than schools with little or no poverty amongst their student population. Test scores became an indicator to determine whether schools were offering a quality education. When $50 \%$ of 5 th graders are performing below grade level in urban areas, in 22 cities across the United States, these schools do not bode well for attracting families to mixed income communities. When compared to district, state, and national 
scores, public schools in HOPE VI communities overwhelmingly underperformed and produced scores that were not competitive.

Last, but not the least, the HOPE VI programs may have made a difference in the

neighborhood quality overall, even if the socio-economic status may not have improved in the schools. The change in neighborhood quality entailed by the New Urbanist principles of walkability, and more community orientation could have a positive influence on the community overall. The change in the community physical infrastructure could have an intangible relationship with the school performance. Such influences may not be discernible through a quantitative analysis, but may be revealed through qualitative approach (as is done in the next chapter).

\subsection{HOPE VI and School SES: Regression Analysis (Model A)}

Regression is one of the most widely used statistical models to study the effects of HOPE VI. It is used as a "tool to express a relationship between two interval-ratio variables in a concise way" (Frankfort-Nachmias and Leon-Guerrero, 2011, p 399). In fact, some of the most notable articles that investigate HOPE VI accountability and performance rely on regression analysis to determine outcomes related to families and their children (Popkin et al., 2004 \& 2002), better neighborhood indicators (Goetz, 2010), housing conditions (Holin, et al., 2003; HUD, 2003), and resident displacement (Jones and Paulsen, 2011). Following the research methods found in the extant literature, my dissertation uses regression models to focus on the organizational level, namely, the schools. 
The regression models look specifically at the schools in HOPE VI communities and the change in student socioeconomic status following implementation. The model will determine whether there is a statistically significant relationship following the implementation of HOPE VI (three years before and after) and the rate of students that qualify for FRLP at the local public schools. The equation for the model (A) is as follows: School SES $=f$ (HOPE VI project site housing characteristics, HOPE VI Public Housing Authority housing characteristics, school characteristics)

Model A describes the relationship between HOPE VI as a revitalization effort (independent variable) and the change in the socio-economic status of public school students, which is measured by the change in the percentage of students receiving Free and Reduced Lunch Program (FRLP) rates. The description of the variables and the data sources are given in Table 5 (see Appendix B for more detailed explanations).

Table 5

Regression Model A: Variables and Descriptions

\begin{tabular}{|l|l|l|}
\hline Variable name & Description of the variable & Data source \\
\hline Change in FRLP & $\begin{array}{l}\text { Change in the percentage of students that qualified for FRLP } \\
\text { at neighboring public schools, three years before and after the } \\
\text { implementation of HOPE VI. }\end{array}$ & $\begin{array}{l}\text { National Center for Education } \\
\text { Statistics (NCES); Greatschools.org }\end{array}$ \\
\hline COMPRATE & HOPE VI construction completion- measured in years & $\begin{array}{l}\text { Literature from each PHA; local } \\
\text { newspaper articles }\end{array}$ \\
\hline DEMO & $\begin{array}{l}\text { Demolition Grant at Project Site (Dummy variable: No= 0; } \\
\text { Yes=1) }\end{array}$ & $\begin{array}{l}\text { United States General Accounting } \\
\text { Office (2003). In HOPE VI (Ed.), } \\
\text { Public housing [electronic resource] }\end{array}$ \\
\hline NOUNITS & $\begin{array}{l}\text { Change in Number of Housing Units at Project Site- numbers } \\
\text { of housing units lost }\end{array}$ & $\begin{array}{l}\text { HUD HOPE VI Revitalization grant } \\
\text { list }\end{array}$ \\
\hline HADEMO & $\begin{array}{l}\text { Demolition Grant at Public Housing Authority (Dummy } \\
\text { variable: No= 0; Yes=1) }\end{array}$ & $\begin{array}{l}\text { United States General Accounting } \\
\text { Office (2003). In HOPE VI (Ed.), } \\
\text { Public housing [electronic resource] }\end{array}$ \\
\hline HANOUNITS & $\begin{array}{l}\text { Change in Number of Housing Units at Public Housing } \\
\text { Authority- numbers of housing units lost }\end{array}$ & $\begin{array}{l}\text { HUD HOPE VI Revitalization grant } \\
\text { list }\end{array}$ \\
\hline HAFUNDS & $\begin{array}{l}\text { HOPE VI Revitalization Funding per Housing Authority- } \\
\text { dollar figure. Represents change in dollars per million }\end{array}$ & $\begin{array}{l}\text { United States General Accounting } \\
\text { Office (2003). Public Housing- } \\
\text { Information on Receivership at Public } \\
\text { Housing Authorities. }\end{array}$ \\
\hline MINORITY & Change in Minority Enrollment (non-white) & $\begin{array}{l}\text { National Center for Education } \\
\text { Statistics (NCES) }\end{array}$ \\
\hline AA & Change in African American Enrollment & $\begin{array}{l}\text { Greatschool.org; NCES } \\
\text { Greatschool.org; NCES } \\
\text { Change in Per Pupil Allotment- dollar figure. Represents }\end{array}$ \\
\hline
\end{tabular}


The key independent variables are related to HOPE VI housing characteristics. On average, HOPE VI construction timeline (from old to new housing) took six years and ten months. Worst-case scenarios range to as many as 15 years, while four sites to date remain incomplete. The fastest transition did not require demolition and was completed in one year. The following variables determined whether HOPE VI renewal efforts (fast versus slow; large versus small scale developments) were related to the change in schools: Construction Completion rates (COMPRATE), Demolition Grant at Project Site (DEMO), Number of Public Housing Units per Site (NOUNITS), Public Housing Authority (PHA) Demolition Grant (HADEMO), PHA Public Number of Housing Units (HANOUNITS), Revitalization Funding per Housing Authority (HAFUNDS)(Brazley \& Gilderbloom, 2007; Brown, 2009; Cahill, Lowry \& Downey, 2011).

Table 6

Descriptive Statistics (Model A)

\begin{tabular}{lcrrrc}
\hline \multicolumn{1}{c}{ Variable } & $\mathrm{N}$ & Minimum & Maximum & Mean & Std.Deviation \\
\hline Change in FRLP & 107 & -27.10 & 28.3 & -12.00 & 8.60 \\
COMPRATE & 114 & 1 & 15 & 6.80 & 2.97 \\
DEMO & 114 & 0 & 1 & 0.21 & 0.41 \\
NOUNITS & 114 & 0 & 26.25 & 1.29 & 3.52 \\
HA DEMO & 114 & 0 & 1 & 0.57 & 0.50 \\
HANOUNITS- & 114 & 0 & 12.44 & 11.74 & 28.21 \\
HAFUNDS* & 114 & $\$ 4.15$ & $\$ 50.0$ & $\$ 27.96$ & $\$ 11.52$ \\
MINORITY & 107 & -.395 & 0.24 & 0.005 & 0.08 \\
AA & 107 & -.419 & 0.34 & -0.005 & 0.0814 \\
PPFUNDS** & 111 & $-\$ .694$ & $\$ 4.47$ & $\$ 1.54$ & $\$ 1.02$ \\
\hline \hline
\end{tabular}

*Represents change in dollars per million; **Represents change in dollars per thousand

The control variables, namely, changes in school characteristics, are based on the extant literature. Funding and student racial demographics are generally key considerations in educational research studies. The first indicator, funding, as measured by per-pupil allotment, is considerably higher in wealthier communities (Holzman, 2011; 
US Department of Education, 2011). Property values along with property taxes help determine this rate. This data was collected from the National Center for Education Statistics and determines whether a change in per-pupil allotment relates to school SES or performance. The second indicator, student racial demographics, takes a two-step approach. First, the percentage of students characterized as minorities (non-white) is collected. Measuring minorities as one group is an insufficient indicator because it does not take into account the various types of minorities present in urban public schools (Ellen \& Horn, 2011; Mickelson, 2011). For example, along the west coast, the diversity of students includes a greater ratio of Asian and Hispanic students and this did not have the same impact on SES rates or testing scores. As a result, it was necessary to collect data for African-American students. The summary descriptive statistics of all the variables are given in Table 6 (see appendix D: Correlation Model A).

The results of the Model A regression are given in Table 7. As the table shows, the regression model does not support the hypothesis that HOPE VI implementation relates to school SES. The overall adjusted R-square of value is low (0.14), indicating that only 14 percent of the change in school SES is explained in this model. Three variables are statistically significant: demolition, minority, and per pupil funds. The significance of these three variables is interesting. The signs minority is negative, implying that when more of the shares are minorities, the less the change in FRLP values (i.e. the SES remains the same as before HOPE VI implementation). The per pupil funding is positive, which is to be expected because this increases the change in FRLP values. 
Table 7

Summary of Regression Analysis (Model A)

\begin{tabular}{lrrrr}
\hline \multicolumn{1}{c}{ Variable } & \multicolumn{1}{c}{$\mathrm{B}$} & $\mathrm{SE}(\mathrm{B})$ & \multicolumn{1}{c}{$T$} & Sig. (p) \\
\hline COMPRATE & -0.26 & 0.37 & -.0 .71 & 0.47 \\
DEMO & -1.22 & 2.75 & -.0 .44 & 0.69 \\
NOUNITS & -0.23 & 3.41 & -0.01 & 0.99 \\
HADEMO & 1.57 & 1.89 & 0.83 & 0.41 \\
HANOUNITS & -6.03 & 0.45 & -1.34 & 0.18 \\
HAFUNDS & 0.73 & 0.08 & 0.95 & 0.35 \\
MINORITY & -26.11 & 14.27 & -1.83 & $0.07^{*}$ \\
AA & -9.65 & 13.19 & -0.73 & 0.47 \\
PPFUNDS & 1.49 & 3.67 & 1.86 & $0.07^{*}$ \\
\hline \hline
\end{tabular}

Notes: $\mathrm{R}^{2}=0.14, \mathrm{~F}=.0156(p<.05) ; \mathrm{N}=99$

\subsection{HOPE VI \& School Performance: Regression Analysis (Model B)}

To determine a statistical relationship between the implementation of HOPE VI, as community revitalization, and the change in schools' academic performance, I ran a second regression model. Model B describes the relationship between HOPE VI as a revitalization effort (independent variable) and the change in public school performance, which is measured by the combined percentage point change of 5th grade students that are proficient in reading and math (dependent variable). Consistent with model $\mathrm{A}$, the change is measured three years before and after the implementation of HOPE VI. The equation for the model $\mathrm{B}$ is as follows:

School Performance $=\mathrm{f}($ HOPE VI project site housing characteristics, HOPE VI Public Housing Authority housing characteristics, school characteristics)

Model B includes each of the variables included in model A, but also adds two additional control indicators. Due to the introduction of magnets and charter schools in some HOPE VI Communities, the change in school enrollment is a necessary variable to include. A decrease in enrollment may have a negative influence if better performing 
students take advantage of school choice. Next, teacher-student ratio is a key variable in educational research literature related to student performance: "From an administrative or economic viewpoint, pupil-teacher ratio is very important, because it is closely related to the amount of money spent per child" (Ehrenberg, Brewer, Gamoran and Willms, 2001, p 2). These two variables would determine if the change in student enrollment and the teacher-student ratio relate to school performance, following the implementation of HOPE VI. The descriptive statistics of all the variables in the Model B are shown in Table 8 (see appendix E: Correlation Model B).

Table 8

Descriptive Statistics (Model B)

\begin{tabular}{lcrrrr}
\hline \multicolumn{1}{c}{ Variable } & $\mathrm{N}$ & Minimum & Maximum & \multicolumn{1}{c}{ Mean } & Std.Deviation \\
\hline PERFORMANCE & 113 & -139.90 & 94.30 & -8.07 & 45.44 \\
COMPRATE & 114 & 1 & 15 & 6.80 & 2.97 \\
DEMO & 114 & 0 & 1 & 0.21 & 0.41 \\
NOUNITS & 114 & 0 & 26.25 & 1.29 & 3.52 \\
HA DEMO & 114 & 0 & 1 & 0.57 & 0.50 \\
HANOUNITS & 114 & 0 & 12.44 & 11.74 & 28.21 \\
HAFUNDS* & 114 & $\$ 4.15$ & $\$ 50.00$ & $\$ 27.96$ & $\$ 11.52$ \\
FRLP & 107 & -27.1 & 28.30 & -12.0 & 8.60 \\
MINORITY & 107 & -0.40 & 0.23 & 0.005 & 0.08 \\
AA & 107 & -0.42 & 0.34 & -0.005 & 0.08 \\
PPFUNDS** & 111 & 111 & $-\$ 0.69$ & $\$ 4.47$ & $\$ 1.54$ \\
T-S-RATIO & 103 & -10.23 & 9.83 & -0.82 & 2.83 \\
ENROLLCH & 106 & -396 & 433 & -13 & 112 \\
\hline
\end{tabular}

*Represents change in dollars per million; **Represents change in dollars per thousand

The results of the regression model B are given in Table 9. There is weak support for the hypothesis that the HOPE VI implementation is related to increase in school performance. The R-square value is 0.29 , implying that the model explains $29 \%$ of the variation in the change in the school performance. There are few significant variables, 
which could suggest a problem of multicollinearity. Only two variables within the model appear to be statistically significant. The variable teacher-student ratio $(p=.001)$ only loosely explains that there is a positive correlation between the changes in ratio to school performance. In addition, the relationship between the number of housing units lost by the local public housing authority $(p<.001)$ relates to school performance. This suggests that when there is a decrease in the number of available public housing units by the public housing authority, there is a possible improvement in school performance and that change is indirect.

Table 9

Summary of Regression Analysis (Model B)

\begin{tabular}{lrrrr}
\hline \multicolumn{1}{c}{ Variable } & \multicolumn{1}{c}{$\mathrm{B}$} & $\mathrm{SE}(\mathrm{B})$ & $\mathrm{T}$ & Sig. $(\mathrm{p})$ \\
\hline COMPRATE & -2.75 & 1.93 & -1.43 & 0.16 \\
DEMO & -24.53 & 15.99 & -1.53 & 0.13 \\
NOUNITS & 37.18 & 18.81 & 1.98 & 0.05 \\
HADEMO & 10.69 & 9.81 & 1.09 & 0.28 \\
HANOUNITS & -7.37 & 1.83 & -4.03 & $.00^{* *}$ \\
HAFUNDS & 0.66 & 0.43 & 1.56 & 0.12 \\
FRLP & -64.54 & 55.66 & -1.16 & 0.25 \\
MINORITY & -20.60 & 109.94 & -0.19 & 0.85 \\
AA & 53.64 & 74.35 & 0.72 & 0.47 \\
PPFUNDS & 3.31 & 4.57 & 0.73 & 0.47 \\
T-S-RATIO & 4.70 & 1.70 & 2.76 & $0.01^{* *}$ \\
ENROLLCH & -0.01 & 0.05 & -0.22 & 0.83 \\
\hline \hline
\end{tabular}

Notes: $\mathrm{R}^{2}=0.29, \mathrm{~F}=.0031(p<0.05) ; \mathrm{N}=95$

\section{$\underline{4.7 \text { Conclusion }}$}

My hypotheses for the first two questions were that neighborhood public schools, following the implementation of HOPE VI, were likely to 1) reduce the school FRLP rates and 2) improve their school performance. The first hypothesis was not supported by the t-test analysis. The change in SES did not prove to be statistically significant over the three and six year periods before and after implementation of HOPE VI. The second 
hypothesis is supported for the school performance; the proportion of $5^{\text {th }}$ graders deemed proficient in reading and math and reading scores increased significantly for six and three years after HOPE VI as compared to the six and three year periods before the implementation of HOPE VI.

Several factors may explain the lack of change in student socio-economic status following HOPE VI. The first is that the HOPE VI plan to create mixed income communities may not have been realized. In a number of communities, supply and demand were not aligned, affordability remained an issue, and, in others, gentrification was evident (Brazley \& Gilderbloom, 2007; Popkin, 2004; Raffel et al. 2003). Also, even in circumstances when mixed-income was a success, there was no guarantee that middle income families would send their children to the neighborhood public school. Urban public schools are undesirable to middle-income and high-income families. One must also consider that magnet and charter school replaced the neighborhood public schools in several communities. Thus, students with the most proactive parents opt out of poor performing schools to attend charter schools and students with higher test scores are systematically offered placement to magnet schools.

Further discussion related to the consistent increase in public school performance in HOPE VI Communities is required. Six years prior to HOPE VI, less than $25 \%$ of all students attending public schools in HOPE VI communities across the country were considered proficient. Proficiency is defined as functioning at grade level or above in reading and mathematics. More alarmingly, $75 \%$ of all students were performing below grade level. Six years after the implementation of HOPE VI, scores were doubled in math and reading. This is a vast improvement but still dismal performance. When $50 \%$ of 5 th 
grades are performing below grade level in urban areas in 22 cities, these schools cannot be considered attractive and does not bode well for attracting families to mixed income communities. When compared to district, state, and national scores, public schools in HOPE VI communities are underperforming and the scores are not competitive.

The findings of this chapter that the SES did not change before and after HOPE VI, but the school performance did change before and after HOPE VI is interesting by itself. The findings would be considered contradictory in the context of the extant literature that portrays that low SES schools do not perform well. To explain the conjectures of why this is so requires a qualitative approach to identify the factors that have influenced school performance in HOPE VI neighborhoods. 


\section{CHAPTER FIVE: FACTORS THAT INFLUENCE SCHOOL PERFORMANCE}

\subsection{Introduction}

Throughout the United States, public school enrollment patterns are typically organized by neighborhood boundaries. These boundaries inextricably link public schools and neighborhoods. If there is a lack of economic integration in the schools, it is a direct reflection of the lack of economic integration in the neighborhoods (United States Department of Housing and Urban Development (HUD), 2004). The communities where HOPE VI projects are located are typically inner-city areas, where the lack of economic integration is particularly apparent. In the previous chapter, I examined the link between the socio-economic status of students and public school performance in HOPE VI neighborhoods.

In this chapter, I use qualitative methods to gain further insights into the factors that affect the HOPE VI neighborhood schools' performance. In contrast to extant research and policy foci on organizational level factors of the school, my focus is on the non-school neighborhood level factors that influence the public school performance. Towards this end, this chapter is a case study of two HOPE VI neighborhood public schools, one which excelled in improving and another which regressed the most in school performance (as measured in terms of math and reading scores). The comparative case study of such two schools at different ends of performance is appropriate to provide insights into the deeper dynamics of the factors that enable or hinder good school performance. 
The two schools included in the case study are the HOPE VI neighborhood public schools in Philadelphia, Pennsylvania and Washington, D.C. To do the comparative case study, I reviewed the practices of the local public housing authority, the public school district, and the two area public schools in each HOPE VI community. Primary sources for the case studies included interviews with officials across these agencies and schools, which were supplemented with neighborhood observations, attendance at community meetings and public events. NVivo, a qualitative analysis software, was used to analyze the interviews. The secondary sources included historical data, congressional documents, articles from professional journals, newspaper articles, professional presentations from national conferences, and testimony before the House Subcommittees for Housing and Community Opportunity.

The rest of this chapter is organized as follows. The next section outlines the process of selecting the two schools for the case study. Then, the process of the case study methodology, including the interview and analysis process is detailed. This is followed by the case studies of the HOPE VI neighborhood public schools in Philadelphia and Washington, DC. After this, the insights from the two case studies are compared for broader lessons. Finally, the chapter concludes with a summary of the major lessons.

\section{$\underline{5.2 \text { Selection of case study schools }}$}

In order to conduct the case study, I selected two schools—one which improved its performance exceptionally, another which regressed the most-for comparison in the HOPE VI neighborhoods. These are two schools at the tail ends of the distribution of 
school performance among all the 165 HOPE VI sites. Such extremes are the outliers in the school performance. Although the findings from the case studies of the outliers may not be generalizable, the outliers provide give good insights into the dynamics of the factors that help or hinder the school performance. Such factors may not be as clearly discernible in the schools in the middle range of school performance.

To identify the two schools that improved the most and the least in school performance, I examined the changes in the math and reading standardized test scores of $5^{\text {th }}$ grade students among all the 116 neighborhood public schools in the HOPE VI communities. The school which made the most gain in the scores was the Andrew Jackson Elementary School, which is the neighborhood public school for the HOPE VI project (Martin Luther King Plaza) in Philadelphia. The school's math score improved by 54.9 points and reading score improved by of 45.2 points, for a total improvement of 100.01 points over a period of eight years (from 2003 to 2010). The HOPE VI project was implemented in 2005. The school that lagged the most in school performance was the Dr. R. Drew Elementary School, which is the neighborhood public school for the HOPE VI project (New East Capitol) in Washington, DC. The school's performance had declined the most during the same period of eight years - math scores reduced by 48.25 points, and reading scores reduced by 43.04 points, for a combined reduction of 91.29 points. Hence, I selected these two public schools for doing a comparative case study.

One of the key factors for case study selection is not only that the dependent variables are different, but that the independent variables are similar so that the key factors for the differences in outcome variables may be identified. In this respect too, the two case study schools became an appropriate choice since the two HOPE VI sites are 
quite similar on several fronts (see Tables 10 and 11 for HOPE VI demolition and revitalization data). The demolition of existing public housing units were similar in both sites-537 units in Philadelphia and 537 units in Washington, DC. The HOPE VI revitalization program envisaged construction of 242 housing units in Philadelphia; in Washington, DC the program envisaged 228 mixed income housing units and an additional 152 Senior Housing units. In both sites, less than $50 \%$ of the original housing units that were demolished were built. The homeownership is quite similar in both sites: 62 percent home-ownership in Washington, DC and 56 percent home-ownership in Philadelphia. Both the housing authorities reported 100\% occupancy. One difference is in terms of the share of former public housing residents who returned to the HOPE VI public housing project: in Philadelphia, 53 percent returned to the site, and in Washington, DC 30 percent of the former residents returned to the site. This difference should not affect my case study selection, since, if at all, the higher percentage of former residents returning in Philadelphia should have adversely affected the school performance (and vice versa in Washington, DC). However, the Philadelphia school excelled and the Washington, DC school lagged behind.

Table 10

HOPE VI Demolition Grants in Philadelphia and Washington, DC

\begin{tabular}{lll}
\hline & Philadelphia & Washington, DC \\
\hline Project Site name & MLK/Hawthorne & East Capitol Dwellings \\
Number of housing units demolished & 537 & 577 \\
Year of demolition & 1999 & 2005 (families relocated 2002) \\
Housing Style & High rise & Barrack-style \\
HOPE VI Demolition Funding & $\$ 4,832,500$ & $\$ 1,288,707$ \\
Vacancy rate & $35 \%$ & $30 \%$ \\
Number of families relocated & 408 & 649 \\
Relocation schemes & 117 Section 8; 112 Other & 428 Section 8; 221 Other \\
& Public Housing; 25 Not & Public Housing \\
& assisted by HUD; 32 Didn't & \\
\hline
\end{tabular}


Table 11.

HOPE VI Revitalization Grants in Philadelphia and Washington, DC

\begin{tabular}{lll}
\hline City & Philadelphia, PA & Washington, $D C$ \\
\hline HOPE VI site name & MLK Plaza & Capitol Gateway \\
Authorization Date & 1998 & 2000 \\
Amount Awarded & $\$ 25,229,950$ & $\$ 30,967,337$ \\
Completion Date & 2008 & 2005 \\
Completion Years & 9 & Year? \\
Profile of Housing units & 242 Total Units & 379 Total Units \\
& $(136$ Homeowner Units; & (151 Senior Housing; 142 \\
& 106 Rental Units) & Homeowners; 86 Rental Units) \\
Homeownership & $56 \%$ & $62 \%$ \\
Returning Families & $53 \%$ & $30 \%$ \\
Returning as Homeowners & 4 & 7 \\
Occupancy & $100 \%$ & $100 \%$ \\
\hline
\end{tabular}

\subsection{Case Study Methodology}

The case study method is widely used in public administration. Yin (1984, p. 23) defines the case study as "an empirical inquiry that investigates a contemporary phenomenon within its real-life context; when the boundaries between phenomenon and context are not clearly evident; and in which multiple sources of evidence are used." Case study is particularly useful for gaining deep insights into complex situations, which cannot be adequately captured through other methods. Jensen and Rodgers (2001, p. 205) contend that case studies are useful because "they satisfy the recognized need for conditional findings and an in-depth understanding of cause and effect relationships that other methodologies find difficult to achieve." Similarly, Soy (1996, p. 1) asserts that "case study research excels at bringing us to an understanding of a complex issue or object and can extend experience or add strength to what is already known through previous research. Case studies emphasize detailed contextual analysis of a limited number of events or conditions and their relationships." Case studies are thus intended to provide deeper insights into a contextual phenomenon. They are not intended to be 
generalizable, nor are they so. They can, however, provide deeper understanding about the dynamics that could be useful as lessons in other contexts. Accordingly, my case studies of the two schools are intended to inform national, state, and local level policies.

In order to conduct the case studies of the two schools, I first examined a range of secondary sources, including official public websites, newspaper and professional articles related to housing and education. I identified the local public housing officials and school administrators based on the secondary sources. I had an email conversation with the officials to ensure that they were familiar with the HOPE VI project and the neighborhood public schools. I selected the persons to interview based on three criteria: (a) Job titles and employment dates were in line with the scope of HOPE VI; (b) the official held an administrative position during the HOPE VI project implementation; and (c) the official's position required an understanding of the HOPE VI program's development and/or impact.

In order to identify my interview subjects, I had an initial meeting with a senior official from each of the Public Housing Authority (e.g., supervisor, compliance officer, redevelopment specialist, interim president) and the two schools (e.g., principals and vice presidents of education). I also attended the community functions. The initial meetings, the community functions, and other sources such as newspaper notices and websites allowed me to identify community partners, neighborhood leaders, and residents. Once I identified the first few interviewees, I used snowball sampling to get more interview participants (see Figure 1). In this way, I conducted face to face and telephone interviews with fourteen officials from both schools and housing developments in Philadelphia and Washington, D.C. during the months of June and July, 2012. The interviews themselves 
were conducted at professional worksites, at the actual HOPE VI site, coffee shops and, in some cases, the residents'/ participants' homes. The residents had organized a walk through in the neighborhood community in both Philadelphia and Washington, DC.

\section{Figure 1. Illustration of Snowball Sampling}

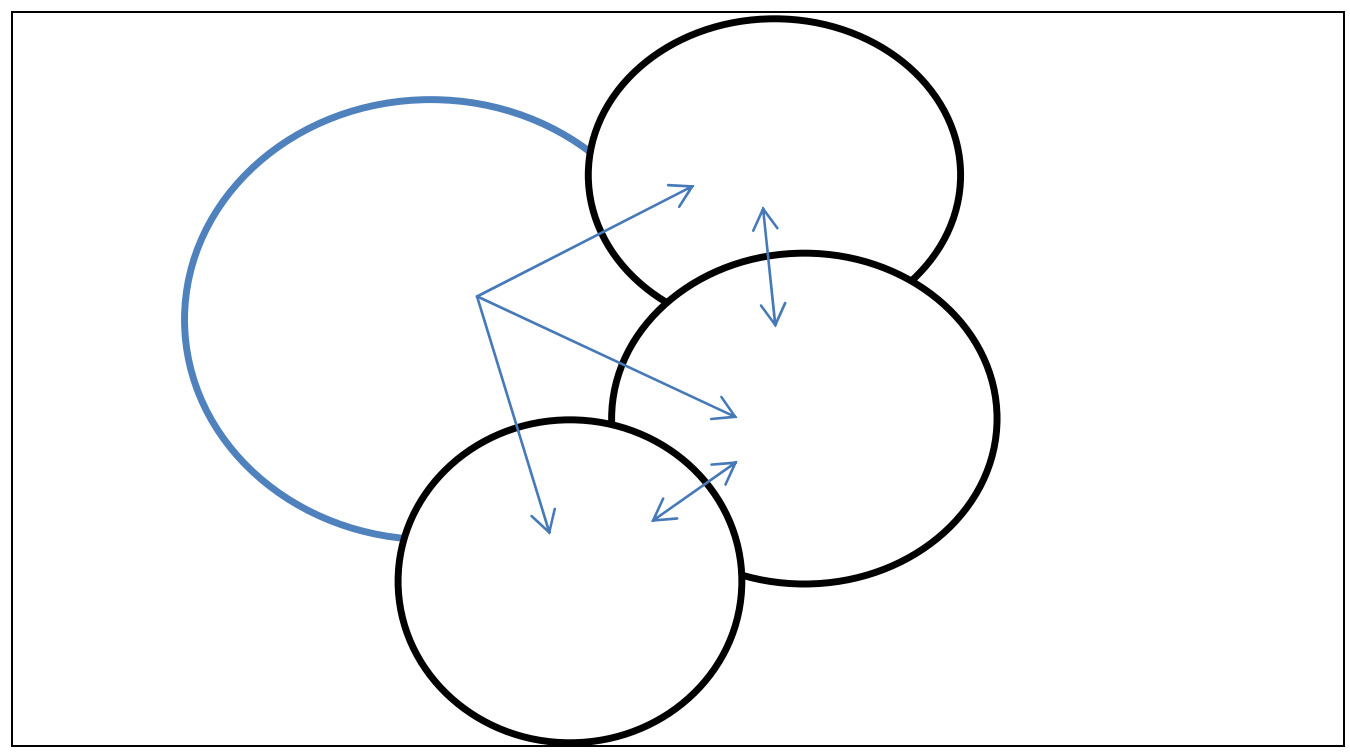

The fourteen interviewees were as follows: three administrators from the Philadelphia Housing Authority (PHA) and District of Columbia Housing Authority (DCHA); three school principals from Andrew Jackson Elementary, Drew Elementary, and a neighboring public school in Philadelphia, called Staten Elementary; five community leaders and residents from the HOPE VI Sites of Martin Luther King (MLK) Plaza in Philadelphia, and Capitol Gateway in Washington, DC.; and three representatives from partnership agencies affiliated with the Philadelphia and Washington, DC sites

Of the 14 interviews, eight were in Philadelphia and six were in Washington, DC. Gender was fairly equally represented as there were eight women and six men agreed to 
participate. The average length of experience of the interviewees was 21 years for public housing officials, 29 years for public education officials, 10 years for community partners, and 7.25 years for residents serving in leadership capacities (Table 12). None of the subjects were compensated, as per the university's Institutional Review Board approved protocol. All respondents provided verbal consent via telephone or written consent via email for the interview, as per the protocol. In addition, I obtained verbal permission from all participants before electronically recording the interviews. In several cases, the interview subjects provided me with additional literature to validate their claims.

Specifically in Philadelphia, the interview subjects' ages ranged from 30 to 70 years, and represented a diverse population that included African-American, Italian, Greek and Caucasians. The experience of the subjects ranged from 17 years for the PHA representative, approximately 15 years for the public school administrator, and nearly 30 years for community partners. The interview subjects included two residents who also served as community leaders. The first was an 'old' resident, a former public housing resident, and well aware of the community's history. She became a first-time homeowner with the HOPE VI revitalization. She had served as the president of the community organization, Hawthorne Empowerment Coalition, for thirteen years. The second subject was a new resident in the HOPE VI community. He had served as the President of the MLK Homeowners Association, President of the Jackson Home \& School Association, and Vice President of Hawthorne Empowerment Coalition. 
Table 12

Interviewee Demographics

\begin{tabular}{|c|c|c|c|c|c|c|}
\hline \multirow[t]{2}{*}{ Agency } & \multirow{2}{*}{$\begin{array}{l}\text { Total } \\
\text { Participants }\end{array}$} & \multicolumn{2}{|c|}{ Participants by sites } & \multicolumn{2}{|c|}{ Gender } & \multirow{2}{*}{$\begin{array}{l}\text { Average years of } \\
\text { experience }\end{array}$} \\
\hline & & $\begin{array}{l}\text { Phila- } \\
\text { delphia }\end{array}$ & $\begin{array}{l}\text { Washing } \\
\text {-ton, DC }\end{array}$ & $\mathrm{F}$ & M & \\
\hline Public Housing Officials & 3 & 1 & 2 & 3 & 0 & 21 \\
\hline $\begin{array}{l}\text { Public School } \\
\text { Administrators }\end{array}$ & 3 & 2 & 1 & 2 & 1 & 29 \\
\hline Community Partners & 3 & 3 & 0 & 1 & 2 & 10 \\
\hline $\begin{array}{l}\text { Residents/Community } \\
\text { Leaders }\end{array}$ & 5 & 2 & 3 & 2 & 3 & 7.25 \\
\hline Total & 14 & 8 & 6 & 8 & 6 & 16.8 \\
\hline
\end{tabular}

I used semi-structured questions to interview the subjects. The interview questions are listed in Appendix D. All the interviews were conducted in English, which was the primary language of the subjects. The interviews themselves ranged from 45 minutes to three hours, which were recorded electronically. I also took copious field notes. Following each interview, I transcribed the recordings. I did not transcribe all of them word for word; I transcribed only the relevant parts of the interviews.

To analyze the interviews, I used the NVivo software. The software supports the collection and organization of documents. Specifically, it is used to consolidate and analyze the interviews and secondary data while providing search, query and visualization tools. To analyze, I imported all the transcriptions into NVivo. Then, I coded all the transcriptions to determine the broad themes, relationships among them, and nuances of each interview. The transcriptions were organized by each site. I could then make a comparative analysis of the themes and relationships between Philadelphia and Washington, DC schools (see Appendix F and G: NVivo Word Frequency tool. I identified six major themes in NVivo, which included: housing development, social 
services, stigma, education, governance, and partnerships). Then, I identified sub-themes for four of these themes, as follows:

1. Housing Development: building issues, gentrification, strengths, weaknesses and recommendations

2. Socials Services: Residents and Career Training

3. Education: educational issues/barriers, what works, educational choice and impact of housing

4. Partnerships: Organization and meetings

Governance and Stigma remained as single codes and did not have sub-themes. The complete process of interview to analysis stage is illustrated in Figure 2.

Figure 2. Overview of the interview and analysis process

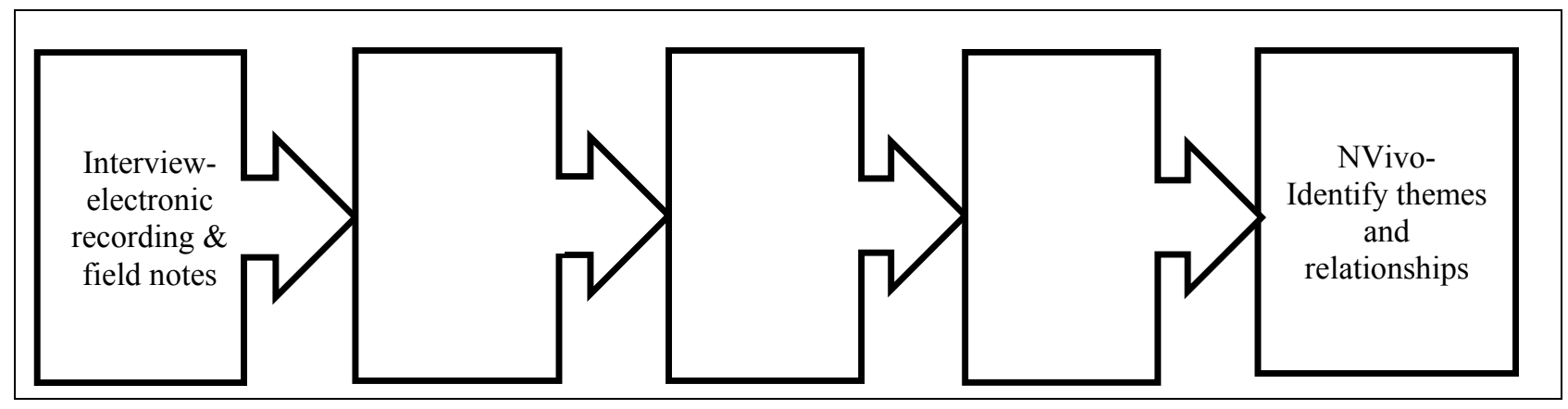

\subsection{Case Study of Andrew Jackson Elementary School in Philadelphia}

Philadelphia is the fifth-most-populous city with the eighth largest school district in the United States. The Philadelphia region has 347 schools in the Philadelphia School District, and over 80 colleges, universities, trade, and specialty schools (US Census Bureau, 2012; Gammage, 2012; Philadelphia School District, 2010). Philadelphia, like 
several cities around the country, has been negatively impacted by urban blight, concentrated poverty, poor design and maintenance of public housing, and the stigmas associated with large-scale high rise public housing. Using the HOPE VI project, the Philadelphia Housing Authority had planned to demolish and revitalize the high-rise public housing projects.

\subsubsection{Background of the Philadelphia Housing Authority}

The Philadelphia Housing Authority (PHA) was established in 1937 with the mission of "providing housing to low-and moderate-income people" (Housing Development Consortium, n.d., p. 1). Like most urban-industrial regions nationwide, Philadelphia had "struggled to provide safe, decent, and sanitary living quarters when the private market failed to produce suitable alternatives" (Brauman, 2012, p. 1). Following the Great Depression, public housing in Philadelphia was not only "class-designated [and] race- segregated" but located in "predominantly white neighborhoods and therefore reserved for White families" (p. 1). Originally, public housing was typically reserved for working-class or middle-class Whites. Later, the growing African-American population was offered public housing in the north, south and west parts of the city. The concentration of the Blacks further deepened the racial segregation in the city.

Public housing policies played an especially important role in shaping the racial dynamics of the postwar city....public housing projects absorbed low-income black families whose housing had been demolished through urban renewal, highway construction, and code enforcement. Essentially, these housing projects solidified black ghettoization in the postwar era. 
Designed to prevent racial transitions and to maintain a rigid color line in urban housing, the massive housing projects also impelled working class and middle-class blacks to newer second ghetto neighborhoods (Mohl, 2001, p. 13).

Between 1953 and 1961, nearly 5000 affordable housing units were built as highrise housing projects, $77 \%$ of which were public housing units. In the late 1970 s, African Americans occupied about two-thirds of all units in the public housing projects. The PHA introduced Section 8 vouchers and "scattered" single-family units since then to deconcentrate public housing projects. Both the methods were costly and onerous on the city. The project maintenance and management costs were also on the rise (Bauman, 2012; Mohl, 2001). The PHA struggled with owning and operating multiple sites, in which the maintenance of the public housing projects started to reduce precipitously. In 1998, the city held hearings on the deplorable conditions of public housing projects and the maintenance woes of PHA. The PHA was accused of "disclosed mismanagement, dire budgetary problems and outright corruption" (Brauman, 2012, p, 1). The list of complaints in public housing projects related to drug trafficking, violence, deplorable housing condition and poor maintenance.

When the federal government introduced the HOPE VI program, Philadelphia was an ideal candidate to demolish the public housing projects and start anew. From 1998 through 2003, the PHA received nine federal grants from HUD, ranging from \$511,000 for scattered sites with 83 units, to $\$ 4,842,500$ for the MLK site with 537 units (HOPE VI Demolition Grants: FY 1996-2003, 2004). Using a combination of HOPE VI funds, private investment, and help from public entities, the PHA demolished five old sites 
(PHA, 2012). The PHA introduced the HOPE VI with much fanfare, claiming that "the HOPE VI program aimed to change peoples' lives and the communities where they live in several ways" (PHA, 2012). The HOPE VI program was to change the physical shape of public housing so that it fits with the surrounding communities instead of becoming an island of isolation. The program would establish positive incentives for residents' selfsufficiency. There would be strict occupancy rules. Consistent with HOPE VI goals, the program would lessen the poverty concentration. The program would enable creating partnerships of opportunity between public and private entities and investors. Currently, the PHA is the nation's fourth largest housing authority. It is the biggest landlord in Pennsylvania with 14,000 affordable housing units, accommodating approximately 81,000 people (PHA, 2012).

\subsubsection{The HOPE VI Project: Martin Luther King Plaza}

The public housing site in Philadelphia was named Martin Luther King Plaza following a speech by Dr. Martin Luther King Jr. at the site. The public housing project, originally built in 1957, was known as Hawthorne Square and consisted of a 15-story high-rise project with four towers that had a total of 576 units. By the late 1990s, residents of the public housing project were largely unemployed and the community was riddled with crime. The high-rise itself was considered highly distressed and 200 of the units were deemed dilapidated or vacant (Mooney, 2007). Using a nearly $\$ 4.8$ million HUD Demolition Grant, the PHA imploded the high-rise buildings on October 17, 1999 (HUD, 2003; Mooney, 2007). 
Following demolition, the PHA received the HOPE VI Revitalization Grant in 1998 for over $\$ 25$ million, in order to develop a mixed income and mixed use community. The MLK Plaza construction began in 2001, with the first homes completed and sold in 2005. The final phase of the project was completed in 2011. After completion, the HOPE VI project offered "245 low-rise homes with 109 owner-occupied and 136 rented spots...the plaza contains two- and three-story townhouses, duplexes and two small apartment buildings [with] Victorian architecture" (Myers, 2011, p. 1). To date, the site boasts of $100 \%$ occupancy with a true mix of households at different income levels.

\subsubsection{School Performance}

Simultaneous with the revitalization of the neighborhood from high-rise public housing projects to a HOPE VI mixed income community, the neighborhood public school—Andrew Jackson Elementary School—underwent a transition. Interviews with the public officials from the PHA, the local public schools, community activists and representatives, and the partnering nonprofit organization were useful in giving insights into the transition process. Principal Ciaranca-Kaplan of the school noted that, "Jackson used to be described as the project school" (personal communication, June 29, 2012). She implied that only students who lived in the public housing projects attended the school. At the time, the students and the adults in the school had low morale and the school was both poor and underperforming. Ms. Bullard, the President of the local nonprofit organization, Hawthorne Coalition, added that there was a definite "stigma for the children who attended the school from public housing" before the HOPE VI revitalization took place. Raed Nasser, President of the local homeowners association of the Hawthorne 
Neighborhood, said that "not only was the school labeled the "project' school," but it was called Little Saigon, "because of the drugs, crime and violence." A former resident in an adjacent neighborhood told me that he would "walk several blocks out of his way to work to avoid walking through the neighborhood." He stated, "I never thought I would choose to become a resident" (personal communication, June 20, 2012).

During the HOPE VI transition period, Andrew Jackson Elementary School, exhibited significant gains in math and reading standardized test scores. In 2003, 16.1\% of students were considered proficient in math, and $22.6 \%$ were proficient in reading (Table 13). In 2009, one year following the completion of the MLK site, $81.4 \%$ were proficient in math and $44.2 \%$ were proficient in reading. As Table 14 shows, the school began outperforming the school district average by 2009 . The high scores continued to be maintained in 2010 and 2011, when $71 \%$ and $84.4 \%$ were considered proficient in math respectively, and $67.8 \%$ then $71.9 \%$ of the children respectively were considered proficient in reading. The school FRLP rate had dropped from 92.0 percent in 2003 to 80 percent in 2009 , but had risen again to $94 \%$ in 2010 .

Table 13

School Performance and FRLP Rate of Andrew Jackson Elementary School, Philadelphia, 2003 to 2011

\begin{tabular}{lccc}
\hline & $\begin{array}{c}\text { Percentage of } 5^{\text {th }} \text { grade students with proficiency in } \\
\text { Math }\end{array}$ & Reading & $\begin{array}{c}\text { School FRLP Rate } \\
\text { (Percentage) }\end{array}$ \\
\hline 2003 & 16.1 & 22.6 & 92.0 \\
2004 & 22.8 & 5.8 & 91.0 \\
2005 & 25.7 & 23.0 & 83.0 \\
2006 & 41.2 & 17.6 & 88.0 \\
2007 & 29.6 & 22.2 & 83.0 \\
$2008^{*}$ & 30.4 & 30.4 & 76.0 \\
2009 & 81.4 & 44.2 & 80.0 \\
2010 & 71.0 & 67.8 & 94.0 \\
2011 & 84.4 & 71.9 & \\
\hline
\end{tabular}


Table 14

Comparison of Proficiency of the School with the School District and State, 2008 to 2011

\begin{tabular}{ccccccc}
\hline Year & \multicolumn{2}{c}{ Jackson Elementary } & \multicolumn{2}{c}{ School District of Philadelphia } & \multicolumn{2}{c}{ Pennsylvania } \\
\cline { 2 - 7 } & Math (\%) & Reading (\%) & Math (\%) & Reading (\%) & Math (\%) & Reading (\%) \\
\hline 2008 & 30.4 & 30.4 & 49.7 & 36.3 & 73.2 & 61.6 \\
2009 & $81.4^{*}$ & 44.2 & 52.4 & 40 & 73.5 & $64.5^{*}$ \\
2010 & 71 & $67.8^{*}$ & 52.3 & 40.3 & $74.4^{*}$ & 64.1 \\
2011 & $84.4^{*}$ & $71.9^{*}$ & 56.5 & 45.8 & 76.3 & 67.3 \\
\hline
\end{tabular}

5.5 Case Study of Dr. R. Drew Elementary School, Washington, DC

The Washington, District of Columbia (DC) is the seventh largest metropolitan area in the nation. As the capital of the United States, it is under the jurisdiction of Congress and not a part of any state. The 123 public schools in the district are run by the District of Columbia Public Schools (DCPS). In addition, there are twelve colleges and universities, which include both public (federal and local) and private (four-year and graduate schools) institutions (United States Census Bureau, 2011; District of Columbia Public Schools, 2011).

The former Secretary of HUD, Henry Cisneros, had characterized the Washington, DC housing projects as the "second worst in the United States" (National Association to Restore Pride in America's Capital (NARPAC), 2003, p. 1). Public housing in Washington, DC, much like the rest of the country, had to grapple with deep and compounding infrastructure problems such as poor maintenance and high crime. The NARPAC blamed the failure of public housing for the urban blight in the city. As the public housing stock became highly distressed, the District of Columbia Housing Authority (DCHA) was among the earliest applicants to receive HOPE VI funding in 1993. 


\subsubsection{District of Columbia Housing Authority}

The DCHA is the largest local public agency in the Washington, DC. According to Adriana Todman, DCHA's current Executive Director, the DCHA is "the largest landlord in DC with an inventory of 8,000 public housing units and 12,000 housing choice vouchers" (DCHA video short, 2012). Public housing was considered a failure in Washington, DC by the early 1990s. In 1995, the HUD judged the DCHA as the second worst offender in the nation. According to the Commission on Severely Distressed Public Housing scorecard, the public housing lot was rated "22 (out of 100) for vacancies, modernization, etc., for its 11,000 unit, 24,000-tenant program" (Loeb \& Harris, 1998). The Control Board Report on DC Housing and Community Development (DC Department of Housing and Community Development, 1997) stated that DCHA had failed in four key ways:

1. DCHA is not organized to respond effectively to DC's housing and community development needs.

2. DCHA management practices and systems are not effective in turning strategy into operational realities.

3. DCHA operations could be more efficient and effective.

4. Poor management practices, direction and operation results in substandard performance and missed opportunities.

As a result of its abysmal record, HUD placed Washington, DC's public housing programs under receivership. Receivership is generally the last resort of HUD, resulting from "longstanding, severe, and persistent management problems that led to deterioration of the housing stock," when other interventions such as technical assistance or sanctions 
have failed (GAO, 2003, p. 1). During the judicial receivership, David Gilmore, the HUD appointed receiver improved the score from 22 to 65 (out of 100) within 30 months. Gilmore improved the DCHA by (a) addressing administrative problems, (b) clearing financial backlogs (e.g. using the $\$ 180$ million of unspent federal dollars), (c) beginning to demolish dilapidated units and renovating them, (d) leveraging private- public partnerships, and (e) creating a separate housing police force (Loeb \& Harris, 1998). Soon thereafter, Michael P. Kelly, an affordable housing leader and advocate in major cities across the country for over 25 years, served as the Chief Executive of the DCHA. By 2000, public housing came out of receivership by expanding affordable housing options, including doubling the voucher program to benefit over 11,000 families.

The HUD provided DCHA with seven HOPE VI grants for developing mixedincome housing, the second highest amount of grants made available to a jurisdiction in the nation (Building America Community Development Entity, Inc., 2012; DC Housing Authority, 2009). The DCHA received three Demolition Grants: $\$ 1,995,000$ for the 133 unit Fort Dupont housing project, $\$ 1,288,707$ for 180 units in East Capitol Dwelling project, and \$732,000 for 128 units in High Land Addition project. From 1993 to 2001,

the total funding amounted to $\$ 203$ million. The DCHA has also organized over $\$ 1.5$ billion through innovative private-public partnerships (HUD, 2003; DC Housing Authority, 2008).

\subsubsection{The HOPE VI Project: Capitol Gateway}

The Capitol Gateway project is located in southeast DC and its neighborhood public school is the Drew Elementary School. Formally known as East Capitol Dwelling/ 
Capitol View Plaza, the housing project originally consisted of 1,199 severely distressed units (Economic Baseline, 2003). The plan was to demolish 1,107 units, of which "577 of the barrack-style units were in the East Capitol Dwelling which was built in 1955; 30\% were vacant at the time of the HOPE VI application" (Cahill, 2011, p. 114). According to the Economic Baseline Report (2003, p. ii), "most of the residents in the area near the East Capitol Dwellings are poor, black families with adult educational attainment at the high school level and unemployment rates higher than the citywide and national averages. They live in densely populated, substandard housing, and many of them receive public assistance." Social concerns such as drug use, criminal behavior, and homicides were exacerbated by deteriorating physical conditions, wherein buildings were desolated and open spaces inside the site served as convenient escape routes for criminals and were difficult to police (Cahill, 2011). Prior to demolition, $99 \%$ of the 649 families were considered low income. Ultimately, 428 families received Section 8 housing vouchers, and 221 families were moved to other public housing sites (Economic Baseline, 2003).

The \$30.8 million HOPE VI grant leveraged an additional \$74 million to construct 515 mixed-income units and 150 units for senior housing. Senior housing was completed in late 2004 and fully occupied by July 2005; occupancy of mixed-income units began in September 2006 (Kahnhauser \& Sanford, 2005; Cahill, 2011). Incorporating the New Urbanist approach, the HOPE VI project featured common open spaces, high design standards, performance controls, streetscape enhancements, and updated public improvements (Edgecombe Group, n.d.). 


\subsubsection{Performance of Drew Elementary School}

In my interview with Steve Roseman, the former principal of the Drew Elementary School, he noted that he was not familiar with the HOPE VI program, but he was well aware of the transition of the neighborhood. During his tenure as principal from 1997 to 2005 , he lost almost $80 \%$ of his school's students when the housing projects were vacated in 2005 for the scheduled demolition of the East Capital Dwelling project. The overwhelming majority of the students lived in this housing project. A smaller group of students traveled to the school from the Clay Terrance public housing project. Although the Drew Elementary school catered to a large number of students who lived in public housing, high percentage of $5^{\text {th }}$ grade students reported proficiency in mathematics $(68.52 \%)$ and reading $(77.78 \%)$ prior to the demolition.

Following the demolition of East Capital Dwelling project in 1999, and completion of the HOPE VI Capital Gateway housing development in 2005, test scores of the Drew Elementary school began to plummet immediately. In 2006 the share of $5^{\text {th }}$ grade students who reported proficiency scores in math and reading were reduced by almost half, to 26.4 percent and 39.2 percent respectively (Table 15). The trend continued in 2007 and 2008. During these two years, only $8.7 \%$ and $6.2 \%$ of the $5^{\text {th }}$ graders reported proficiency in math respectively. With respect to reading scores during the two years, the proficiency was 14.8 percent and 12.5 percent during the two years. The FRLP rates during these years were higher than $75 \%$ (the threshold for high-poverty schools), except for two years in 2007 and 2008.

My discussions with the former principal, current residents, and community board members focused on how the major changes in the neighborhood affected the 
performance of Drew Elementary School. A common theme emerged among the interviewees: incoming residents were opting out of the public school system as they were sending their children to the local charter schools. The charter school, called the Maya Angelou Public Charter School, had opened in 2004 adjacent to the former East Capital public housing project site. Another charter school, the DC Stars Public Charter, also opened more recently in September 2012 for kindergarten to third grade class students. The DC Stars Charter is located on the site of Capitol Gateway, where another school (Shaed Elementary school) was located, but had closed fifteen years ago (Capital Gateway Resident Association-Community Meeting, personal communication, July 26, 2012). Another theme that emerged from the interviews is that most residents in the new Capitol Gateway community were working professionals who did not have school-aged children (A. Anderson, personal communication, August 1, 2012).

Table 15

School Performance and FRLP Rate of Drew Elementary School, Washington, DC, 2003 to 2011

\begin{tabular}{lccc}
\hline & $\begin{array}{c}\text { Percentage of } 5^{\text {th }} \\
\text { Math }\end{array}$ & grade students with proficiency in & $\begin{array}{c}\text { School FRLP Rate } \\
\text { (Percentage) }\end{array}$ \\
\hline 2003 & 63.2 & 62.6 & 78.0 \\
2004 & 58.4 & 55.6 & 82.0 \\
2005 & 68.5 & 77.8 & 88.0 \\
2006 & 27.4 & 39.2 & 91.0 \\
2007 & 8.7 & 14.8 & 63.0 \\
$2008^{*}$ & 6.2 & 12.5 & 71.0 \\
2009 & 34.1 & 30.8 & 90.0 \\
2010 & 14.9 & 19.5 & 95.0 \\
\hline
\end{tabular}

\section{$\underline{5.6 \text { Comparative Analysis of Factors that Influence School Performance }}$}

In the comparative analysis of the factors that influence school performance, I identified the following major themes that emerged in the case studies of the two schools: 1) Public Housing Revitalization and Community Development; 2) Public Education and 
Community Involvement; 3) Housing and School Partnerships. The following sections elaborate on the nuances of these themes that link public housing and public education.

\subsubsection{Public Housing Revitalization and Community Development}

The demolition and revitalization initiatives went through many phases in both HOPE VI sites in Philadelphia and Washington, DC. Whereas the demolition in Philadelphia faced resistance from community residents, the Washington, DC project did not. The community relations that emerged in Philadelphia as a result were favorable to creating a broad set of initial conditions that enabled the housing authority to create community partnerships. The residents also took active participation in the revitalization process. In Washington DC, the project did not face much opposition; in fact, there was support for the project. Yet, the community support did not continue in an active manner to ensure engagement with the project revitalization. This difference set the initial conditions for the community development in the two project sites, which became important for the residents' participation in school performance later on.

The Philadelphia Housing Authority (PHA) took a very straightforward approach to community development by contracting with Universal Companies. Universal Companies, founded by the famous Philadelphia songwriter Kenny Gamble, who also grew up in the South Philadelphia area, is a not-for-profit community development corporation that specializes in reversing the effects of urban blight (Universal Companies, 2012). Due to an initial high level of resistance from existing residents, PHA and Universal organized a series of informational meetings to gain trust and respect for the community and its members. Rylanda Wilson, a PHA Supervisor said that the results of 
the transition should be "obvious and measurable...and this must lead each family to selfsufficiency." The HOPE VI Community and Supportive Services (CSS) in Philadelphia used a case management model of service delivery that had five major dimensions (R.Wilson, personal communication, June 22, 2012; PHA, HOPE VI CSS, 2012):

1) Outreach and Communication: This began with a one year plan for demolishing the previous public housing project, Martin Luther King (MLK) Plaza, where there were weekly meetings with the residents. The task force began in 2004 and the meetings were held consistently. Newsletters were also sent to families. 2) Career Development: Social services and trainings were provided by University of Pennsylvania and Universal Companies. The Department of Housing and Urban Development and HOPE VI recorded performance based accountability indicators on a quarterly basis. There were 408 individuals from the MLK Plaza project who received training: family counseling, job skill training, high school equivalency, and higher education. 3) Resident owned business development: The training included entrepreneurship training and business development. Funding for this provided job training, employment, and contract opportunities to low and very-low income residents in connection with projects and activities in their neighborhoods. 4) Homeownership: Homeownership goals were also part of outreach. Under this, the program offered financial literacy sessions. 5) Supportive services: These services included child care, transportation, physical and behavioral health care, nutrition, household management, family counseling, substance abuse counseling, and violence prevention.

In order to meet the above services for several of the HOPE VI sites, the PHA relied on various service providers. In the case of the MLK Plaza site, the PHA 
subcontracted services to the Universal Companies and University of Pennsylvania. Noting the high quality of the services provided by them, Rylanda Wilson observed, "Rarely do you find an organization like Universal that does everything and does it well...they had a willingness to do everything. Other providers required technical assistance; people specialized in one area. They [Universal] had everything" (R.Wilson, personal communication, June 22, 2012).

Wilson spoke about the transition of MLK Plaza as a sometimes difficult task to accommodate the needs of residents, building timelines, and safety issues. Demolition was initially slated as a two- phase process for the four towers of high-rise buildings. Residents were to move into two of the towers while the adjacent units were demolished. Prior to demolition, obvious safety concerns would have to be addressed. It was both unsafe and unsanitary to have families live on a construction site. The change in plans caused some dissent among the residents. This is the first crucial step when Universal would take leadership to create community partnership and to get community residents to agree. Universal companies hired residents as staff, as a form of outreach. The new staff would help communicate the transition. Universal Companies acted as the conduit for partnership. They created a meaningful partnership between the residents and PHA, so that it was a happy partnership. According to Wilson, "PHA was happy to partner!" (R.Wilson, personal communication, June 22, 2012).

Tamelia Hinson, the Executive Vice President of Real Estate and Operations at Universal, spoke similarly about the working relationship with PHA. She noted that the "PHA set stringent requirements for families to return. To qualify in the new community, you had to be a working family. Universal set out to provide job training, supportive 
services, and job placement for the families, to help ensure their return" (T. Hinson, personal communication, July 3, 2012). She continued:

Initially, the transition was very difficult. The residents of the high-rise did not want to move, did not want the high-rises imploded, nor did they trust that a return was guaranteed. Many families had lived in the 'project' for over 30 years - grandparents, children and grandchildren had lived in the community. Some residents were there in 1965 when the Reverend Martin Luther King Junior gave his speech. We held a series of over 50 community meetings at local churches or buildings, and provided families with literature. Community members were able to openly state their objections, while the mayor, city council men and women, Community Capital Development (CCD), and Kenny Gamble illustrated how community change would improve their lives and wellbeing. Universal was "not in the business of simply putting out residents; instead Universal would prepare residents to return to the community... There was a wide scale effort to stabilize the community" (T. Hinson, personal communication, July 3, 2012).

Hinson also noted that one of the most difficult obstacles was that some families had never lived outside of the housing projects. They were unfamiliar with traditional rental markets. The requirement for the first and last months' rent, as well as a security deposit, was a shock to former residents as they tried to navigate the transition. The Section 8 voucher had specific requirements that public housing did not. Hinson observed, 
The level of illiteracy was astounding. Universal had a grand plan to invest and create a shared vision of job training and placement, but the reality was that some residents lacked basic skills. There were residents that could not fill out a housing or job application. Thus, Universal would have to serve not merely as job training but a resource center for families. They instituted case management for families to address various social issues. To address basic training dilemmas - computer literacy and financial literacy courses were added." (T. Hinson, personal communication, July 3, 2012).

Meanwhile, there were residents who were literate and stable, and well-prepared for the first -time homebuyers program. According to Raheem Islam, Jr. "31 residents were enrolled in the college courses," in which Universal would help families understand the financial aid process for higher education (R. Islam Jr., personal communication, July 3, 2012). But Hinson recalled that the transition would have to handle the residents' fears, as well as create a level of buy-in among the residents. Also, the re-entry requirements included additional caveats: credit checks, drug screening, and a background check for criminal history. Universal then provided credit counseling for families. Hinson notes that, "Screening of criminal records created a real hardship for some families. For the women this was almost a non-issue, but the former male residents were hindered." Hence, the screening process began to look at the type of crime and the length of time since the crime was committed. If the crime was over 10 years old and was a low-level offense, the family could be considered for admittance. The drug screening was the final obstacle to overcome. Hinson maintained that every family member who would reside in 
the household that was over 18 years of age would have to take the drug test. If any member was found positive, the family's application would be rejected or the individual would be removed from the application and could not live in the home. Hinson states that marijuana was the main disqualifier in drug screening cases (personal communication, July 3, 2012).

What Universal learned from the revitalization of MLK Plaza is that each case had a different need. According to James Bishop, Jr., "Transitions had to be customized and personalized." Also, Universal understood that because of the plethora of needs, not only would their organization grow but partnerships would help facilitate the gaps (J. Bishop, personal communication, July 3, 2012). Consequently, Universal built partnerships with a range of organizations (Table 16).

Table 16

List of Universal Companies ' partnerships to support HOPE VI transitional residence

1. Pennsylvania Housing Finance Agency: PHFA

4. Philadelphia Workforce Development Corporation

7. Bureau of Employment and Training Programs

10. Greater Philadelphia Urban Affairs Coalition

13. Simon Carr/ Constellation Baptist Church

16. Northern Homes For Children

19. Department of Public Welfare TANF

22. Dixon House/Diversified

25. Career Link

28. Drug and Alcohol Program, DPH

31. Travelers Aid Family Services

34. Child Care Information Services

37. Mental Retardation-DPW
2. Department of Public Welfare TANF

5. Children Health Insurance Program(CHIP)

8. PCA, Philadelphia Corporation for Aging

11. Department of Health-Lead Poisoning Prevention Program

14. Philadelphia Department of Human Services (DHS)

17. YMCA

20. Inter-Cultural Family Services

23. Emergency Shelter Office

26. Riverside Care, Inc.

29. Catholic Social Services

32. Peoples Emergency Center;

35. Pennrose Management Company

38. Horizon House, Inc.
3. Mayor's Office of Community Services.

6. Welfare Rights Organizing Coalition (WROC)

9. Care Link Community Support Services

12. DPW-Domestic violence and rape crisis services

15. Office of Vocational Rehabilitation-Department

18. Salvation Army

21. Good Will

24. Homework Help Line-NBC10

27. Habitat for Humanity.

30. United Way

33. DPW-Food stamps

36. Drug and Alcohol Program, DPH

39. Legal Services Community 
While the partnership of PHA and Universal led to the mobilization of an extensive set of resources to combat resistance and lead to long term self-sufficiency, the Washington, DC site did not endure the same level of resistance. As the current Interim President of DC Housing Enterprise with DCHA and Vice President of A\&R Companies, the contracted HOPE VI developer, Cheryl Parker Hamilton said:

There was no resistance to the transition! The residents wanted a new neighborhood, and social services were needed and provided by DCHA. We aimed to make people's lives better! Because of my prior experience with nearby Willow Creek HOPE VI project, we learned to get community input. We began with meetings early on where architects make presentations to the residents and monthly meetings were held with the housing authority.

While community relations were strong, the actual site had problems. A\&R found that the building efforts were sidetracked because of the sloped and steep land. It would be costly to fix and prepare the land for building. And like the Willow Creek site, the site had terrible soil.

A master plan was prepared to address these conditions. Mrs. Parker-Hilton highlighted how the crucial element of financing mixed income developments was overcome: "The housing authority pushed for mixed-income, but financing becomes difficult with that framework. Banks will finance a string of rentals and then a string of 'for sale' homes" (personal communication, July 30, 2012).

Kerry Smyser, a Redevelopment Specialist and Project Manager at DCHA, had worked from the start of HOPE VI project and later became a board member of the 
Capitol Gateway Residents Association. She explained that, with an emphasis on establishing self-sufficiency, the DCHA had partnered with residents to create the East Capitol View Community Corporation. The Community Corporation was modeled after the Willard CDC (another HOPE VI project in Washington, DC), which was quite successful in addressing the need for social services with the Section 3 compliance of job training and placement. Smyser noted that the Community Corporation was not as successful as the Community Service Program (CSP), which was funded partially through the HOPE VI grant and provided numerous services (case management, job training and placement, financial literacy, GED/ HS Diploma \& college preparation, drug \& alcohol abuse counseling, and homeownership). Even though the Community Corporation hired an executive director and a coordinator, Smyser felt the mission of the program was misinterpreted. The goal was "self-sufficiency, not mere social work... If a child needed a coat, the organization provided a coat. But the goal was to provide programs and support so that families could earn skills and money to be self-sufficient and buy a coat" (K. Smyser, personal interview, July 30, 2012). Of course addressing short-term needs was necessary, but the overarching aim of developing skills was overlooked.

Smyser also speaks of the other transitional issues. She noted that the primary hindrance was "relocating families away from the site. It became difficult to provide services; they were dependent on the system. They had to get used to a new environment. Transportation was an issue, and some had lived on site all their lives. Follow up was difficult, but the case mangers pushed referrals" (personal communication, July 30, 2012). She clarified, "Even during the move the 'connections' within the community 
were their greatest asset. Residents had long-term relations and attended church together so they would share information. The relocation process began in 2002, although families didn't move back until 2006. In some cases it was almost a five-year span. The seniors moved back in 2004 and 2005. We tried to avoid moving the seniors but were unable to carry out construction with people on site" (K.Smyser, personal interview, July 30, 2012).

Looking at the project in retrospect, Smyser offered several recommendations to improve community engagement. First, social integration and community development must start immediately. In the case of DCHA, renters and homeowners were brought in simultaneously but not brought together. According to her, "It is necessary to promote social integration, get to know neighbors and find early commonalities... even if social engineering is necessary". Second, continuation of steering committee and monthly meetings are essential. Monthly stakeholder meetings were discontinued when HOPE VI money ended. The Resident Association and its Board were not connected until 90\% of homes were sold to homeowners. There was a gap between when steering committee meetings ended and the homeowners association started. It was important that a Housing Authority official and developer serve on the board. Third, DCHA had to do a better job of explaining the vision of the project. Market rate buyers were often not told about the mixed-income approach until after the sale. The Housing Authority was not sufficiently involved with the sale of market-rate homes. It must share its mission with sales persons and explain its mission. Smyser, however, concluded, "I'm proud of the community. There was a time [before HOPE VI was implemented] that I didn't stay in the 
community, now I'm there walking late at night." In the end, "Collaboration is key" (K. Smyser, personal communication, July 30, 2012).

The comparative case of Philadelphia and Washington, DC in terms of the HOPE VI demolition and revitalization is interesting in illuminating the initial conditions that served to result in different community characteristics for participation in the school performance. In Philadelphia, the community residents were actively engaged throughout the whole process, and they became involved in the school performance too. In Washington DC, the project did not face resistance, but at the same time the residents were not actively engaged. In fact, the residents withdrew from the public school system, as the charter schools emerged in the neighborhoods. The residents chose to exercise voice in the neighborhood public school of Philadelphia project, but had chosen to exit the neighborhood public school of Washington DC project.

\subsubsection{Public Schools and Community Involvement}

To understand the transition within the local schools during the redevelopment, I interviewed both past and current school officials. Whereas the performance of the Andrew Jackson Elementary School in Philadelphia flourished, the R. Drew Elementary School in Washington, DC declined over time. The interviews provided good insights into the community related factors that led to the difference in performance between the two schools.

In Philadelphia, the school principal (in her third year at the time of interview), Miss Kaplan, said that she had noticed the change in the neighborhood because of the mixed-income project of the HOPE VI, which, in her mind had led to gentrification of the 
neighborhood. On the positive side, she noted that there was a rebirth of the "How to Walk to school" initiative: "The young professionals that have moved to the community are beginning to start families and they want their children to walk to school" (L. Kaplan, personal communication, June 29, 2012). Based on the popular book, How to Walk to School: Blueprint for Neighborhood School Renaissance (Kurland \& Edelberg, 2009) which provides a plan for reclaiming neighborhood schools, the group of moms and soon-to-be-mothers created the Passyunk Square Civic Association's education committee. In 2009, the committee met with regional superintendent, Ralph Burnley, and the then Superintendent, Dr. Arlene C. Ackerman. Their goal was to, "reshape curriculum and teaching, lower the class size, and sell Jackson to a neighborhood highly skeptical of city public schools" (Graham, 2010, p. 1). With the blessing of both superintendents, the group repaired and painted the playground, planted a garden, re-opened the library, and in late 2009 sat in as part of the hiring committee to select the current principal (Graham, 2010; L. Kaplan, personal communication, June 29, 2012).

In 2008, under the leadership of Dr. Arlene C. Ackerman (former Philadelphia superintendent), Andrew Jackson was slated to become an Empowerment School. Schools are classified as Empowerment Schools if they have not achieved Adequate Yearly Progress (AYP) goals under the No Child Left Behind guidelines, but were in Corrective Action Level II (CA-II), for the 2008-9 school year. The 45-day action plan for remedy would include "differentiated professional development, monthly walkthroughs, quarterly assessments in reading and math, a parent ombudsman, a student advisor, additional volunteers, and the assistance of Empowerment School Response Teams... Support [also] included increased resources, and additional school personnel as 
well as support from the central and regional offices" (School District of Philadelphia, 2008, p. 1).

Principal Kaplan noted many school-based initiatives, but spoke more in-depth about the neighborhood change as a factor for the school's improvement. She said, "Jackson used to be described as the project school," implying that only students that lived in the projects attended. Even if this were not true, the reputation of the school was that it was both poor and underperforming. Residents would avoid the school, if they could. The principal's sentiment was that with the "change from the high-rise style of projects, the stigma associated with the neighborhood has been removed; the major safety [issues] that were present before are no longer present" (Kaplan, personal communication, June 29, 2012).

One of the most noticeable differences in the school is the level of diversity (see Table X). Since the implementation of HOPE VI and NCLB in 2002, the number of Hispanic children that attend Jackson had almost tripled, while enrollment of African American students was cut in half. The proportion of White and Asian children remained consistent at 12 percent and 18 percent respectively. There are twenty-nine languages spoken at the school. In 2010, as many as $93 \%$ of students qualified for FRLP, which is the highest rate in the school's history. In 2010, Andrew Jackson was rated a "2" on the School Performance Index (SPI), which is on a scale of "1 to 10 , with " 1 " being the highest rating). "This indicates the school's relative performance to the entire district and similar schools. The SPI is calculated using outcomes of academic progress and growth on the Pennsylvania System of School Assessment (PSSA) and academic achievement 
(performance on PSSA) as well as the satisfaction of parents, teachers, and students (as measured by surveys) (School District of Philadelphia, 2012).

In contrast to Philadelphia, in Washington DC, the school's performance declined over time. Before and during the transition, the Drew school was a well-performing school - in spite of a high percentage of low-income students, the school had outperformed the District of Columbia School District. The school's performance does not conform with my earlier hypothesis that Free and Reduced Lunch Program (FRLP) rates are related to school performance. Yet in the years following the HOPE VI program implementation, the test scores declined precipitously. The current principal who served during the period of decline was unavailable for discussion. However, the former principal, Steven Roseman, provided insights into the decrease in scores. When the housing projects were vacated for the scheduled East Capital Dwelling demolition in 2005 , the school lost approximately $20 \%$ of the school's student population. Also, some redistricting occurred to include students from the nearby Clay Terrance Housing Development. Roseman described the community and parent involvement at Drew, prior to the mass student relocation, in the following way:

Scattered at best. I can't say that we had a real Parent Teacher Association (PTA). PTA meetings are normally scheduled at $6: 30 \mathrm{pm}$ or $7: 00 \mathrm{pm}$ at night when parents are home from work. Parents were not hostages in their homes, but they did not want to come out late at night... In spite of this, I truly believe that every parent cared about their children; they want the best for their child. I immersed myself in the community so I'd go to the home to talk to parents: How can we change the behavior? I just 
wasn't afraid. I probably should have been but I wasn't (S. Roseman, personal communication, July 31, 2012).

Despite the meager level of parent participation, the school continued to make strong academic gains. Roseman explained that incentives in the form of monetary rewards were created according to the No Child Left Behind (NCLB) Adequate Yearly Performance (AYP) policy. Drew received three such rewards in the amounts of $\$ 25,000$ (twice) and $\$ 15,000$. With the funds, the school adopted the "Success for All Reading Program" and later undertook the "Success for All Math Program." In addition to a twohour reading sessions, all personnel taught reading, including the PE teacher, language teacher, administrators, etc. Everyone, except the school counselor, taught reading. This produced smaller class sizes and homogeneous grouping. Beyond an improved reading and math program, Roseman noted that, "The staff didn't leave unless they retired. Everyone stayed. It was a really stable staff. Teachers were no longer new to the program” (S. Roseman, personal communication, July 31, 2012).

Ironically, the successful gains in reading and math scores meant that remedial federal funds for the school decreased, to the extent that "we could no longer afford to buy the program. This led to a fractured use of the program... Lack of funds led to fewer resources" (S. Roseman, personal communication, July 31, 2012). The adjustment to decreased funding, combined with the loss of the student population, marked the beginning of the school's decline. A change in administration happened simultaneously with the decline in school performance. Since 2006, Drew has had two different principals. 
The interviewed residents provide further insights into the school and community relationship. All had opted out of the local public school. Mister Roberson, a resident and board member of Capital Gateway, and the father of a seventh grader, stated that he “doesn't know one family that sends their child to Drew Elementary school. The school has very poor performance. Most families apply for "Out of Boundary" (lottery system for public school attendance) or apply for charter schools. My child attends a charter school" (S. Roberson, personal communication, July 26, 2012). Another resident, Mister Brown, a retired federal employee, remarked, "The charter school system has weakened the public school. It is a false system. My grandson, who is one semester away from becoming a graduate of University of Maryland, attended the first charter high school in DC" (A. Brown, personal communication, July 28, 2012). When asked about Drew Elementary School, a board member Miss Anderson stated, "Drew Elementary has poor test scores and our community doesn't really have the school age group. We are basically urban professional; no families."

Overwhelmingly, residents of the Capitol Gateway Community opted out of the local public school and took advantage of the charter school or "Out of Boundary" Programs. Table 17 gives the enrollment in the school by race and ethnicity. The former school principal sighed, "I just wish that neighborhood had embraced Drew School" (A. Roseman, personal communication, July 31, 2012). Although the school was successful in the past, the current poor performance made it difficult to attract "new" families. The introduction of charter schools and other options in school choice was another factor that affected the public school's performance. 
Table 17

Enrollment at Andrew Jackson Elementary School

\begin{tabular}{llllllll}
\hline Year & White & $\begin{array}{l}\text { African } \\
\text { American }\end{array}$ & Asian & Hispanic & $\begin{array}{l}\text { American } \\
\text { Indian }\end{array}$ & $\begin{array}{l}\text { Not } \\
\text { Specified }\end{array}$ & Total \\
\hline 2002 & 50 & 191 & 51 & 40 & 1 & 0 & 333 \\
2003 & 50 & 191 & 51 & 40 & 1 & 0 & 333 \\
2004 & 50 & 213 & 51 & 47 & 0 & 0 & 361 \\
2005 & 34 & 215 & 60 & 57 & 1 & 0 & 367 \\
2006 & 43 & 198 & 63 & 57 & 1 & 0 & 362 \\
2007 & 51 & 196 & 68 & 68 & 0 & 0 & 383 \\
2008 & 55 & 177 & 67 & 74 & 0 & 11 & 384 \\
2009 & 46 & 148 & 56 & 88 & 0 & 15 & 353 \\
2010 & 41 & 108 & 61 & 111 & 0 & 16 & 337 \\
\hline
\end{tabular}

The differences in the neighborhood public schools in Philadelphia and Washington DC point to the importance of non-school factors, particularly community involvement, in the school performance. In Philadelphia, the community actively took up the issue of the schools through community organizations. The organizations influenced the school district and the school administration to improve the neighborhood level physical factors (e.g. walkability) that increased the community's involvement in the school activities. The principal also noted that change in socio-economic status of the neighborhood may have influenced the community's level of involvement in the school system. Although the change in socio-economic status is revealed at the broad level of quantitative analysis of HOPE VI, such a method does not capture the delicate nuances by which community involvement emerged in Philadelphia. In Washington DC, where the school was already performing well, declined over time. The community did not actively participate in the schools; rather, with higher income families in the neighborhood, the children were sent to charter schools. 


\subsubsection{Housing and School Partnerships}

The last theme of school performance in linking public housing and public education is the partnerships between housing and education officials. During my site visits and interviews with officials in both Philadelphia and Washington, DC, it became increasingly clear to me that there were no official partnerships created between the local housing authority and the local public school. The two housing authorities were engaged in large scale urban revitalization through HOPE VI, but had neglected to partner with the organization that helps drives a community success: the public school. It was left to the local communities to bridge partnerships between the housing authority and the public schools. The Philadelphia project was, by and large, more successful in creating such housing and school partnerships that sought to serve the residents of the HOPE VI project. In Washington, DC there were no direct or indirect connections between the public housing authority and the school.

Figure 3 illustrates the highly clustered and overlapping partnerships of the HOPE VI MLK Plaza project in Philadelphia. Analysis of interviews with NVivo helped in mapping the partnerships in the figure. Communication with my interviewees highlighted how the partnerships came about and how involved they were in the public school system:

- The Philadelphia Housing Authority (PHA) had subcontracted with Universal Companies, which provided community management and social services. Although the subcontractor role of the Universal Companies may not qualify the arrangement as an organic collaboration, the mutually supporting relationship between the two agencies cannot be denied. The Universal Companies played a 
key role in developing community partnerships, which was readily acknowledged by the PHA officials involved in the HOPE VI project.

- The local community organizations deeply interacted with both the housing and the school officials. For example, the President of Hawthorne Empowerment regularly attended the monthly community meetings hosted by both the Universal Companies and PHA. While the relationships were not warm initially, the warmth developed over time. As she noted, "partnerships between Universal and PHA were obvious and the two parties interacted, but neither of the two organizations were deeply involved with the Hawthorne Coalition... we [Coalition] did not always get along with their representatives...Today, the relationship with Universal is considerably better because we reach out to their key representatives, founders Kenny Gamble and Raheem Islam” (P. Bullard, personal communication, June 28, 2012).

- Overlapping roles of individuals between the public schools and the housing groups helped in bridging the relationship between the housing and the school officials. For example, the vice president of the Hawthorne Empowerment Group also served as the president of the Home and School Association and President of the MLK Homeowners Association. The overlapping roles were helpful in linking the aims and goals of each organization.

- Personal links between the school officials and community organizations helped in making neighborhood connections for the schools. For example, the Jackson Elementary School principal worked closely with the Home and School and the Passyunk Square Civic Association. The principal, Mr. Kaplan spoke about the 
improvement in the Home and School Association because of the involvement of different stakeholders. According to her, "Previously it was corrupt and was run by staff, not parents. Now the group has been revamped and is more diverse, and the president speaks four languages" (L. Kaplan, personal communication, June 29, 2012). The members of the Passyunk Square Civic Association sat in on the hiring committee and were responsible for the hiring of Principal Kaplan. Outside of community partnerships, Jackson is also supported by several educational organizations which include: University of Pennsylvania, Healthy School Club, Temple University, and Uniturn.

Figure 3. Housing and School Partnerships in Philadelphia HOPE VI project

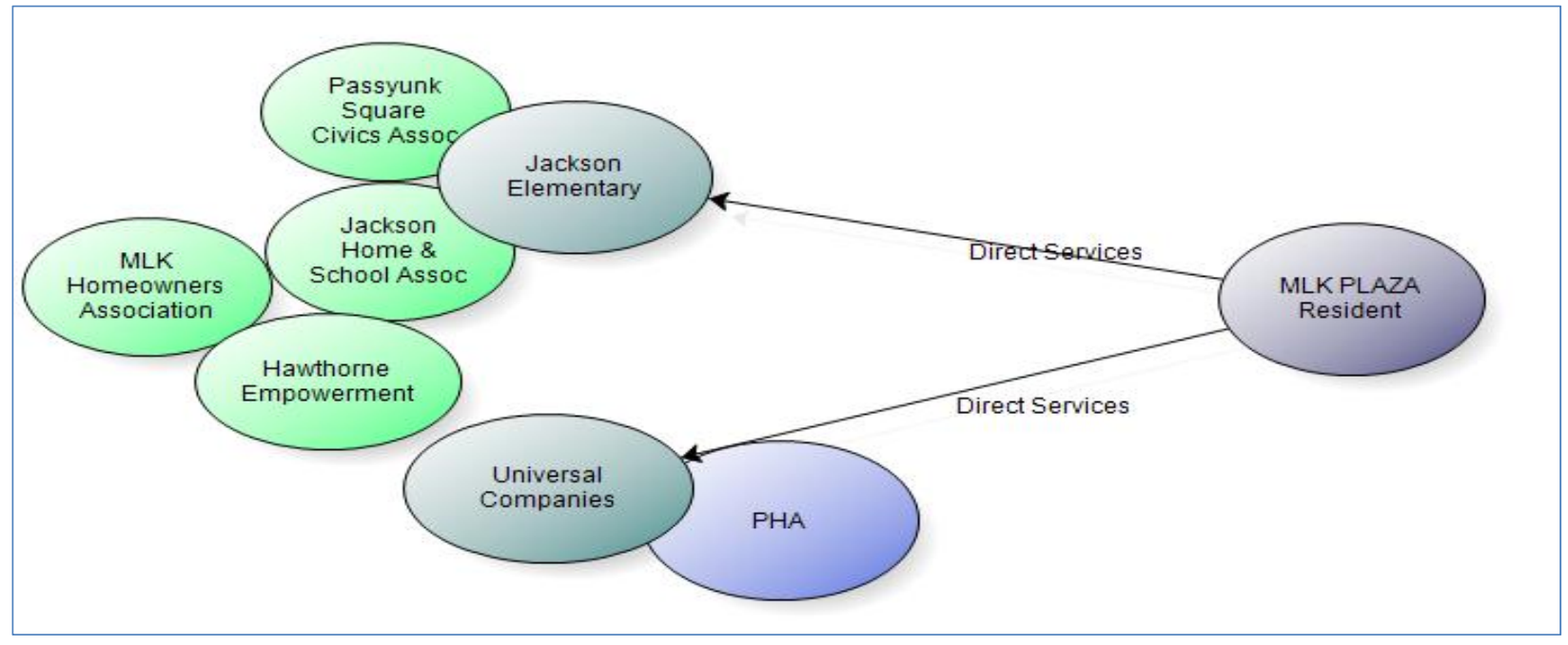

In Washington DC, the housing and school partnerships were weakly developed, if at all. Figure 4 illustrates the partnerships in HOPE VI Capitol Gateway project (arrived at using NVivo software). The partnerships are much less clustered and limited in nature. The interviewees' comments also revealed the limited extent of the partnerships: 
- Only the board of the Capitol Gateway Resident Association reflected a broader set of officials. The Board comprised of a DCHA official, the site management and developer representative, and residents. Even this organization did not have a school official. As one of the board members, Mr. Anderson noted, "In terms of partnerships, I don't see any relevance. I'm neutral. If you know what a homeowners board does...we are here to keep the community members up to date, provide information, look at the fees and payments, and review the legal liens on the homes. We keep the community from becoming an eyesore. That's the core role of the board" (personal communication, August 1, 2012). As such the organization did not have an impact on school performance.

- The DCHA had a contractual partnership agreement with Community Service Program (CSP), which provided social services at the site. Besides the PHA official, however, no other interviewee spoke of the Community Service Program.

- There were no community partnerships with the local school. In fact, residents and board members overwhelmingly spoke of the poor performance of the Drew Elementary and chose local charter schools if they had school-aged children or grandchildren. The DCHA official noted that during the implementation of HOPE VI, the housing authority did reach out to the DC Public School District but the district did not engage. Consequently, there was no connection with Drew Elementary. Also, the school was adjacent to the community, but not within the boundaries of the HOPE VI site. Consequently, no partnerships developed. The DCHA official did mention possible linkage with the new DC Stars Charter School scheduled to open in September 2012 on the HOPE VI site. 
Figure 4. Housing and School Partnerships in Washington DC HOPE VI project

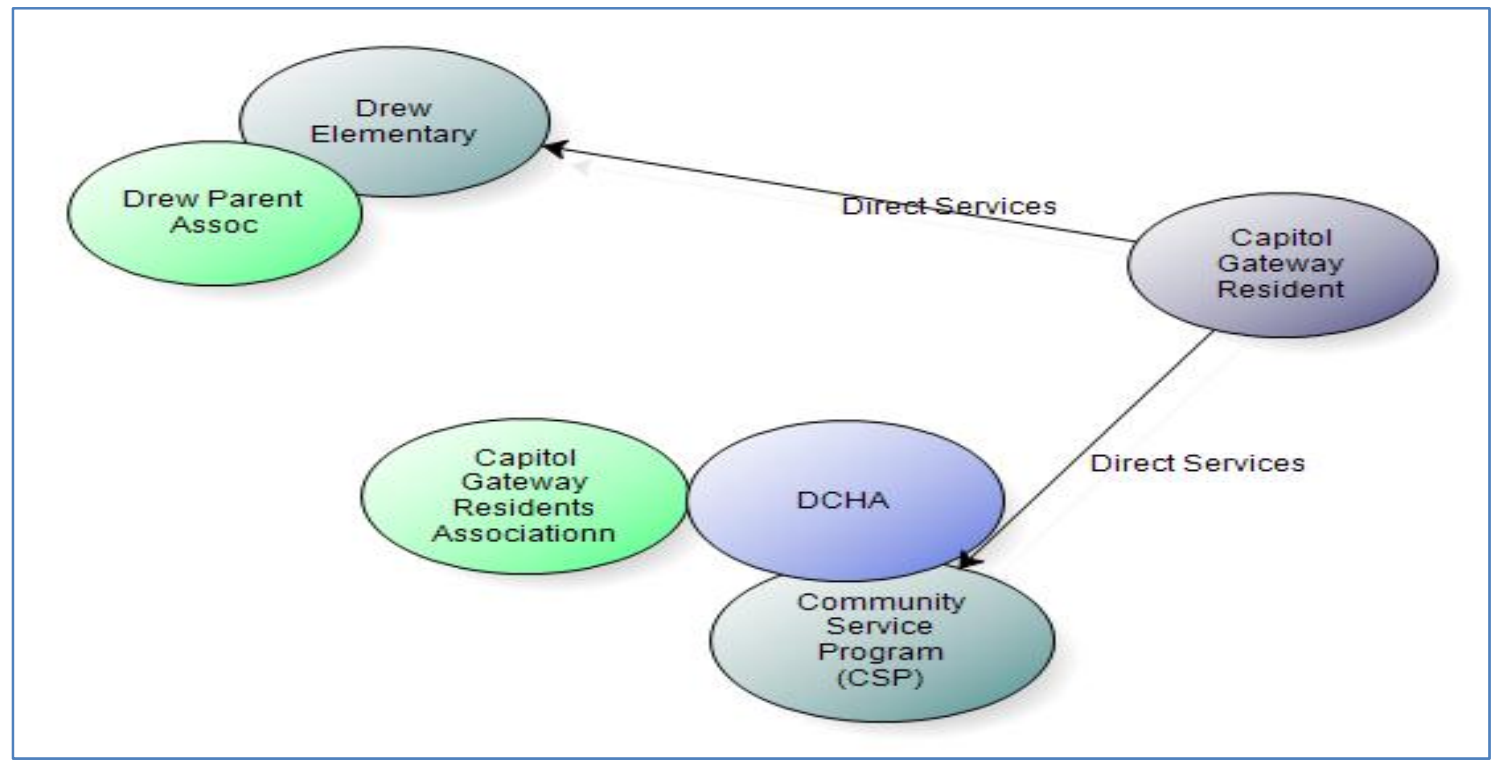

\section{$\underline{5.7 \text { Conclusion }}$}

This chapter used qualitative research methods to examine the factors that influence neighborhood public school's performance in HOPE VI communities. Specifically, it used the case study method to examine two HOPE VI neighborhood schools - one in Philadelphia and another in Washington DC. The two schools are at the opposite ends of performance improvement—whereas the Philadelphia school improved in its school performance, the Washington DC school declined in school performance. The case study method provides insights into the non-school factors that influenced school performance in the two cases.

Three overlapping themes related to school performance emerged in the case study: 1) Public Housing Revitalization and Community Development; 2) Public Education and Community Involvement; 3) Housing and School Partnerships. First, the demolition and revitalization process in the two cities engendered differences in how they 
resulted in the participation from local communities. In Philadelphia, a strong local community organization emerged in the face of resistance to the HOPE VI demolition efforts, which set the initial conditions for future partnerships. In Washington DC there was no such opposition; but there was no overarching ground support either.

Second, even with mixed income housing in Philadelphia, the higher income families were committed to send their children to the local public school as a result of the community organization efforts. In Washington DC, the higher income families separated themselves from the public school system and sent their children to the charter schools in the neighborhoods. These neighborhood level factors are possibly as significant as the school level organizational factors in improving school performance.

Third, there were no direct partnerships between public housing officials and public education administrators before, during, or after the implementation of HOPE VI. Yet, in Philadelphia, the local community organizations acted as a bridge between the housing and school officials. In Washington DC, the housing and school officials did not have any linkages. The separation of housing and school efforts by the officials does not reflect the neighborhood reality of the deep connection between the issues that connect them both. Housing values are higher in good quality public school districts for good reasons. This reality underlies the "housing policy is de facto education policy" approach. Hence, one policy imperative that emerges from this case study is to build more relationships between the housing and school officials at the local level for more effective school performance. 


\section{CHAPTER 6: CONCLUSION}

\section{$\underline{6.1 \text { Introduction }}$}

In response to severely-distressed public housing and concentrated poverty, HOPE VI enacted a national action plan to revitalize public housing. The goal of the program was to transition the most-distressed urban public housing projects into mixedincome developments. Clustered by real-estate, public school enrollment patterns are typically organized by neighborhood boundaries. Since these boundaries inextricably link schools and neighborhoods, this dissertation examined the influence of HOPE VI public housing on neighborhood public school performance. Despite nearly two decades since the program's inception, the literature on HOPE VI's influence on neighborhood schools is thin.

Three seminal works formed the theoretical basis of this research: Jane Jacobs' The Death and Life of Great American Cities (1961), William Julius Wilson's The Truly Disadvantaged (1987), and Jean Anyon's Hidden Curriculum (1980). Using an interdisciplinary approach, this dissertation built on the listed seminal works by examining the three principal research questions:

1. Following the implementation of HOPE VI, was there a change in neighborhood public school socioeconomic status (SES) rates?

2. Following the implementation of HOPE VI, did the performance of neighborhood public schools change?

3. What factors relate to the performance of public schools in HOPE VI communities? 


\subsection{Main Contributions to Literature}

My hypotheses were that neighborhood public schools, following the implementation of HOPE VI, were likely to 1) reduce the school FRLP rates and 2) improve their school performance, based on the extant literature that mixed SES contributes to better neighborhood public school performance. However, the first hypothesis is not supported by the quantitative methods of t-test or the regression model. The change in SES did not prove to be statistically significant over the three and six year periods before and after implementation of HOPE VI. The second hypothesis is supported for the school performance; the proportion of $5^{\text {th }}$ graders deemed proficient in reading and math scores increased significantly for three and six years after HOPE VI. Based on the theoretical framework, literature review and extensive research, several issues require attention.

First, HOPE VI with its demolition of high rise public projects followed by mixed income communities was able, in most cases, to transition neighborhoods. Essentially, HOPE VI is the practical application of Jane Jacob's "diversity improves cities' philosophy." Diversity, she argued dealt extensively with families of various incomes (later termed mixed-income) and the need for places to have a variety of uses to serve various functions (later termed mixed-use). Like Anyon, William Julius Wilson focused

on concentrated poverty and its impact on urban areas. Wilson attributed concentrated poverty to social isolation following desegregation and the changing economy which no longer offered jobs for low skill works. HOPE VI sought to address concentrated poverty and social isolation by creating mixed income communities. 
While the research and literature review related to school performance overwhelming conclude that high poverty public schools are consistently at a stark disadvantage to their low poverty, high tax base counterparts (Carey, 2003; Cohen, 2009), the research was unable to support this claim. In fact, Puma (1993) found that nonpoor students perform consistently better than their low-income classmates, the performance of non-poor students nevertheless declines as the proportion of their classmates below the poverty line increases (Puma et al., 1993). Essentially, with no statistically significant change to school SES, the expectation that school performance would change was lessened. As might be expected, the quantitative approach using the regression found no statistically significant connections between HOPE VI public housing and neighboring public school performance. Yet, the t-test noted a significant change in test scores 6 years and 3 years before and after HOPE IV implementation.

As noted in previous chapters, several issues help to explain the lack of any observed relationships between HOPE VI, student socio-economic status, and school performance rates in this study. To date, HOPE VI has yet to establish "a single formula or standard definition of mixed-income housing" (HUD, 2003, p. 3). There are no regulated percentages of housing that must be reserved for low income occupants. In each HOPE VI location across the country it is left to public housing officials, developers and planners to determine a healthy and sustainable mix. Second, the HOPE VI plan to create mixed income communities nationwide may not have been realized. In a number of communities, supply and demand were not aligned, affordability remained an issue, and, in others, gentrification was evident (Popkin, 2004; Brazley \& Gilderbloom, 2007; Raffel et al. 2003). Even in circumstances when mixed-income was a success, there was no 
guarantee that middle income families would send their children to the neighborhood public school. This leads to a third important issue; urban public schools are undesirable to middle-income and high-income families. Public confidence in public schools has dropped considerably during the last 30 years (Carr, 2007). One must also consider that magnet and charter schools replaced the neighborhood public schools in several communities. Thus, students with the most proactive parents opt out of poor performing schools to attend charter schools and students with higher test scores are systematically offered placement to magnet schools.

The statistically significant change in school performance may be attributed to one key factor. Six years prior to HOPE VI, less than $25 \%$ of all students attending public schools in HOPE VI communities across the country were considered proficient. Six years after the implementation, scores were doubled in math and reading. This is a vast improvement, but when compared to district, state, and national scores, these are still dismal results. When $50 \%$ of 5 th grades are performing below grade level in 22 cities across the country, these schools cannot be considered attractive and does not bode well for attracting families to mixed income communities.

To further explore the results of the quantitative analysis which included a review of 165 HOPE VI sites and their 116 feeder public schools across the nation, the site selection of Martin Luther King Plaza in Philadelphia, Pennsylvania and the Capitol Gateway in Washington, DC were selected based on the following criteria: the zoned public schools had the highest and lowest rate of change in math and reading standardized test scores of $5^{\text {th }}$ grade students following the implementation of HOPE VI, respectively. Andrew Jackson Elementary School in Philadelphia reported the highest 
rate of change in school performance, while the Dr. R. Drew Elementary School reported the lowest rate of academic change.

During the HOPE VI transition period, the Andrew Jackson Elementary School, the local feeder school in Philadelphia's HOPVE VI revitalization efforts of MLK Plaza, exhibited the highest measurable gains in math and reading standardized test scores. In the earliest records (2003) of Andrew Jackson Elementary Schools, less than a sixth (16.1\%) of students were considered proficient in mathematics, while less than a fourth of students scored proficient or above in reading. By 2009, one year following the completion of the MLK site, scores in math equaled $81.4 \%$ and $44.2 \%$ in reading. 2010 and 2011 proved even better results which steadily increased math at $71 \%$ followed by $84.4 \%$ and reading $67.8 \%$ then 71.9 . By 2009 , Jackson began outperforming the district average, and then began outperforming the state average with 2010 reading scores and 2011 math and reading.

In contrast, Washington, DC's HOPE VI project of Capital Gateway reported the most dramatic decrease in test scores. Prior to the 2005 demolition of the high rise projects, the students reported high proficiency rates in mathematics $(68.52 \%)$ and reading $(77.78 \%)$. Following the demolition, construction completion, and renaming of the housing development to Capital Gateway in 2005, test scores of Drew immediately plummeted. In 2006 scores were cut in half, resulting in only $26.45 \%$ of $5^{\text {th }}$ grade students testing as proficient in math and 39.22\% in reading. In 2007 results were again abysmal with less than a tenth of $5^{\text {th }}$ graders $(8.72 \%)$ proficient in math and $14.77 \%$ proficient in reading. The year 2008 saw greater dips with math proficiency at $6.25 \%$ and reading proficiency at $12.5 \%$. 
Together, the two cases lead to an analysis that determined preliminary factors that may contribute to change in public school performance in HOPE VI areas. To effectively track these results, a broad base of information was collected. The primary sources lead to two site visits with fourteen total interviews which included: administrators from the local housing authorities, private management company representatives, current and former school principals, local community leaders and residents. Following selective transcriptions, the use of the NVivo system helped systematically analyze information. The secondary sources consisted of historical data, congressional documents, articles from professional journals, newspapers articles, professional presentations at national conferences, and testimony before the House Subcommittees for Housing and Community Opportunity.

The findings of the in-depth case studies determined that the relationship between public housing and the public school is not easily identified, yet several variables help suggest distinctive connections. At the new HOPE VI housing site, the age and demographics of the residents determined the needs of the community. Families have a greater need for quality elementary education versus young professionals without children. The level of school choice played a vital role in families' educational decision making. Charter schools are a heavily relied upon option in order to opt out of failing public schools. Community ownership and partnerships with public schools is essential to school success. The "Walk to School' movement is just one of many community driven initiatives around the country that seeks to reclaim neighborhood schools by improving the curriculum and teaching, lowering the class size, and selling the school to highly skeptical residents. Lastly, the overlapping and open dialogue between community- and 
school- based organizations provide a level of scaffolding that supports the child, parent and community at large. It may be essential to pool the resources of the community so that not only is 'No Child Left Behind' but no family is left behind. In fact, this is the premise behind the two recent federal programs initiated under the current Obama Administration, Choice Neighborhood and Promise Neighborhoods. Choice Neighborhoods authorized in 2010 under the Department of Housing and Urban Development (HUD) is an extension of HOPE VI with its goal of creating mixed income communities while incorporating an emphasis on early childhood education. Meanwhile, the Promise Neighborhood established by the Department of Education (DOE) in 2010 is based on the success of the Harlem Children's Zone in NY to "significantly improve the educational and developmental outcomes of children and youth in distressed communities" (DOE, 2012, p. 1). While the federal programs have broadened its goals by integrating the simultaneous needs of communities and schools, the two federal programs continue to function in isolation.

\subsection{Implications for Policy and Practice}

The findings for this dissertation are useful to provide insights into how the federally funded Choice Neighborhood and Promise Neighborhood initiatives, which seek to target both community and academic development, could be carried out in a better fashion. The implications for policy and practice are as follows. 


\section{HUD must acknowledge and address the barriers related to creating mixed income}

communities

Creating mixed income communities is a difficult undertaking. HOPE VI, in many communities, suffered from several key consequences. The first was that attractive mixed-income residential communities steadily raised real estate values (Brazley \& Gilderbloom, 2007; Popkin et al, 2004) leading to gentrification. Second, in many other cases, homes priced at market value were undersold and remained vacant. Another key element to consider for mixed income developments is that neighborhoods with a low tax base (such as areas with housing projects), also offer low levels of amenities. When individuals or families consider spending upwards of $\$ 500,000$ (which is the price of housing in some mixed-income developments), the city's delivery of services must also include: safety, convenient transportation, quality schools (public and private), access to consumption (luxury goods) and leisure (entertainment, theatre). Finally, while reports indicate that desegregation in the last three decades has declined, it resulted from blacks steadily integrating into communities which were once off limits. Essentially, whites are less likely to move to communities where the residents are predominately black. These issues pose a serious hardship for the development and success of the HOPE VI projects.

\section{HUD must establish a definition for mixed-income communities.}

Eleven years following the implementation of HOPE VI, HUD (2003, p. 3) announced that "in practice, there is no single formula, or standard definition of mixedincome housing." To date, there is no regulated percentage of housing that must be reserved for low income occupants. In each HOPE VI location across the country it is left 
to public housing officials, developers and planners to determine a healthy and sustainable mix. Without parameters for a reasonable and sustainable mix, no method of accountability is possible nor does not it protect or ensure that low-income families would receive a suitable number of housing units.

Public housing revitalization must plan for housing shortages

As National Low Income Housing Coalition (NLIHC), President Sheila Crowley pointed out, "HOPE VI doesn't solve the critical housing problems of the very poor and exacerbates them by making fewer units accessible" (cited in Pitkoff, 1999). With fewer units available coupled with higher real estate prices, the lowest income families were forced to transition to new neighborhoods. It is important to note that in some cases families became homeless during this transition.

To attract families to revitalized neighborhoods, school performance must be considered

The premise of this research is based on the fact that public school enrollment is typically organized by neighborhood boundaries (also known as 'neighborhood schools'). These boundaries inextricably link public schools and neighborhoods. In order to create true and balanced mixed income developments, the sites must provide access to quality schools. Families with children buy homes with an eye to school quality. The social fabric of a community is as important as the physical environment.

Public school officials must embrace marketing and rebranding to promote the positive qualities while combating the negative perception of urban public schools.

Urban public schools are often perceived to be undesirable by middle income and high income families. Public confidence in public schools has dropped considerably in 
the last 30 years (Carr, 2007). Well performing urban public schools (e.g., those with high test scores, where safety is not an issue and students go on to attend college) do not catch the public attention. In some cases, public schools outperform their neighboring charter schools. Yet, charter schools have fully embraced the need to market and brand their specialized mission and objectives. Every charter school has an academic focus and is required to incorporate a high level of community engagement. While public schools offer a plethora of academic options, there is little to no concerted effort to advertise the many benefits of a public school education. Consequently, middle income parents not only avoid urban public schools, but make personal sacrifices so that their children can fully exercise school choice. Public school officials must address both the perception and reality in order to attract middle income families.

Formal and direct partnerships between public housing and public schools are essential.

Philadelphia appeared to benefit from overlapping, indirect partnerships between the public school and several community groups. The various interviews representing a number of organizations were aware and could define the mission of partnering groups. Meanwhile, DC's level of neighborhood partnerships was extremely low. Residents, board members, housing authority representatives and school officials all reported that few official community partnerships exist. The lack of both indirect and direct partnerships with the public housing authority or the identified community groups profoundly alienated the school. The literature on HOPE VI also supports that direct partnerships between public housing and public school are extremely low. 
Community service providers are effective when developed as grassroots or "insider" organizations.

Services should duplicate and continue the aims of HOPE VI (outreach and communication, career development, business development, homeownership counseling and various supportive services), while garnering buy-in from residents. Community trust is an essential element. Philadelphia service provider of Universal Companies demonstrated expertise in community development while also having a grassroots approach. In addition, specialized social services developed collective family growth.

Community and Stakeholders must have buy-in. Social integration and community development should be continuous and ongoing.

The level of community engagement was high in both Philadelphia and the District of Columbia. Community meetings with all stakeholders were constant and continuous. Yet, Philadelphia offered an example where residents were hired as members and leaders of the outreach initiative. In this case, Universal Companies served as a conduit of partnership between the housing authority and the residents. It is important to note that DC encountered a lapse in community meetings between when HOPE VI funds ended and residents actually moved in. In addition, the homeowners association was not authorized until $90 \%$ of homes were sold. This created a disjointed process.

Members on the Community Board should represent key stakeholders. Official partnerships between government agencies are essential.

Community initiatives more closely tied to HOPE VI appeared to positively influence school performance. Both HOPE VI sites neglected to create official 
partnerships between the housing authority and the local public school. Nonetheless, Philadelphia was successful in creating overlapping partnerships that sought to serve the residents of MLK while intertwining the needs of the school. Several partner organizations were highly clustered to meet the needs of families and their children, which also created support for Jackson Elementary School. In DC, the strongest evidence of partnership was the board configuration of the Capitol Gateway Resident Association. The board consists of a DCHA representative, the site management \& developer representative and residents. A collective mission and vision was expressed by each member.

\subsection{Recommendations for Future Research}

To date, only two case study-based reports have examined the link between HOPE VI initiatives and local schools. In their study, Abravanel, Smith and Cove (2006) concluded that they could not adequately define "what it means to join housing revitalization with school improvement" (p. 44). Meanwhile, Raffel, et al. (2003) opined that the most effective approach for attracting families to HOPE VI is to create magnet schools, but also noted political and bureaucratic resistance. While the present study represents a step forward in addressing the research gap by combining quantitative and qualitative data, the results point to several areas of consideration for future research. Currently, there is no consistent measure for 'mixed-income' communities. Future studies will need to identify the level of mix and occupancy rates to determine whether the rate of mix SES influences school enrollment patterns. Second, to determine the influence that communities have on public schools, research must determine ratio of families with 
children and without children. In addition, the number of school aged children in each HOPE VI neighborhoods requires collection. At the new HOPE VI housing site, the age and demographics of the residents determined the needs of the community. Lastly, school choice requires greater attention. At the site level, exploring school choice as it relates to family income will better link the nexus between public housing and public schools. Several questions must be posed: (a) Are middle- and high- income families opting out of public schools, and at what rate? (b) In spite of neighborhoods improving, are public schools enrolling a high rate of low-income students? (c) What are the strategies that public school districts and their local schools use to attract higher income parents? Addressing the listed topics and accompanying questions will lead to a more appropriate investigation of the relationship between public housing and public schools.

\section{$\underline{6.5 \text { Conclusion }}$}

The exploration of housing policy as de facto school policy set the premise for this dissertation. Championed by David Rusk (2011), president of Metropolitan Research Cooperation, who argued that "High poverty neighborhoods produce high poverty schools...In high poverty schools most children will fail no matter how many extra resources are poured into their schools or how much accountability is required of their teachers..." (p. 21). In fact, "School based remedies... are only to be considered remedies if 'separate but equal' schools are the only option" (p. 28-29).

While my research found that identifying causation and/or relationships between HOPE VI public housing and public education was problematic, several topics between the agencies were observed. The following patterns were evident: HOPE VI was 
responsible for decreasing the number of public housing units available to low income residents, communities improved housing conditions for returnees as the most distressed housing projects were replaced with new construction or extensive rehabilitation, and concentrated poverty was reduced by simply reducing the number of available public housing units. HOPE VI struggled to attract families to new communities, school performance was not considered during revitalization, and public housing authorities and public schools continue to work in isolation. Thus, a direct link between improved public housing and school performance was not established.

In addition and as noted in previous chapters, in the two school districts some stakeholders believed that the single greatest obstacle appeared to be the lack of partnership between government run agencies. This was a missed opportunity to cultivate and build on the resources of each organization, pool resources and to most effectively meet the needs of families and their children.

The goal of this dissertation was to highlight the nexus between neighborhood housing conditions, poverty, and the performance of neighboring public schools. Additionally, to the researcher's knowledge, this is the first qualitative and quantitative study that explored community-based, neighborhood-level revitalization factors that influenced school performance. Within the context of urban studies, the research contributes to the theoretical frameworks in each of the three disciplines: public housing, poverty and public education. This may bode well for both practice and policy. In fact, this research lends recommendations to an official federal and local partnership between the HUD's Choice Neighborhood and the DOE's Promise Neighborhood Initiatives created under the Obama administration which each calls for comprehensive community 
and school engagement. At this time, the two federal programs continue to run as separate entities and in isolation. 


\section{REFERENCES}

A Sampling of GCHP's Venture Portfolio- March 2012 (2012). Gulf Coast Housing Partnership. p. 17. Retrieved from http://www.gchp.net/projects/gchp_presentation.pdf

Anyon, J. (1980). Social class and the hidden curriculum of work. Journal of Education, $162(1)$

Abravanel, M., Smith, R., \& Cove, E. (2006). Linking public housing revitalization to school improvement. The Urban Institute, June, 1-42.

Anderson, E., \& Jones, J. (2002). The geography of race in the United States. Retrieved from http://www.umich.edu/ lawrace/

Arendt, R. (2000). Congress for the, N. U. Charter of the new urbanism / essays by Randall Arendt; edited by Michael Leccese and Kathleen McCormick. New York: McGraw Hill.

Armstrong, A., Gould Ellen, I., McCabe, B., Schwartz, A. (2012). Do federally assisted households have access to high performing public schools? Poverty and Race Research Action Council. Retrieved from http://furmancenter.org/files/publications/PRRACHousingLocationSchools.pdf

Aud, S., Hussar, W., Kena, G., Bianco, K., Frohlich, L., Kemp, J., \& Tahan, K. (2011).The condition of education 2011. (National Center for Education Statistics under No. NCES 2011-033). Washington, DC: U.S. Department of Education, National Center for Education Statistics. November 28, 2011

Banks, K. (2001). The effect of school poverty concentration in WCPSS. Research Watch $E \& R$ Report. Retrieved from www.wcpss.net/results/reports/2001/0123 Poverty.pdf

Bauman, John F. (1987). Public Housing, Race, and Renewal: Urban Planning in Philadelphia. Temple University Press. Philadelphia, PA

Bauman, J., Hummon, N., \& Muller, E. (1997) "Public Housing, Isolation, and the Urban Underclass: Philadelphia's Richard Allen Homes, 1941-1965,” in Joe William Trotter, Jr. and Eric Ledell Smith, African Americans in Pennsylvania: Shifting Historical Perspectives. Penn State Press. University Park, PA

Becker, L. (1998). Effect size calculators. Measures of effect size -Strength of association. Retrieved from http://www.uccs.edu/lbecker/glm_effectsize.html 
Belley, P., \& Lochner, L. (2007). The changing role of family income and ability in determining educational achievement. Journal of Human Capital, University of Chicago Press, 1(1), 37-39.

Bohl, C. (2000). New urbanism and the city: Potential applications and implications for distressed inner city neighborhoods. Housing Policy Debate, 11(4), 761-801.

Bolton, R. (1992). "Place prosperity" vs. "people prosperity" revisited: An old issue with a new angle. Urban Studies, 29(2), 185-185-203.

Braconi, F. (2001). Housing and schooling. The Urban Prospect: Housing, Planning, and Economic Development in New York, 7(2), 1-4.

Brazley, M., \& Gilderbloom, J. I. (2007). HOPE VI housing program: Was it effective? The American Journal of Economics and Sociology, 66, 433+.

Brauman, J. (2012). Public Housing. The Encyclopedia of Greater Philadelphia. Rutgers University. New Brunswick, NJ

Brooks, F., Lewinson, T., Aszman, J., \& Wolk, J. (2011). Voucher users and revitalized public-housing residents 6 years after displacement. Research on Social Work Practice.

Brown, L. N. (2009). HOPE VI: An analysis to determine the HOPE VI program's influence on home sales. Community Development: Journal of the Community Development Society, 40, 54+.

Building America Community Development Entity, Inc. (2012) Michael P. Kelly, Executive Director Philadelphia Housing Authority. Washington, DC. Retrieved from http://www.buildingamericacde.com/Michael_Kelly.html

Buron, L., Popkin, S. J., Levy, D. K., Harris, L. E., Khadduri, J., Comey, J., . . Woodley, W. (2002). The HOPE VI resident tracking study: A snapshot of the current living situation of original residents from eight sites. Washington, DC: Abt Associates Inc \& Urban Institute.

Cahill, M., Lowry, S., \& Downey, P. M. (2011). Movin' out: Crime displacement and HUD's HOPE VI initiative. No. 2007-IJ-CX-0020). Washington, DC: Urban Institute.

Cahill, M. (2011). Using the weighted displacement quotient to explore crime displacement from public housing redevelopment sites. Cityscape: A Journal of Policy Development and Research.

Campisi, A. (January 9, 2012). Catholic school closings hit South Philadelphia especially hard. Philadelphia Inquirer. Retrieved from http://articles.philly.com/2012-0109/news/30607918 1 catholic-school-closings-elementary-schools-annunciation 
Carey, K. (2003). The funding gap: Low-income and minority students still receive fewer dollars in many states. The Education Trust, Fall, 1-15.

Carlino, G., \& Saiz, A. (2008). Beautiful city: Leisure amenities and urban growth. FRB of Philadelphia Working Paper no. 08-22, doi: http://ssrn.com/abstract=1280157

Carr, N. (2007). Courting middle-class parents to use public schools. Education Digest, $72(6), 35-41$.

Carter, S. 2000. No excuses: Lessons from 21 high performing, high poverty schools. The Heritage Foundation. Washington, DC

Center on Education Policy. (2011). State policy differences greatly impact AYP numbers: A background paper from the center on education policy. Retrieved from www.cep-dc.org

Clampet-Lundquist, S. (2004). Moving over and moving up? Short-term gains and losses for relocated HOPE VI families. Cityscape: A Journal of Policy Development and Research, 7(1), 57--80.

Clark, W. A. V. (1986). Residential segregation in American cities: a review and interpretation. Population Research and Policy Review. 5(2).

Cohen, J. (2009, January 22). Fund distribution for title I. Message posted. Retrieved from http://www.newamerica.net/blog/ed-money-watch/2009/examining-funddistribution-title-i-9635

Cohen, J (1992). Statistics a power primer. Psychology Bulletin. 112: 155-159.

Coleman, J. S., Campbell, E. Q., Hobson, C. J., McPartland, J., Mood, A., Weinfeld, F., \& York, R. L. (1966). Equality of educational opportunity. No. ED 012 275). 1966: National Center for Educational Statistics.

"Congress for the New Urbanism". (1997). What is CNU?: The congress for the new urbanism (CNU). Retrieved from http://www.cnu.org/who_we_are

Cousins, T. G. (2001) Mixed-income housing: The east lake experience. City Park NOLA. Retrieved from http://www.cityparknola.org/web/index.asp? $\operatorname{mode}=$ full\&id $=66$

Crane, R., \& Manville, M. (2008). People or place? revisiting the who versus the where of urban development. Lincoln Institute of Land Policy, Land Lines, 2(7), 1-7.

Crowley, M., Roscigno, V. J., \& Tomaskovic-Devey, D. (2006). Education and the inequalities of place. Social Forces, 84, 2121+. 
Curley, A. M. (2005). Theories of urban poverty and implications for public housing policy. Journal of Sociology \& Social Welfare, 32, 97+.

Dahl, G. B., \& Lochner, L. (2008). The impact of family income on child achievement: Evidence from the earned income tax credit. NBER working paper no. 14599. National Bureau of Economic Research.

District of Columbia Department of Housing and Community Development. (1997). Control Board Report on DC Housing and Community Development. Retrieved from http://www.narpac.org/PWH.HTM\#CBDHCD

District of Columbia Housing Authority (2008). Development/ HOPE VI: Capitol Gateway. DCHA website. Washington, DC. Retrieved from http://dchousing.org/default.aspx?docid=18

District of Columbia Housing Authority. (2009). DC Housing Authority Executive Director Resigns Position. DCHA website. Retrieved from http://www.dchousing.org/default.aspx?docid=342

District of Columbia Public Schools 2010-2011 (2011). School Opening Report. District of Columbia Public Schools. Washington, DC. Retrieved from http://dc.gov/DCPS/About+DCPS/Strategic+Documents/School+Opening+Repor t/2010-2011+School+Opening+Report

District of Columbia Housing Authority (2012). DCHA Housing Short Video [ 7:09]. Washington, DC. Retrieved from http://youtu.be/rVKTBFAPBfE

Donohue, K. (2006). Progress Payments for Construction at Savoy Place New Orleans, Louisiana. U. S. Department of Housing and Urban Development Office of Inspector General. doi: IED-08-006.

Economic Baseline Study for the HOPE VI Program at East Capitol Dwellings in the District of Columbia. (2003). Howard University. Retrieved from http://www.coas.howard.edu/hucup/papersandreports/HUCUP_HVI_baseline_rep ort_east_capitol_dwellings2003.pdf

Edgecombe Group, Inc. (n.d.). Capitol Gateway Estates HOPE VI Mixed-Use Urban Redevelopment Project. Presentation Handout. Hyattsville, MD. Retrieved from http://edgecombegroup.com/UrbanDesignandUrbanPlanning/NewEastCapital_por trait_2Pages.pdf

Ehrenberg, R. G., Brewer, D. J., Gamoran, A. \& Willms, J. D. (2001).The class size controversy. CHERI Working Paper \#14. Retrieved from Cornell University, ILR School site: http://digitalcommons.ilr.cornell.edu/workingpapers/25/

Ellen, I. G., \& Horn, K. (2011). Do households with housing assistance have access to high quality public schools? Evidence from New York City. In P. Tegeler (Ed.), 
Finding common ground: Coordinating housing and education policy to promote integration (pp. 9-14). Washington, DC: Poverty \& Race Research Action Council and the National Coalition on School Diversity. Retrieved from www.prac.org/pdf/HousingEducationReport-October2011.pdf

Embry Jr., R. C. (2011). "Housing policy is school policy": A modest proposal? In P. Tegeler (Ed.), Finding common ground: Coordinating housing and education policy to promote integration (pp. 31-32). Washington, DC: Poverty \& Race Research Action Council and The National Coalition on School Diversity. Retrieved from www.prrac.org/pdf/HousingEducationReport-October2011.pdf

Fernanadez, M. (2008, November 24, 2008). Children who live in public housing suffer in school, study. New York Times, pp. A21. doi:http://www.nytimes.com/2008/11/24/nyregion/24children.html

Florida Department of Education. (2005). Public school options. Retrieved November 30, 2011, from http://www.fldoe.org/flbpso/

Frankfort-Nachmias, C. \& Leon-Guerrero, A. (2011) Social statistics for a diverse society. 6th edition. Pine Forge Press. Thousand Oaks, CA.

Fraser, J. \& Kirk, E. (2007). The Role of Public, Private, Non-profit and Community Sectors in Shaping Mixed-income Housing Outcomes in the US. Urban Studies. 44(12).

Fraser, J., \& Nelson, M. H. (2008). Can mixed-income housing ameliorate concentrated poverty? The significance of a geographically informed sense of community. Geography Compass, 2(6), 2127-2144. doi:10.1111/j.1749-8198.2008.00175.x

Gammage, J. (March 11, 2012). "Against all odds, Philadelphia retakes No.5 spot among largest U.S. cities”. Philadelphia Inquirer Newspaper. Retrieved from March 12, 2012 .

Gallagher, M., \& Beata, B. (2007). Moving on: Benefits and challenges of HOPE VI for children. The Urban Institute., Brief No. 4, 1-10.

Gannon-Rowley, T., Morenoff, J. D., \& Sampson, R. J. (2002). Assessing. Annual Review of Sociology, p. 443.

Glass, G. V. 1. (1975). In Gottman J. M. j. a., Gottman J. M., Gottman J. M. J. a., Willson V. L. and Willson V. L. j. a. (Eds.), Design and analysis of time-series experiments. Boulder: Colorado Associated University Press.

Glaeser, E., \& Jacob, V. (2001). Racial Segregation in the 2000 Census: Promising News. Brookings Institute Center on Urban and Metropolitan Policy. Washington, DC 
Graham, K . (April 4, 2010). "Parents work to rejuvenate a public school. Philadelphia Inquirer. Retrieved from http://ebookbrowse.com/philly-parents-work-torejuvenate-a-public-school-philadelphia-inquirer-docx-d37540209

Greg, C. (2011). Universal Gets 'Promise Neighborhood' Grant. The Monitor, National association of Black Journalist. Retrieved from http://nabjconvention.org/2011/08/universal-gets-promise-neighborhood-grant/

Goetz, E. (2010). Better neighborhoods, better outcomes? explaining relocation outcomes in HOPE VI. Cityscape: A Journal of Policy Development and Research, 12(1).

Harding, D. J. (2003). Counterfactual models of neighborhood effects: The effect of neighborhood poverty on dropping out and teenage pregnancy (1). The American Journal of Sociology, 109

Haugan, P. (2012). Agencies plan Stewart Homes redevelopment, seek feedback. Independent Record. $\mathrm{p} 1$. Retrieved from $\mathrm{http} / / /$ helenair.com/news/local/agenciesplan-stewart-homes-redevelopment-seek-feedback/article 2f7f2268-43ff-11e19d5d-0019bb2963f4.html

Holin, M., Buron, L., Locke, G. and Cortes, A. (2003) Interim Assessment of the HOPE VI Program Cross-Site Report. Retrieved http://ssrn.com/abstract=1760002

Holzman, M. (2011) Disparities in school funding: To each according to his income. The Schott Foundation for Public Education. National Opportunity to Learn Campaign. Retrieved from http://www.otlcampaign.org/school-fundingdisparities

HOPE VI Demolition Grants: FY 1996-2003 (October, 2004) United States Department of Housing and Urban Development. Retrieved from http://portal.hud.gov/hudportal/documents/huddoc?id=DOC_9890.pdf

Housing Development Consortium (n.d.) Glossary. Seattle, WA. Retrieved from http://www.housingconsortium.org/about-hdc/contact/

Howell, E., Harris, L. E., \& Popkin, S. J. (2005). The health status of HOPE VI public housing residents. Journal of Health Care for the Poor and Underserved, 16(2)

Husock, H. (2004, February 14). Public housing developments bring HOPE but history says projects call for caution. Seattle P $i$.

Jacobs, J. (1961). The Death and Life of Great American Cities. New York: Random House, Inc.

James, M. (1999, January 27). Judge says Hollander Ridge Plans may proceed. The Baltimore Sun, pp1. Retrieved from http://articles.baltimoresun.com/1999-0127/news/9901270175 1 1 hollander-elderly-housing-city-housing 
Jensen, J. L., \& Rodgers, R. (2001). Cumulating the intellectual gold of case study research. Public Administration Review, 61(2), 236-246.

Jones, R.W., \& Paulsen, J. (2011) HOPE VI Resident Displacement: Using HOPE VI Program Goals To Evaluate Neighborhood Outcome. Cityscape 13 (3): 87-104.

Kahlenberg, R. D. (2001) All together now: Creating middle-class schools through public school choice. Washington, D.C.: Brookings Institute Press

Kahnhauser, K \& Sanford, S. (2005). Housing Issues in the District of ColumbiaGentrification, Housing Choice Vouchers and HOPE VI. Center for Social Justice Office of Research. Georgetown University. Washington, DC

Katz, P., Bressi, T. W., \& Scully, V. J. (1994). The new urbanism: Toward an architecture of community. New York: McGraw-Hill.

Kleit, R., Carlson, D., and Kutzmark, T. (2003). HOPE VI Redevelopment Evaluation Report. Report to the Seattle Housing Authority. Seattle, Washington.

Kline, L. (2007, September 26). HHA delays Stewart homes reconstruction. Independent Record. p1. Retrieved from http://helenair.com/news/article d6682b6d-b091$\underline{545 \mathrm{f}-860 \mathrm{e}-61 \mathrm{abd} 46 \mathrm{~d} 2 \mathrm{bbc} \cdot \mathrm{html}}$

Kraus, N. (2008). Concentrated poverty and urban school reform: "The choice is yours" in Minneapolis. Equity \& Excellence in Education, 41(2)

Kurland, S \& Edelberg, J. (2009). How to walk to school: Blueprint for neighborhood school renaissance. Rowman \& Littlefield. Lanham, MD

Laymon, S. and Weiss, C (2003). About the ANOVA Test. QMSS e-Lessons: Quantitative Methods in Social Sciences. Retrieved from http://ccnmtl.columbia.edu/projects/qmss/anova/about the anova test.html

Loeb, V. and Harris, E. (February 16, 1998). DC Housing Receiver is 'Changing Communities and Changing Lives. Washington Post. Washington, DC.

Lubell, J., and Brennen, M. (2007). Framing the issues - the positive impacts of affordable housing on education. No. July. Washington, DC: Center for Housing Policy. doi:http://www.nhc.org/media/documents/FramingIssues_Heath.pdf

Luebchow, L. (2007). Equitable resources in low income schools: Teacher equity and the federal title I comparability requirement. Washington, DC: New America Foundation. doi:http://www.newamerica.net/publications/policy/equitable_resources_low_inc ome_schools 
Lupton, R. (2003). Neighborhood effects: Can we measure them and does it matter? London, UK: Centre for Social Exclusion, London School of Economics and Political Science, CASE paper 73

Massey, D. S., \& Denton, N. A. (1993). American apartheid: Segregation and the making of the underclass. Cambridge, Mass.: Harvard University Press.

Mayer, S. E. (1997). What money can't buy: Family income and children's life chances. Cambridge, Mass.: Harvard University Press.

McCoy, D., \& Vincent, J. (2011). Framing the connections: Integrating housing, transportation and education in city and regional planning. In P. Tegeler (Ed.), Finding common ground: Coordinating housing and education policy to promote integration (pp. 53-60). Washington, DC: Poverty \& Race Research Action Council and the National Coalition on School Diversity. Retrieved from www.prrac.org/pdf/HousingEducationReport-October2011.pdf

McCurdy, H. and Cleary, R.E. (1984) Why can't we resolve the research issue in public administration? Public Administration Review. 44(1). P 49-55.

McKinney, S., Flenner, C., Frazier, W., \& Abrams, L. (2007). Responding to the needs of at-risk students in poverty. Essays in Education, 17, 1-18. doi:http://www.usca.edu/essays/vol172006/mckinney.pdf

McNeil, M. (April 28, 2011). Duncan issues far more NCLB waivers than predecessors: Calls mount for leeway as rewrite of law lags. Education Week. Retrieved from http://www.edweek.org/ew/articles/2011/04/22/29nclb_ep.h30.html

Mickelson, R. A. (2011). Exploring the school-housing nexus: A synthesis of social science evidence. In P. Tegeler (Ed.),

Finding common ground: Coordinating housing and education policy to promote integration (pp. 5-8). Washington, DC: Poverty \& Race Research Action Council and the National Coalition on School Diversity. Retrieved from www.prrac.org/pdf/HousingEducationReport-October2011.pdf

Mohl, R. (2001) Race and Housing in the Postwar City: An Explosive History. Journal of the Illinois State Historical Society. 94 (1).

Montgomery, D., Peck, E. and Vining, G. (2006). Introduction to Linear Regression Analysis, 4th ed, Wiley-Interscience. Hoboken, NJ

Mueller, E., \& Tighe, J. R. (2007). Making the case for affordable housing: Connecting housing with health and education outcomes. Journal of Planning Literature, May 2007(21), 371-371-385. 
Myers, J. (July 7, 2011). PHA finalizes MLK Plza. South Philly Review. Retrieved from http://www.southphillyreview.com/news/PHA-finalizes-MLK-Plaza$\underline{125110623 . h t m l}$

Meyerson, A. 2000. Low-Income Schools that Work. The Heritage Foundation. Retrieved on October 1, 2009 from http://www.heritage.org/press/commentary/ed042700.cfm

Mooney, N. (2007). Mixed Income or Gentrification? Hawthorne's Spatial

Transformation. Urban Studies Program, Senior Seminar Program. University of Pennsylvania. Philadelphia, PA.

National Association to Restore Pride in America's Capital. (2003). Public Housing Introduction. Washington, DC. Retrieved from http://www.narpac.org/PWH.HTM

National Commission on Severely Distressed Housing. (1992). The final report. No. T36763. Washington, DC: A Report to the Congress and the Secretary of Housing and Urban Development.

National Law Center on Homelessness \& Poverty. (2007). Blocks to their future: A report on the barriers to preschool education for homeless children. National Law Center on Homelessness \& Poverty. Washington, DC

No progress on NYC housing authority project 13 years in the works (2012, July 30). The Real Deal- New York City Real Estate News. p. 1. Retrieved from http://therealdeal.com/blog/2012/07/30/no-progress-on-nycha-housing-projectkicked-off-in-1999/

Orfield, G., Kucsera, J., \& Siegel-Hawley, G. (2012) E Pluribus...Separation. Deepening Double Segregation for More Students. The Civil Rights Project. Los Harvard University.

Orr, M., Stone, C., \& Stumbo, C. (2002) Concentrated poverty and educational achievement: Politics and possibility in the Baltimore region. University of Maryland. unpublished manuscript.

Peske, H., \& Haycock, K. (2006). Teaching inequality: How poor and minority are shortchanged on teacher quality. Washington, DC: The Education Trust. doi:http://www.edtrust.org/sites/edtrust.org/files/publications/files/TQReportJune 2006.pdf

Pitcoff, W. (1999). New hope for public housing? HOPE VI promises to rebuild lives and revitalize community but the specter of displacement looms large in its future.

National Housing Institute, (104)

doi:http://www.nhi.org/online/issues/104/pitcoff.html 
Popkin, S. J., Levy, D. K., Harris, L. E., Comey, J., Cunningham, M. K., \& Buron, L. (2002). HOPE VI panel study: Baseline report. The Urban Institute. Metropolitan Housing and Communities Policy Center, 1-283.

Popkin, S. J., Katz, B., Cunningham, M. K., Brown, K. D., Gustafson, J., \& Turner, M. A. (2004). A decade of HOPE VI : Research findings and policy changes. The Urban Institute, 1-72.

Popkin, S. J., Eiseman, M., \& Cove, E. (2004). How are HOPE VI families faring? children. Urban Institute, 6.

Popkin, S. J., Katz, B., Cunningham, M. K., Brown, K. D., Gustafson, J., \& Turner, M. A. (2004). A decade of HOPE VI : Research findings and policy changes. The Urban Institute, 1-72.

Popkin, S. J., \& Cove, E. (2007). Safety is the most important thing. How HOPE VI helped families. Urban Institute, 2.

Philadelphia Housing Authority HOPE VI Community and Supportive Services (CSS) (n.d). Distributed by Philadelphia Housing Authority . Received June 22, 2012.

Philadelphia Housing Authority (2012) HOPE VI Program. PHA website. Retrieved from http://www.pha.phila.gov/aboutpha/funding/hope-vi-program.aspx

Proscio, T. (2004) Schools, Community \& Development: Erasing the Boundaries. The Enterprise Foundation, Columbia, MD.

Puma, M. J., Calvin C. Jones, Donald R., and Roberto F. (1993). Prospects: The Congressionally Mandated Study of Educational Growth and Opportunity: Interim Report. Washington, DC: U.S. Department of Education.

Public housing and public schools: How do students living in NYC public housing fare in school? (2008). No. Fall. New York, NY: Furman Center for Real Estate and Urban Policy-The Institute for Education and Social Policy (IESP). doi:http://furmancenter.org/files/FurmanCenterandIESPPolicyBriefPublicHousing andPublicSchools 000.pdf.

Raffel, J., Denson, L. R., Varady, D., \& Sweeney, S. (2003). Linking housing and public schools in HOPE VI public housing revitalization program: A case study of four developments in four cities. University of Delaware Center for Community Research \& Service. Retrieved from doi:http://www.ccrs.udel.edu/linkinghousing-and-public-schools-hope-vi-public-housing-revitalization-program-casestudy-analysis

Rich, M. (2012, September 19). Segregation Prominent in Schools, Study Finds. The New York Times. Retrieved from 
http://www.nytimes.com/2012/09/20/education/segregation-prominent-inschools-study-finds.html

Quiad, L. (2009, July 29). Obama offers 'race to the top' contest for schools. The Guardian, Retrieved from http://www.guardian.co.uk/world/feedarticle/8625198?FORM=ZZNR7

Regression (2012). Investopedia US. Retrieved from http://www.investopedia.com/terms/r/regression.asp\#axzz23UE9DC2P

Report of the Century Foundation Task Force on the Common School, Divided We Fail, (2002), citing James S. Coleman et al., Equality of Educational Opportunity. Government Printing Office, 1966, p. 22).

Raffel, J., Denson, L. R., Varady, D., \& Sweeney, S. (2003). Linking housing and public schools in HOPE VI public housing revitalization program: A case study of four developments in four cities. University of Delaware Center for Community Research \& Service, October 1, 2009. doi:http://www.ccrs.udel.edu/linkinghousing-and-public-schools-hope-vi-public-housing-revitalization-program-casestudy-analysis

Resmovits, J. (2011, November 30). No child left behind debate centers on federalism. Huffington Post, Retrieved from http://www.huffingtonpost.com/2011/08/16/nochild-left-behind-reauthorization-federalism_n_927718.html

Rinker, M. E. (2007). Belmont heights estates: A HOPE VI success story. Shimberg Center for Affordable Housing. 17(3), 1-6.

Rusk, D. (2011). "Housing policy is school policy": A commentary. In P. Tegeler (Ed.), Finding common ground: Coordinating housing and education policy to promote integration (pp. 21-30). Washington, DC: Poverty \& Race Research Action Council and The National Coalition on School Diversity.

Salama, J. (1999). The redevelopment of distressed public housing: Early results from HOPE VI projects in Atlanta, Chicago, and San Antonio. Housing Policy Debate, 10(1), 95-142.

School District of Philadelphia. (2012) Andrew Jackson Elementary School Profile. School Performance Index. Retrieved from https://webapps.philasd.org/school_profile/view/2510

School District of Philadelphia. (2012). Imagine 2014. Building a System of Great Schools. School Reform Commission. Retrieved from http://blogs.sjr.com/isf/wp-content/uploads/Imagine2014.pdf

School District of Philadelphia. (September 17, 2008). Superintendent Arlene C. Ackerman unveils plan for addressing 85 under-performing schools in The School 
District of Philadelphia. School District of Philadelphia website. Retrieved from http://www.phila.k12.pa.us/announcements/under_performing.html

Shwartz, A. \& Tajbakhsh, K. (1997) Mixed-Income Housing: Unanswered Questions. Cityscape: A Journal of Policy Development and Research. 3(2).

Schwartz, H. (2011). Housing policy is school policy- recent research in Montgomery County. In P. Tegeler (Ed.), Finding common ground: Coordinating housing and education policy to promote integration (pp. 15-20). Washington, DC: Poverty \& Race Research Action Council and the National Coalition on School Diversity. Retrieved from www.prrac.org/pdf/HousingEducationReport-October2011.pdf

Soy, S. K. (1997). The case study as a research method. Unpublished paper, University of Texas at Austin.

Statistical analyses using SPSS. (1997). Retrieved October 10, 2011, from http://www.ats.ucla.edu/stat/spss/whatstat/whatstat.htm

Stoloff, J. A. (2004). A brief history of public housing. Paper Presented at the Annual Meeting of the American Sociological Association, Retrieved from doi:http://www.allacademic.com//meta/p_mla_apa_research_citation/1/0/8/8/5/pa ges108852/p108852-1.php

Student Assignment Policy (2012). Boston Public School. Retrieved from http://www.bostonpublicschools.org/assignment

Tegeler, P. (2011). Finding common ground: Coordinating housing and education policy to promote integration. Research \& Policy Roundtable Washington, DC: Poverty $\&$ Race Research Action Council and the National Coalition on School Diversity. Retrieved from www.prrac.org/pdf/HousingEducationReport-October2011.pdf

The White House. (2008). The Clinton Presidency: Expanding education opportunity. Retrieved November 30, 2011, from http://clinton5.nara.gov/WH/Accomplishments/eightyears-05.html

Tsupros, N., Kohler, R., \& Hallinen, J. (2009). STEM education: A project to identify the missing components. Intermediate Unit 1 and Carnegie Mellon, Pennsylvania.

United States Census Bureau. (2012). “American Fact Finder” Retrieved May 4, 2012 http://factfinder2.census.gov/faces/tableservices/jsf/pages/productview.xhtml?pid $=\mathrm{ACS} 11 \_5 \mathrm{YR} \_\mathrm{DP} 02$

United States Census Bureau. (2011) “American Fact Finder” Retrieved May 4, 2012 from http://factfinder2.census.gov/faces/nav/jsf/pages/index.xhtml 
United States Department of Education. (2012). 2012 Promise neighborhoods at- aglance. Office of Innovation and Improvement, U.S. Department of Education. Retrieved from www2.ed.gov/programs/promiseneighborhoods/fy12pnfsr.doc

United States Department of Education. (2011). Reforming districts through choice, equity, and accountability: An overview of the voluntary public school choice directors meeting report. Retrieved November 30, 2011, from http://www2.ed.gov/programs/choice/index.html

United States Department of Education. (2011). Comparability of State and Local Expenditures Among Schools Within Districts: A Report From the Study of School-Level Expenditures. Office of Planning, Evaluation and Policy Development. Washington, DC. Retrieved from http://www2.ed.gov/rschstat/eval/title-i/school-level-expenditures/school-levelexpenditures.pdf

United States Department of Education. (2004). Title I - Improving The Academic Achievement Of The Disadvantaged. Elementary and Secondary Education. Retrieved from http://www2.ed.gov/policy/elsec/leg/esea02/pg1.html

United States Department of Health and Human Services. (January 20, 2011). Poverty guidelines, research, and measurement. Retrieved November 30, 2011, from http://aspe.hhs.gov/poverty/11fedreg.shtml

United States Department of Housing and Urban Development (2000). Principles for inner city neighborhood design: A collaboration of the congress for the new urbanism and the U.S. department of housing and urban development. doi:http://www.huduser.org/Publications/pdf/principles.pdf

United States General Accounting Office (2003). In HOPE VI (Ed.), Public housing: HOPE VI resident issues and changes in neighborhoods surrounding grant sites (ED.). [electronic resource] Washington, D.C: U.S. General Accounting Office.

United States General Accounting Office (2003). Public Housing- Information on Receivership at Public Housing Authorities. Report to the Chairman, Subcommittee on Housing and Transportation, Committee on Banking, Housing, and Urban Affairs, U.S. Senate. Washington, DC

United States Department of Housing and Urban Development (2003). Mixed-income housing and the HOME program [prepared by ICF consulting] .United States Office of Community Planning and Development (Eds.). Washington, D.C.

United States General Accounting Office. (1994). Elementary school children: Many change schools frequently, harming their education. (Report to the Honorable Marcy Kaptur, House of Representatives No. GAO/HRD-94-45). Washington, 
DC: U. S. General Accounting Office.

doi:http://archive.gao.gov/t2pbat4/150724.pdf

United States General Accounting Office. (1998). HOPE VI microform: Progress and problems in revitalizing distressed public housing: Report to congressional committees. Washington, D.C.; Gaithersburg, MD P.O. Box 6015, Gaithersburg 20884-6015: The Office distributor.

United States General Accounting Office (2002) Title I Funding. Poor Children Benefit Though Funding per Poor Child idffers. Report to the Congressional Addressees. Washington, DC. Retrieved from http://www.gao.gov/new.items/d02242.pdf

United States National Commission on Excellence in Education \& United States Department of Education. (1983). A nation at risk: The imperative for educational reform. A report to the Nation, the Secretary of Education, and United States Department of Education. Washington, D.C: The Commission: [Supt. of Docs., U.S. G.P.O. distributor].

Universal Companies (2012) At a Glance...Improving Communities...Changing Lives. Universal Companies -Brochure. Philadelphia, PA. Received June 14, 2012.

Varady, D. P., Raffel, J. A., Sweeney, S., \& Denson, L. (2005). Attracting middle-income families in the HOPE VI public housing revitalization program. Journal of Urban Affairs, 27(2), 149-164. doi:10.1111/j.0735-2166.2005.00229.x

Vogell, H. (2011, July 6). Investigation into APS cheating finds unethical behavior across every level. The Atlanta Journal-Constitution. p. 1. Retrieved from http://www.ajc.com/news/investigation-into-aps-cheating-1001375.html

Wendorf, C. (2012). Statistics for psychologists. Calculating and interpreting Basic statistics using SPSS. Retrieved from http://www4.uwsp.edu/psych/cw/statistics/textbook.htm

Wilson, W. J. (1987). The truly disadvantaged: The inner city, the underclass, and public policy. Chicago: University of Chicago Press.

Wilson, W.J. (1991). Studying Inner-City Social Dislocations: The Challenge of Public Agenda Research: 1990 Presidential Address. American Sociological Review. $56(1)$

Yin, R. K. (1984). Case study research: Design and methods. Newbury Park, CA: Sage.

Zielenbach, S. and Voith, R. (2010). HOPE VI and neighborhood economic development: The importance of local market dynamics. Cityscape: A Journal of Policy Development and Research, 12(1), 99-132 


\section{APPENDIX}

Appendix A: $\quad$ HUD HOPE VI Revitalization Grant Developments

Appendix B: $\quad$ Variable Names and Definitions, Regression Change in SES Model A

Appendix C: $\quad$ Variable Names and Definitions, Regression Change in School Performance, Model B

Appendix D: $\quad$ Correlation Model A

Appendix E: $\quad$ Correlation Model B

Appendix F: $\quad$ NVivo Word Frequency Model- Public Housing

Appendix G: $\quad$ NVivo Word Frequency- School Officials

Appendix H: $\quad$ Open-Ended Interview Questions

Appendix I: $\quad$ IRB Participant Consent

Appendix J: $\quad$ IRB Research Proposal 
Appendix A: HUD HOPE VI REVITALIZATION GRANT DEVELOPMENTS

\begin{tabular}{|c|c|c|c|c|c|}
\hline State & City & PHA & \# Projects & Year(s) & \$ Award \\
\hline NY & Albany & Albany Housing Authority & 1 & 1998 & $\$ 28,852,200$ \\
\hline VA & Alexandria & Alexandria Redevelopment and Housing Authority & 1 & 1998 & $6,716,250$ \\
\hline PA & Pittsburgh & Allegheny County Housing Authority & 2 & 1997 & $18,396,552$ \\
\hline GA & Atlanta & Housing Authority of the City of Atlanta & 5 & 1993 & $167,232,035$ \\
\hline NJ & Atlantic City & Atlantic City H.A. and Urban Redevelopment Agency & 2 & 1999 & $70,000,000$ \\
\hline MD & Baltimore & Housing Authority of Baltimore City & 6 & 1994 & $166,553,218$ \\
\hline MS & Biloxi & Housing Authority of the City of Biloxi & 2 & 2000 & $70,000,000$ \\
\hline MS & Birmingham & Housing Authority of the Birmingham District & 1 & 1999 & $34,957,850$ \\
\hline MA & Boston & Boston Housing Authority & 3 & 1993 & $114,992,350$ \\
\hline FL & Bradenton & Housing Authority of the City of Bradenton & 1 & 1999 & $21,483,332$ \\
\hline NJ & Bridgeton & Housing Authority of the City of Bridgeton & 1 & 2001 & $10,945,944$ \\
\hline NY & Buffalo & Buffalo Housing Authority & 2 & 1997 & $28,015,038$ \\
\hline MA & Cambridge & Cambridge Housing Authority & 1 & 1998 & $5,000,000$ \\
\hline NJ & Camden & Housing Authority of the City of Camden & 2 & 1994 & $77,177,229$ \\
\hline NC & Charlotte & HA of the City of Charlotte & 3 & 1993, 1996, 1998 & $100,966,409$ \\
\hline TN & Chattanooga & Chattanooga Housing Authority & 1 & 2000 & $35,000,000$ \\
\hline PA & Chester & Housing Authority of Chester City & 2 & 1996 & $24,700,732$ \\
\hline PA & West Chester & Chester County Housing Authority & 1 & 1997 & $16,434,200$ \\
\hline IL & Chicago & Chicago Housing Authority & 8 & $1994,1996,1998,2000,{ }^{\prime} 01$ & $157,918,550$ \\
\hline $\mathrm{OH}$ & Cincinnati & Cincinnati Housing Authority & 2 & 1998,1999 & $66,093,590$ \\
\hline SC & Columbia & HA of the City of Columbia, SC & 1 & 1999 & $25,843,793$ \\
\hline $\mathrm{OH}$ & Columbus & Columbus Metropolitan HA & 1 & 1994 & $42,053,408$ \\
\hline SC & Columbia & HA of the City of Columbia, SC & 1 & 1999 & $25,843,793$ \\
\hline $\mathrm{OH}$ & Columbus & Columbus Metropolitan HA & 1 & 1994 & $42,053,408$ \\
\hline $\mathrm{OH}$ & Cleveland & Cuyahoga Metropolitan HA & 3 & $1993,1995,1996$ & $10,733,334$ \\
\hline TX & Dallas & Dallas Housing Authority & 2 & 1994,1998 & $61,507,186$ \\
\hline VA & Danville & Danville Redev. and HA & 1 & 2000 & $20,647,784$ \\
\hline
\end{tabular}




\begin{tabular}{|c|c|c|c|c|c|}
\hline $\mathrm{OH}$ & Dayton & Dayton Metropolitan HA & 3 & 1999 & $18,311,270$ \\
\hline IL & Decatur & Decatur Housing Authority & 1 & 1999 & $34,863,615$ \\
\hline $\mathrm{CO}$ & Denver & HA of the City and County of Denver & 2 & 1994, 1998 & $52,242,508$ \\
\hline $\mathrm{Ml}$ & Detroit & Detroit Housing Commission & 3 & $1994,1995,1996$ & $111,651,729$ \\
\hline DC & Washington & District of Columbia HA & 5 & 1993, '97,'99,2000, 2001 & $141,153,314$ \\
\hline NC & Durham & HA of the City of Durham & 1 & 2000 & $35,000,000$ \\
\hline $\mathrm{TX}$ & El Paso & HA of the City of El Paso & 1 & 1995 & $36,224,644$ \\
\hline NJ & Elizabeth & HA of the City of Elizabeth & 1 & 1997 & $28,903,755$ \\
\hline IN & Gary & HA of the City of Gary & 1 & 1999 & $19,847,454$ \\
\hline $\mathrm{MC}$ & Greensboro & Greensboro, NC Housing Authority & 1 & 1998 & $22,987,722$ \\
\hline SC & Greenville & HA of the City of Greenville, SC & 1 & 1999 & $21,075,322$ \\
\hline $\mathrm{MD}$ & Hagerstown & HA of the City of Hagerstown & 1 & 2001 & $27,357,875$ \\
\hline MT & Helena & Helena Housing Authority & 1 & 1997 & 939,700 \\
\hline NC & High Point & HA of the City of High Point, NC & 1 & 1999 & $20,180,647$ \\
\hline $\mathrm{MA}$ & Holyoke & Holyoke Housing Authority & 1 & 1996 & $15,000,000$ \\
\hline TX & Houston & Houston Housing Authority & 2 & 1993, 1997 & $57,889,231$ \\
\hline IN & Indianapolis & Indianapolis Housing Authority & 2 & 1995, 2003 & $46,777,298$ \\
\hline FL & Jacksonville, & Jacksonville Housing Authority & 2 & 1996, 2002 & $41,552,000$ \\
\hline NJ & Jersey City & HA of the City of Jersey City & 2 & 1997, 2001 & $65,764,658$ \\
\hline MO & Kansas City, & Housing Authority of Kansas City & 4 & $1993,1996,1997,1998$ & $70,579,800$ \\
\hline WA & Tukwila & King County Housing Authority & 1 & 2001 & $35,000,000$ \\
\hline TN & Knoxville & Knoxville's Community Development & 1 & 1997 & $22,064,125$ \\
\hline $\mathrm{FL}$ & Lakeland & HA of the City of Lakeland, FL & 1 & 1999 & $21,842,801$ \\
\hline KY & Lexington & Lexington-Fayette Urban County HA 300 & 1 & 1998 & $19,331,116$ \\
\hline CA & Los Angeles, & HA of the City of Los Angeles & 2 & $19,931,998$ & $73,045,297$ \\
\hline KY & Louisville & Housing Authority of Louisville & 1 & 1996 & $20,000,000$ \\
\hline GA & Macon & Macon Housing Authority & 1 & 2001 & $19,282,336$ \\
\hline TN & Memphis & Memphis Housing Authority & 2 & 1995,2000 & $82,281,182$ \\
\hline PA & Sharon & Mercer County Housing Authority & 1 & 2000 & $9,012,288$ \\
\hline $\mathrm{FL}$ & Miami & Miami-Dade Housing Agency & 2 & 1998,1999 & $39,697,750$ \\
\hline
\end{tabular}




\begin{tabular}{|c|c|c|c|c|c|}
\hline WI & Milwaukee & HA of the City of Milwaukee & 3 & $1993,1998,2000$ & $91,219,946$ \\
\hline $\mathrm{AL}$ & Mobile & Mobile Housing Board & 1 & 1998 & $4,741,800$ \\
\hline TN & Nashville & Metropolitan Development and Housing Agency - Nashville & 2 & 1997,1999 & $48,563,876$ \\
\hline MA & New Bedford & New Bedford Housing Authority & 1 & 1998 & $4,146,780$ \\
\hline NJ & N. Brunswick & HA of the City of New Brunswick & 1 & 1998 & $7,491,656$ \\
\hline CT & New Haven, & HA of the City of New Haven & 1 & 1993 & $45,331,593$ \\
\hline LA & New Orleans & Housing Authority of New Orleans & 2 & 1994,1996 & $69,255,908$ \\
\hline NY & New York & New York City Housing Authority & 3 & $1995,1996,1998$ & $89,106,165$ \\
\hline NJ & Newark & HA of the City of Newark & 2 & 1994,1999 & $84,996,000$ \\
\hline KY & Newport & Newport, KY Housing Authority & 1 & 2000 & $28,415,290$ \\
\hline VA & Norfolk & Norfolk Redev. and HA & 1 & 2000 & $35,000,000$ \\
\hline SC & N. Charleston & North Charleston Housing Authority & 1 & 2001 & $30,347,921$ \\
\hline $\mathrm{CA}$ & Oakland & HA of the City of Oakland & 4 & $1994,1998,1999,2000$ & $83,754,400$ \\
\hline $\mathrm{FL}$ & Orlando & HA of the City of Orlando & 1 & 1997 & $6,800,000$ \\
\hline NJ & Paterson & HA of the City of Paterson & 1 & 1997 & $21,662,344$ \\
\hline IL & Peoria & Peoria Housing Authority & 1 & 1997 & $16,190,907$ \\
\hline PA & Philadelphia & Philadelphia Housing Authority & 4 & 1993, 1997, 1998, 2001 & $136,455,901$ \\
\hline$A Z$ & Phoenix & City of Phoenix Housing Dept. & 1 & 2001 & $35,000,000$ \\
\hline PA & Pittsburgh & Pittsburgh Housing Authority & 3 & 1993, 1995, 1996 & $65,656,954$ \\
\hline OR & Portland & HA of Portland & 1 & 2001 & $35,000,000$ \\
\hline VA & Portsmouth & Portsmouth Redevelopment and HA & 1 & 1997 & $24,810,883$ \\
\hline NC & Raleigh & HA of the City of Raleigh & 1 & 1999 & $29,368,114$ \\
\hline $\mathrm{CA}$ & Richmond & HA of the City of Richmond, CA & 1 & 2000 & $35,000,000$ \\
\hline VA & Richmond & Richmond Redevelopment and HA & 1 & 1997 & $26,964,118$ \\
\hline VA & Roanoke & City of Roanoke Redevelopment and Housing Authority & 1 & 1998 & $15,124,712$ \\
\hline MO & St. Louis & St. Louis Housing Authority & 2 & 1995(1), 2001 & $81,771,000$ \\
\hline FL & St. Petersburg & HA of the City of St. Petersburg & 1 & 1997 & $27,000,000$ \\
\hline $\mathrm{TX}$ & San Antonio & San Antonio Housing Authority & 2 & 1994,1995 & $97,095,794$ \\
\hline CA & San Francisco & City and County of San Francisco & 4 & 1993, 1995, 1996, 1997 & $115,278,018$ \\
\hline WA & Seattle & Seattle Housing Authority & 4 & 1995, 1998, 1999, 2000 & $135,137,383$ \\
\hline
\end{tabular}


Appendix B: Variable Names and Definitions, Regression Change in SES Model A

\section{Dependent Variables}

Variable name Definitions

Data sources

CHGSES Rate of change in the number students that qualified for FRLP three years before and after the implementation of HOPE VI.

Greatschool.org; NCES

\section{Independent Variables}

\begin{tabular}{lll} 
Variable names & \multicolumn{1}{c}{$\begin{array}{c}\text { Definitions Hypothesized } \\
\text { effect }\end{array}$} \\
\hline Housing characteristics & + & Data sources \\
\hline COMPRATE & HOPE VI Completion Rate, \# of years until housing returned to community & + \\
DEMO & Demolition Grant at Project Site (No=0; Yes=1) & + \\
NOUNITS & Change in Number of Housing Units at Project Site & + \\
HADEMO & Demolition Grant at Public Housing Authority (No=0; Yes=1 ) & + \\
HAUNITS & Change in Number of Housing Units at Public Housing Authority & + \\
HAFUNDS & Revitalization Funding per Housing Authority & + \\
\hline School characteristics & Change in Per Pupil Allotment & + \\
\hline PPFUNDS & Change in Minority Enrollment (non-white) & National Center for Education Statistics \\
MINORITY & Change in African American Enrollment & Greatschool.org; NCES \\
AA &
\end{tabular}


Appendix C: Variable Names and Definitions, Regression Change in School Performance, Model B

\section{Dependent Variables}

\begin{tabular}{|c|c|c|c|}
\hline Variable names & \multicolumn{2}{|l|}{ Definitions } & Data sources \\
\hline CHGPERF & \multicolumn{2}{|c|}{$\begin{array}{l}\text { Change in the number of } 5^{\text {th }} \text { grade students scoring proficient in math and reading on } \\
\text { standardized statewide test, measured three years before and after the Implementation of } \\
\text { HOPE VI. Proficiency scores are combined for math and reading }\end{array}$} & Greatschools.net; NCES \\
\hline \multicolumn{3}{|c|}{ II. Independent Variables } & \\
\hline Variable names & \multicolumn{2}{|l|}{$\begin{array}{l}\text { Hypothesized } \\
\text { Definitions effect }\end{array}$} & Data sources \\
\hline COMPRATE & HOPE VI Completion Rate, \# of years until housing returned to community & + & \multirow{6}{*}{$\begin{array}{l}\text { Literature from each PHA } \\
\text { HUD Literature }\end{array}$} \\
\hline DEMO & Demolition Grant at Project Site $(\mathrm{No}=0 ; \mathrm{Yes}=1)$ & + & \\
\hline NOUNITS & Change in Number of Housing Units at Project Site & + & \\
\hline HADEMO & Demolition Grant at Public Housing Authority $(\mathrm{No}=0 ; \mathrm{Yes}=1)$ & + & \\
\hline HANOUNITS & Change in Number of Housing Units at Public Housing Authority & + & \\
\hline HUDFUNDING & Revitalization Funding per Housing Authority & + & \\
\hline \multicolumn{4}{|c|}{ School characteristics } \\
\hline MINORITY & Change in Minority Enrollment (non-white) & + & \multirow{4}{*}{$\begin{array}{l}\text { NCES; Greatschool.org } \\
\text { Greatschools.org; NCES }\end{array}$} \\
\hline AA & Change in African American Enrollment & + & \\
\hline TSRATIO & Change in the Student to Teacher Ratio & + & \\
\hline ENROLL & Change in Overall School Enrollment & - & \\
\hline
\end{tabular}


Appendix D: Correlations, Model A

\begin{tabular}{|c|c|c|c|c|c|c|c|c|c|c|}
\hline & $\begin{array}{l}\text { Change in } \\
\text { FRLP }\end{array}$ & $\begin{array}{l}\text { COMP } \\
\text { RATE }\end{array}$ & DEMO & $\begin{array}{l}\text { NO } \\
\text { UNITS }\end{array}$ & $\begin{array}{l}\text { HA } \\
\text { DEMO }\end{array}$ & $\begin{array}{l}\text { HA } \\
\text { NOUNITS }\end{array}$ & $\begin{array}{l}\text { HA } \\
\text { FUNDS }\end{array}$ & MINORITY & AA & PPFUNDS \\
\hline $\begin{array}{l}\text { Change in } \\
\text { FRLP }\end{array}$ & & & & & & & & & & \\
\hline COMPRATE & 0.421 & & & & & & & & & \\
\hline DEMO & 0.463 & 0.929 & & & & & & & & \\
\hline NOUNITS & 0.401 & 0.192 & $0.000 * *$ & & & & & & & \\
\hline HADEMO & 0.717 & 0.443 & $0.000 * *$ & $0.003 * *$ & & & & & & \\
\hline HANOUNITS & 0.123 & 0.192 & $0.000 * *$ & $0.000 * *$ & $0.003^{* *}$ & & & & & \\
\hline HAFUNDS & $0.040 *$ & $0.004 * *$ & 0.202 & $0.030 *$ & $0.010^{* *}$ & 0.092 & & & & \\
\hline MINORITY & 0.310 & $0.000 * *$ & 0.772 & 0.924 & 0.228 & 0.583 & 0.391 & & & \\
\hline AA & $0.052 *$ & 0.026 & 0.500 & 0.142 & 0.352 & 0.635 & 0.306 & $0.000 * *$ & & \\
\hline PPFUNDS & 0.040 & $0.001 * *$ & 0.662 & 0.260 & 0.679 & 0.597 & 0.568 & 0.163 & 0.960 & \\
\hline
\end{tabular}

$* * \mathrm{p}<0.01$ level.

$* p<0.05$ level. 
Appendix D: Correlations, Model B

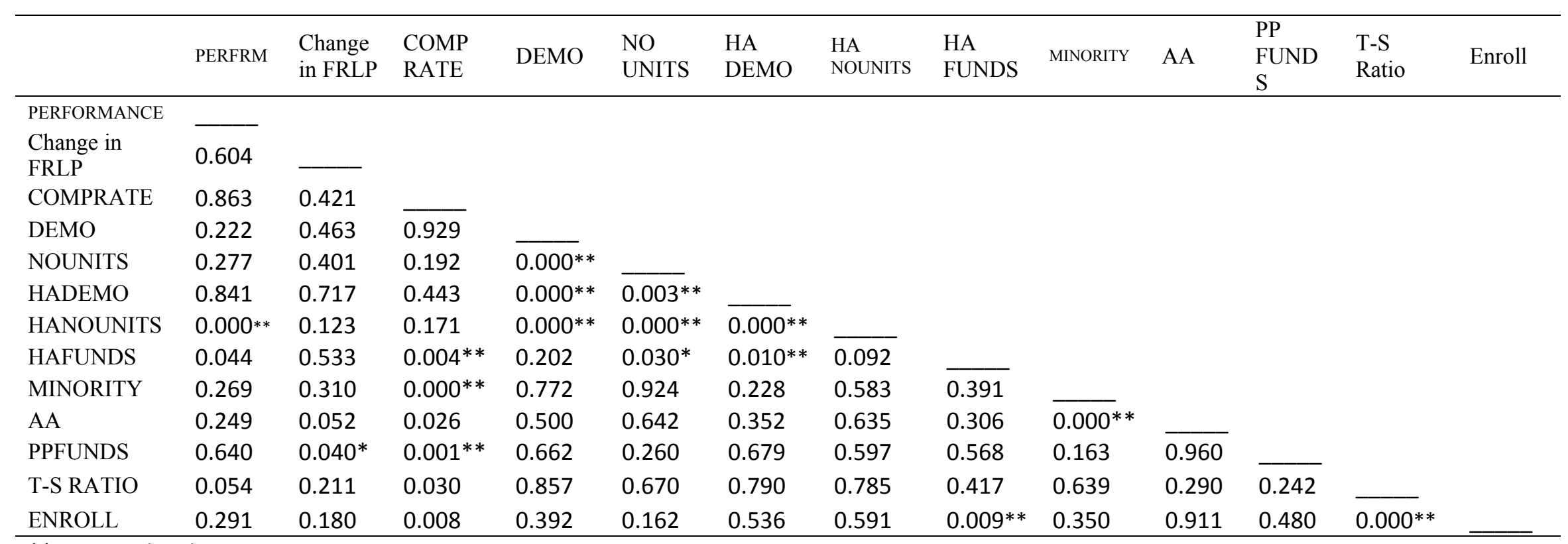

$* * p<0.01$ level.

$* p<0.05$ level. 
Appendix F: NVivo Word Frequency Query of Housing Officials

To operationalize the link between public housing and community development, the selective transcribed interviews of all public housing officials were inputted into the NVivo word frequency query. The illustration provides a visual list of the most frequently occurring words from the combined sources. More importantly, the system creates hierarchy in terms of important concepts and overlapping ideas between the representatives in the two cities (Philadelphia, PA and Washington, DC). .

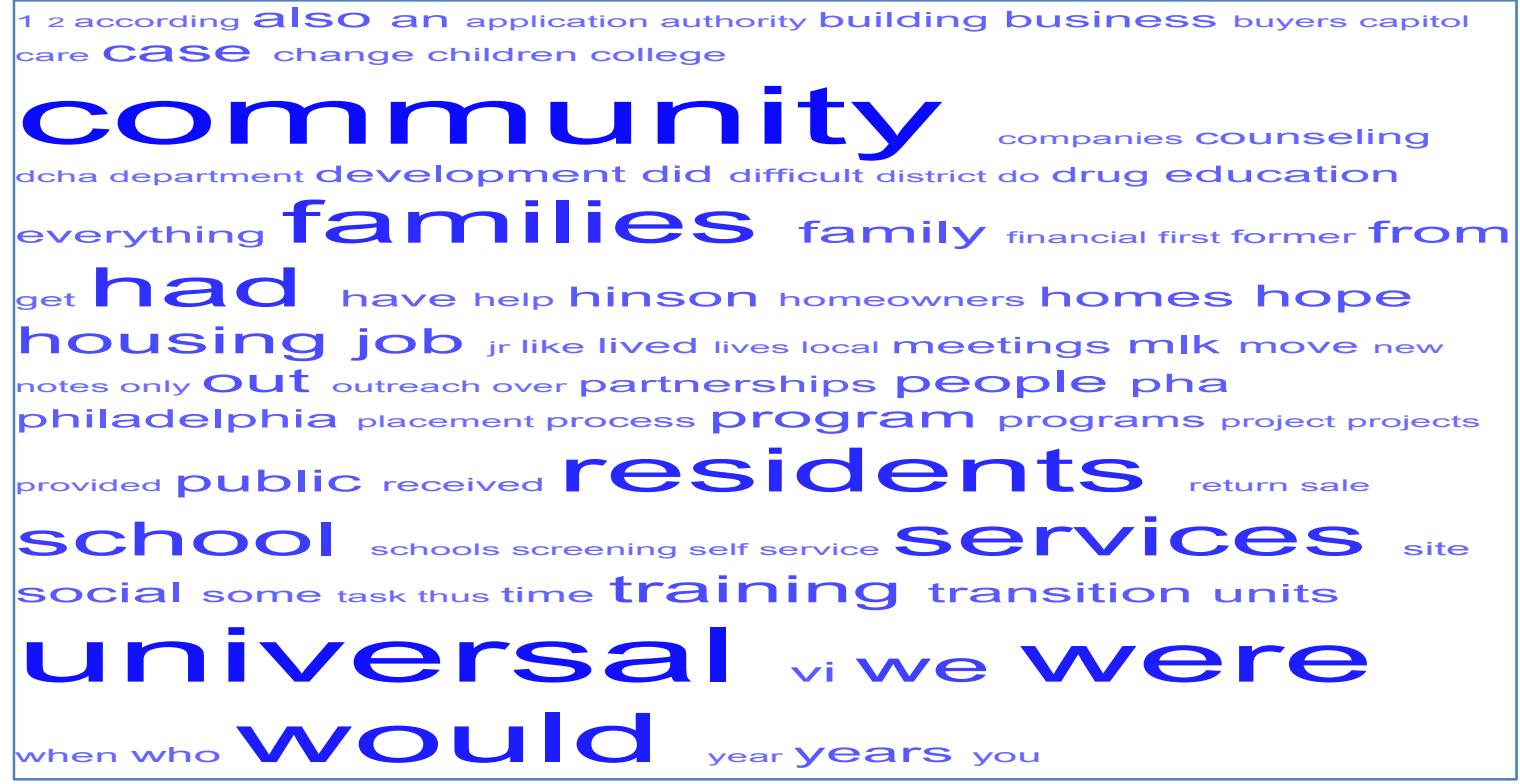


Appendix G: NVivo Word Frequency Query of Public School Officials

To operationalize the link between public education and community development, the selective transcribed interviews of all school principals were inputted into the NVivo word frequency query. The illustration provides a visual list of the most frequently occurring words from the combined sources. More importantly, the system creates hierarchy in terms of important concepts and overlapping ideas between the representatives in the two cities (Philadelphia, PA and Washington, DC).

000001199728 about academic addition after all also an assistant ayp based change community companies could data down drew education elementary families from funds had has he her high highsmith home housing how $\mathbf{i}$ include initiatives jackson just kaplan language leaders longer made manage math more ms neighborhood new notes now only out parent parents partnerships performance principal prior program programs projects public reading retired
served services several she staff standardized student Students success support
taught teacher teachers time transition uc under universal want we well Were
which work would year years you young 
Appendix H: Open-Ended Interview Questions

\section{$\underline{\text { Interview Questions for Housing Authority Officials }}$}

1. What is your name?

2. What is your organizational affiliation and job title?

3. Describe your involvement with the HOPE VI process (before, during, and/or after implementation)?

4. Do you feel schools are impacted by affordable housing initiatives, specifically HOPE VI? Please explain.

5. During the development \& implementation of HOPE VI, what relationship did the Philadelphia Housing Authority have with the School District of Philadelphia or the neighborhood public school?

6. In your opinion, which initiatives hindered efforts to create PHA partnerships with public schools?

7. In your opinion, which initiatives facilitated efforts to create PHA partnerships with public schools?

8. What are some of the major factors that positively contributed to the HOPE VI's effectiveness as it relates to:
a. Families,
b. Children, and
c. Public schools?

9. What are your recommendations for improving partnerships at the local level between school officials and the public housing authority?

10. What aspects of the HOPE VI program, do you think, could have been done differently (as it relates to public schools)? 


\section{$\underline{\text { Interview Questions for Public School Officials }}$}

1. What is your name?

2. What is your organizational affiliation and job title?

3. Are you aware of the HOPE VI Revitalization Program? Describe your involvement, if any, with the HOPE VI process (before, during, and/or after implementation)?

4. Do you feel that neighborhood schools were impacted by neighborhood revitalization, specifically HOPE VI? Please explain.

5. During your tenure, what relationship did the Andrew Jackson/Drew Elementary School have with the Philadelphia/District of Columbia Housing Authority and/or the HOPE VI Program?

6. In your opinion, which initiatives facilitated efforts to create Public School partnerships with the Philadelphia/ District of Columbia Housing Authority?

7. In your opinion, which initiatives hindered efforts to create PHA partnerships with public schools?

8. What are your recommendations for improving partnerships at the local level between school officials and the public housing authority?

9. Based on your experience and expertise, what aspects of the HOPE VI program could have been done differently (as it relates to public schools)?

\section{Demographics}

\begin{tabular}{|l|l|l|l|l|l|}
\hline $\begin{array}{l}\text { Gender/ } \\
\text { Sex }\end{array}$ & Age Group & Education & $\begin{array}{l}\text { Experience } \\
\text { in this } \\
\text { position }\end{array}$ & $\begin{array}{l}\text { Experience } \\
\text { in this field }\end{array}$ & Race Identification \\
\hline$M / F$ & $20 / 30 / 40 / 50 / 60+$ & $\begin{array}{l}\text { Highest } \\
\text { Level } \\
\text { Completed }\end{array}$ & $>1-20+$ & $>1-20+$ & $\begin{array}{l}\text { American Indian or Alaska } \\
\text { Native; Asian; Black or } \\
\text { African American; } \\
\text { Native Hawaiian; or Other } \\
\text { Pacific Islander; White }\end{array}$ \\
\hline & & & & & \\
\hline
\end{tabular}


Appendix I: IRB Participant Verbal Consent

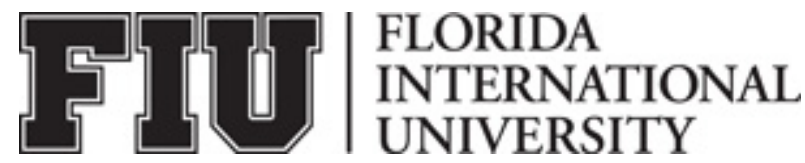

\section{ADULT VERBAL CONSENT TO PARTICIPATE IN RESEARCH STUDY}

Dear (Name of Participant),

I am Donna Comrie, a PhD student in Public Affairs at Florida International University. I am conducting my dissertation research entitled, Influence of HOPE VI Public Housing on Public Schools. As a part of my research, I am conducting interviews of twelve school and public officials to evaluate neighborhood public school performance. If you agree to participate, I shall ask you questions on your views related to HOPE VI neighborhood revitalization.

There are no foreseeable risks or benefits to you for participating in this study. However, your responses will help identify the opportunities and challenges to enable partnerships between school officials and neighborhood developers at the federal (HUD) and local (PHA) levels.

The interview could take up to two (2) hours. Your participation in this research is voluntary. I will record the interviews using audio or video equipment. I will use your name, position, and the interview responses you give as a part for my dissertation. If you would like to talk with someone about your rights related to being a subject in this research study or about ethical issues, you may contact the FIU Office of Research Integrity by phone at 305-348-2494 or by email at ori@,fiu.edu.

Do you consent to participate in this research study?

[Proceed with research questions, if the participant consents. Else, end the interview here.] 
Appendix J: IRB Research Proposal

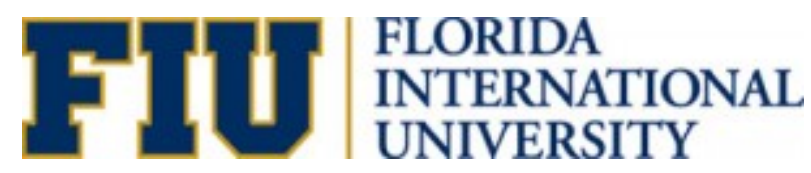

IRB RESEARCH PROPOSAL

\section{Influence of HOPE VI Public Housing on Public Schools}

\section{RESEARCH OBJECTIVES:}

- The study seeks to evaluate neighborhood public school performance as it relates to community change. The use of case studies which includes in-depth interviews and secondary sources will determine the factors that contribute to improved public school performance in HOPE VI areas.

- The theoretical framework of the dissertation will have two major focuses which will explore Jean Anyon's (1980) Hidden Curriculum and William Julius Wilson's 1987 work, The Truly Disadvantaged. The two authors provide a premise and structure to investigate social class as it relates to schools and neighborhoods

- The empirical goal of this research is to link the effects of neighborhood and public housing revitalization through HOPE VI to public school performance.

The purpose of recorded individual in-depth interviews seeks to eliminate the pressure of group think, allows for probing to answer the 'why' questions, maximizes use of time and information, and allows for interview transcriptions.

\section{SUBJECT RECRUITMENT:}

- Twelve total interviews will include: administrators from the local HUD/HOPE VI (2), Public Housing Authority (PHA) administrators (2), DOE officials (2), school principals (2), school board officials (2) and local community leaders (2). Participants are not restricted by age or sex. 
The findings of the quantitative analysis (counterfactual comparison and interrupted time series) in 165 HOPE VI sites in 22 cities, looking specifically for the schools with the (1) greatest rate of change for SES students and (2) greatest rate of improvement in school performance, will lead to two site selections and each city's housing and school representatives. Each subject is recruited based on their position during the HOPE VI project.

- Contact methods will include phone calls, email, and personal letters. Prior to the actual recorded interview, both an informal and formal discussion will take place, written research goals, abstracts, and questions will be provided and subjects will provide a verbal consent.

- The eligibility criterion for participants is based on job title and/or experience at HUD, PHA or the local public schools as it relates to the implementation of HOPE VI (1990-2010).

- Names and the titles of subjects are found on public websites and publications of HUD, Public Housing authority, and school district listings. Newspapers and journal articles may also help narrow the search. The sources have no direct risk or benefit.

\section{METHOD AND PROCEDURES:}

- Recorded interviews will be transcribed. The analysis from transcriptions will become recommendations for the dissertation. Risk to the interviewees may occur in the form of public identification as part of the dissertation and/or future publications.

- The findings of the quantitative analysis (counterfactual comparison and interrupted time series) of the 165 HOPE VI sites, looking specifically for the schools with the (1) greatest rate of change for SES students and (2) greatest rate of improvement in school performance, will lead to two site selections and the inclusion of local representatives.

- Start date: 6/01/2011; End dates of Study: 5/30/2012 
- No tests or exams included. Interview will include open ended questions.

- No alternative procedures or treatments are expected.

- Prior to the interview, data collection will include records (FRLP \%, math scores and reading scores) from the Department of Education at the state level (22 states) for schools included in 165 HOPE VI communities. Data collection as part of the case study will include the following secondary sources: historical data, congressional documents, articles from professional journals, newspapers articles, professional presentations at national conferences, and testimony before the House Subcommittees for Housing and Community Opportunity.

- There are no costs to participate in the study.

- Interviewees are not provided with compensation.

\section{BENEFITS:}

- Possible benefit to subjects may include recognition in the dissertation and future publications.

- No course credit or coercive situations included.

- Beyond possible recognition in the dissertation and/or future publications, there are no direct benefits to the subjects. Anticipated benefits to society and knowledge development may include: filling the gap in the literature linking housing to education at the organizational level, informing policy makers by developing best practices, and impacting the Obama Administration's newly developed Choice Neighborhoods Initiative, which is an expansion of the HOPE VI program to include high-quality educational opportunities with an emphasis on early childhood education.

- Recognition in the dissertation or future publication may serve as a low level risk or no risk. Interview responses will serve as research recommendations which may benefit society.

\section{RISKS TO SUBJECTS:}

- Recognition in the dissertation or future publication may serve as a low level risk or no risk. 
- Every effort will be made to reduce all risks, discomforts, and/or inconveniences which may include notice to interviewees of all research methods and possible results, accuracy in recording and transcribing, copies of analysis, and notice of publications.

- There is no medical, psychological or other care available through the study for research related to risks.

- Minimal or no risks related to social life are outweighed to possible societal benefit.

- Participating in an in-depth interview may have no more risk to the participant than providing professional judgment or information related to work improvements.

\section{INFORMED CONSENT:}

Informed Consent (adult only) will be obtained verbally from the interview subjects. Upon the subject's agreement, I shall proceed with the interview questions.

\section{CONFIDENTIALITY OF DATA:}

\section{Confidentiality of data MUST be addressed for all studies.}

- Confidentiality of records identifying subjects will be maintained by the interviewer in an electronic file format with password protection. Subjects are notified that their names and current positions may become part of the dissertation and/or future publications.

- Data collected will include the following identifiable information: name, age, race, current professional title and/or position, years of experience, and listing of previous professional experience.

- The data containing identifiable information are protected as an electronic file format by the interviewer and may be released for use in the dissertation or in future publications.

- The consent letter, all written communication, and discussions will notify participants that information obtained will be recorded in such a manner that 
human subjects can be identified, directly or through identifiers linked to the subjects.

- Storage and disposal of data and information are kept as an electronic file with the interviewer.

- Audiotapes of the in-depth interviews will be outsourced for transcription but will be returned, used, stored and disposed (if necessary) by the interviewer in file cabinets. Dissertation committee members may have access to audiotapes as needed to verify information and complete the dissertation.

- The final analyzed results will be published in both individual and group formats and it may (and in some cases will) be possible to track the responses back to the individuals.

Sensitive data is not collected as part of the dissertation's interview process.

- No information will be obtained about sensitive or illegal behavior.

- Study will not include Protected Health Information (PHI) 
DONNA A. COMRIE

Born, Bronx, New York

1998

B.S, Elementary Education

Pennsylvania State University

State College, Pennsylvania

2002

M.A., International Development

Roehampton University

London, UK

2006

Administrative (K-12) Principal Certification

Cheyney University

Cheyney, Pennsylvania

1998-2003

Elementary \& Middle School Teacher

United States: Philadelphia, California and Florida

Abroad: Kingston, JA and London, UK

2003-2006

Educational Consultant \& Grant Writer (Partner)

C\&W Consultants

Philadelphia, PA

2006-2008

Chief Executive Officer \& Principal

Wakisha Charter School

Philadelphia, PA

2008-2013

Teaching \& Research Assistant

Florida International University

Miami, Florida

2013-Present

Educational Consultant \& Grant Writer

Comrie Consulting, LLC

Hollywood, Florida

Educational Consultant, Southeast Division

Achieve3000, Inc.

Newark, NJ 


\section{PRESENTATIONS}

Comrie, Comrie, D.A. (2010). Effects of Policy on Public Education. Paper presented at the annual conference of the Southeastern Conference for Public Administration, 'Effects of Policy on Public Education'. Wilmington, North Carolina.

Comrie, D.A. (2011). Influence of HOPE VI Public Housing on Public Schools[pilot]. Paper accepted to the annual conference of the American Society for Public Administration. Seattle, Washington.

Comrie, D.A. (2012). Influence of HOPE VI Public Housing on Public

Schools[quantitative results]. Paper presented at FIU Annual Scholarly Forum. Miami, Florida.

Comrie, D.A. (2012). Influence of HOPE VI Public Housing on Public Schools. Paper presented at the annual conference of the American Society for Public Administration, 'Ask the Expert Discussion Circle' Housing Policy. Las Vegas, NV 